\title{
O uso do Algoritmo Genético na Construção de Mapas de Perfusão Cerebral e sua Aplicação em pacientes com Anemia Falciforme.
}

Nivia Aparecida da Silva

Tese apresentada à Faculdade de Filosofia, Ciências e Letras de Ribeirão Preto da USP, como parte das exigências para a obtenção do título de Doutor em Ciências, Área: Física Aplicada à Medicina e Biologia. 


\section{O uso do Algoritmo Genético na Construção de Mapas de Perfusão Cerebral e sua Aplicação em pacientes com Anemia Falciforme.}

Nivia Aparecida da Silva

Tese apresentada à Faculdade de Filosofia, Ciências e Letras de Ribeirão Preto da USP, como parte das exigências para a obtenção do título de Doutor em Ciências, Área: Física Aplicada à Medicina e Biologia.

Orientador: Prof. Dr. Draúlio Barros de Araújo. 


\section{FICHA CATALOGRÁFICA}

\section{Silva, Nivia Aparecida da}

O uso do Algoritmo Genético na Construção de Mapas de Perfusão Cerebral e sua Aplicação em pacientes com Anemia Falciforme.

Ribeirão Preto, 2008. 137p..: 24il; 30 cm

Tese de Doutorado, apresentada à Faculdade de Filosofia, Ciências e Letras de Ribeirão Preto. Área: Física Aplicada à Medicina e Biologia.

Orientador: de Araújo, Draúlio Barros

1. Perfusão cerebral. 2.Mapas hemodinâmicos. 3. Algoritmo Genético. 4. Anemia falciforme 
A minha mãe Cecília, passarinha. 


\section{Agradecimentos}

Agradeço a Deus e a Nossa Senhora Aparecida por terem me dado a oportunidade de me perder, pra que eu pudesse me reencontrar.

Estes últimos anos foram os mais difíceis nessa minha curta caminhada. Este processo de estudo culminou não só com o meu crescimento profissional, mas principalmente no meu crescimento pessoal. Então, como é de se esperar, eu tenho muitas pessoas para agradecer, porque eu tive ajuda de cada uma delas, do seu modo, no seu momento e cada uma me ajudou a concluir esta tese, indiretamente, mas com muito apoio emocional.

E nesse tempo eu tive o apoio incondicional da minha mãe, que acabei descobrindo ser a melhor pessoa e amiga do mundo. E ao meu pai, por ter sido um pai maravilhoso na minha infância, por ter me ajudado na graduação.

Ao meu orientador Draúlio, pela orientação, disposição e paciência. Agradeço também aos professores Carlinhos, Gustavo, Osvaldo Baffa, Patrícia Nicolutti, Iouri e Galina. Ao coordenador da pós-graduação Alexandre pela compreensão e ajuda. Aos maravilhosos funcionários Inês, Denise e Gisele por toda ajuda e conselhos que me deram. Agradeço também aos alunos que compraram meus cintinhos, colares e produtos pra me ajudar a me manter aqui em Ribeirão. Assim como todos os colegas de laboratório.

Ao Paulo por ter estado comigo numa fase da nossa vida e por ter rompido nossa união de para que eu pudesse crescer, aprender e evoluir como ser humano. E também pela ajuda financeira, que me possibilitou permanecer em Ribeirão Preto.

Ao grande anjo que surgiu em minha vida, Taiza. A pessoa mais doce que eu conheço, que me ajudou a ver a luz quando eu estava rodeada de escuridão. Ao seu marido, Endrigo, que conseguiu médicos e atendimento pra mim, de imediato. 
A minha primeira psiquiatra Maria Cecília que cuidou impecavelmente de mim. E o Dr. Vinicius que continuou o tratamento, me ouvindo, doando todos os medicamentos necessários. Também a minha psicóloga Lizete por ter me ajudado neste processo de crescimento. Por ter me feito ver a vida de um ângulo diferente.

Aos amigos, Cássia, Márcio, Tiago Fusco, e tantos outros que me ajudaram a me divertir e ser uma pessoa mais amigável e melhor. E em especial a minha amiga Cris pelas mensagens de apoio, pela ajuda financeira e por estar presente em minha vida, mesmo a longa distância. Igualmente ao amigo Bráulio, meu muito obrigado.

Minha amiga Lucimara, por ter me mostrado o mundo através da sua visão, de seus e-mails e de suas fotos pelo mundo. E ao amigo Adelson, pelas conversas, apoio e amizade e por comprar meus produtos só pra me ajudar.

Aos funcionários do HC, em especial Luciana e Regis e Léia, amores da minha vida. A todos os colegas de laboratório e dos treinos de aikido, pela ajuda, pela disposição e pela amizade. Um agradecimento especial ao Lefê, por todas as vezes que me ouviu chorar. E mesmo sem falar uma palavra, era como se eu tivesse tido a melhor conversa.

Meu obrigado especial ao Daniel por ter me amparado, me ajudado, me apoiado em muitos momentos dessa nova fase da minha vida, me fazendo sonhar novamente.

Finalmente, a todos que muitas vezes enxugaram minhas lágrimas, me ouviram, me aconselharam, me ajudaram continuar e acreditaram em mim, quando eu mesma já havia desistido. De todo coração, meus mais sinceros agradecimentos.

E é claro, ao suporte financeiro da Capes e CNPq. 
'Eu pedi Força...

...e Deus me deu dificuldades para me fazer forte.

Eu pedi Sabedoria...

...e Deus me deu Problemas para resolver.

Eu pedi Prosperidade...

...e Deus me oportunidades para trabalhar.

Eu pedi coragem...

...e Deus me deu Perigo para superar.

Eu pedi Amor...

...e Deus me deu amigos.

Eu pedi Favores...

...e Deus me deu possibilidades.

Eu não recebi nada que pedi...

...mas tudo de que precisava."

Autor desconhecido 


\section{Resumo}

A imagem por ressonância magnética (IRM) tem se tornado uma poderosa ferramenta clínica na avaliação da anatomia cerebral. Recentemente, várias técnicas têm tornado possível a caracterização da função cerebral através da estimativa de alguns parâmetros metabólicos. Uma dessas técnicas é a perfusão cerebral, que descreve a passagem de sangue através da rede vascular cerebral, e permite estimar, não invasivamente, algumas características das funções hemodinâmicas tais como Volume de Sangue Cerebral (CBV), Fluxo de Sangue Cerebral (CBF) e Tempo de Trânsito Médio (MT'T). Neste trabalho foi desenvolvido um programa computacional, baseado na plataforma Matlab, que analisa as imagens e cria mapas de perfusão. Primeiro foi comparado o desempenho do método de ajuste de curvas convencional Levenberg-Marquardt (LM) versus o Método que utiliza o Algoritmo Genético (AG). Os resultados mostraram que os AGS são muito mais estáveis, com relação aos seus parâmetros de controle, do que o método usual LM e, portanto, fornece evidencias da eficácia do AG em relação ao método convencional. Como um segundo e principal objetivo nós aplicamos o método para construir e examinar os mapas de perfusão em pacientes com anemia falciforme (sickle cell disease -SCD), particularmente em relação a complicações neurológicas e anormalidades vistas como uma técnica de imagem complementar. Além disso, os mapas de perfusão agregam informação a respeito de aspectos funcionais do sistema vascular, que é complementar a informação anatômica. Os nossos resultados com mostraram que esses mapas são uma ferramenta importante para auxiliar na avaliação clínica dos pacientes com anemia falciforme, como também podem ser aplicados para avaliar áreas em risco tão bem quanto ajudar no tratamento clínico de tais pacientes. 


\section{Abstract}

Magnetic Resonance Imaging (MRI) has become a powerful clinical tool for evaluation of brain anatomy. Several recently techniques have made possible the characterization of brain function via assessment of metabolic parameters. One of these techniques is the cerebral perfusion, which describes passage of blood through the brain's vascular network, and allows estimating, non-invasively, some characteristics of hemodynamic functions such as Cerebral Blood Volume (CBV), cerebral blood flow (CBF) and mean transit time (MTT). In this work a computational program was development, based on Matlab platform, which analyze perfusion images and create perfusion maps. First, the performance of conventional Levenberg-Marquardt Method (LM) versus a Genetic Algorithms (GAs) was compared. The results showed that the GAs are more stable than usual LM method with relation to their control parameters and therefore provides evidence the effectiveness of the GAs with relation to a conventional method. As a second and principal objective we applied the method to construct and examine perfusion maps of patients with sickle cell disease (SCD), particularly in relation to the neurological complications and to abnormalities seen with complementary imaging techniques. Moreover, perfusion maps aggregate information about functional aspects of the vascular system, which is complementary to anatomical information. Our results show that these maps are an important tool to support clinical evaluation of sickle cell disease patients, as it may be applied to evaluate brain areas at risk as well as a help in the clinical treatment of such patients. 


\section{Lista de Abreviaturas}

ACA

ACM

ACP

AG

AVC

AIF

ASL

BHE

BOLD

$\mathrm{CBF}$

CBV

CSF

CT

DSC

$\mathrm{dHb}$

EPI

FID
Artéria Cerebral Anterior

Artéria Cerebral Média

Artéria Cerebral Posterior

Algoritmo Genético

Acidente Vascular Cerebral

Sigla do idioma inglês que representa: Arterial Input Function

Sigla do idioma inglês que representa: Arterial Spin Labelling

Barreira Hematoencefálica

Sigla do idioma inglês que representa: Blood Oxygen Level Dependent

Sigla do idioma inglês que representa: Cerebral Blood Flow

Sigla do idioma inglês que representa: Cerebral Blood Volume

Sigla do idioma inglês que representa: Cerebral Spinal Fluid

Tomografia computadorizada por raios-X

Sigla do idioma inglês que representa: Dynamic Susceptibility Contrast

Hemoglobina deoxigenada

Sigla do idioma inglês que representa: Eco-Planar Imaging

Sigla do idioma ingles que representa: Free Induction Decay 
fMRI

Gd- DTPA

$\mathrm{Hb}$

IRF

LCR

LM

MRI

MTT

NMR

PET

Pixel

$\mathrm{RF}$

ROI

SNC

SPECT

Tc

TE

TPB

TI

TR

TTM

VOI
Sigla do idioma inglês que representa:

Functional Magnetic Resnoance Imaging

Ácido dietilenotriaminopentaácido

Hemoglobina oxigenada

Sigla do idioma inglês que se representa: impluse response function

Líquido cefalorraquidiano

Método de Levenberg-Marquardt

Sigla do idioma inglês que representa:

Magnetic Resonance Imaging

Sigla do idioma inglês que representa:

Mean Transit Time

Sigla do idioma inglês que representa:

Nuclear Magnetic Resonance

Sigla do idioma inglês que representa:

Positron Emission Tomography

Elemento da imagem

Radiofreqüência

Região de interesse

Sistema Nervoso Central

Sigla do idioma inglês que representa:

Single Photon Emission Computer Tomography

Tempo de Chegada

Tempo ao Eco

Tempo ao Pico do bolus

Tempo de inversão

Tempo de Repetição

Tempo de trânsito médio

Volume de interesse 


\section{Conteúdo}

\section{Introdução}

1.1 Circulação Sangüínea.........................................................................01

1.2 Circulação do Sistema Nervoso...........................................................02

1.2.1 Anatomia da Circulação Cerebral..........................................03

1.2.2 Vascularização Arterial do encéfalo.....................................05

1.2.3 A Barreira Hematoencefálica............................................10

1.3 Microcirculação Cerebral...................................................................12

1.3.1 Doenças e Desordens Cerebrais..........................................13

\section{Perfusão Cerebral}

2.1 A importância da Imagem de Perfusão.............................................19

2.2 Conceitos de Perfusão Cerebral......................................................21

2.3 Medidas de Perfusão.....................................................................22

2.3.1 Medidas usando traçadores não-difusíveis........................23

2.4 Modelo para obtenção dos parâmetros de interesse......................24

$2.5 \quad \mathrm{O}$ agente de contraste......................................................................28

2.6 Medidas Hemodinâmicas..................................................................36

2.6.1 Volume de Sangue Cerebral.............................................37

2.6.2 Fluxo de Sangue Cerebral.....................................................43

2.6.3 Tempo de Trânsito Médio........................................................45

2.6.4 Atraso e Dispersão.................................................................4

\section{Métodos de ajuste de curvas}

3.1 Método do Gradiente Descendente...................................................52

3.2 Método de Gauss-Newton................................................................54

3.3 Método de Levenberg-Marquardt....................................................56 
3.4 O Algoritmo Genético.......................................................................58

3.4.1 População e Seleção..................................................................60

3.4.2 Operadores genéticos..............................................................63

3.4.3 Parâmetros genéticos...............................................................68

3.4.4 Critérios de parada..................................................................69

3.4.5 Vantagens e Restrições..............................................................70

\section{Material e Método}

4.1 Aquisição das Imagens........................................................................

4.2 Processamento das Imagens................................................................72

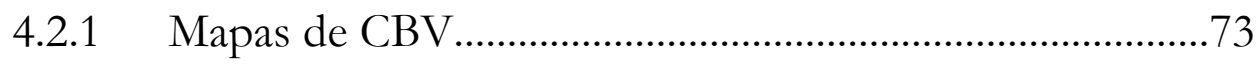

4.2.2 Mapas de MTT..................................................................... 74

4.2.3 Mapas de CBF...................................................................

4.3 Voluntários e pacientes.......................................................................76

$5 \quad$ Resultados e Discussão

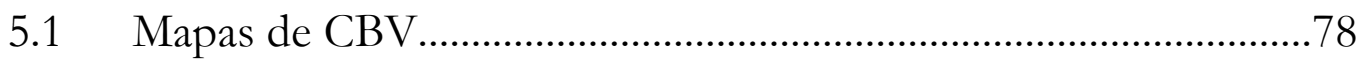

5.1.1 Comparação de eficiência entre ambos os métodos......... 80

5.1.2 Comparação da influência de Tc......................................... 82

5.2 Mapas hemodinâmicos em pacientes com Anemia Falciforme 84

6 Conclusão e Perspectivas ...........................................................93

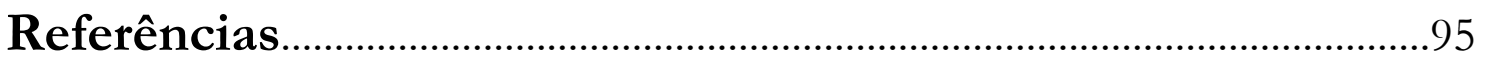

Apêndice 110

A. A função gama.

B. Programas computacionais para construção de mapas de perfusão, em Matlab, usando Algoritmo Genético. 


\section{Lista de Figuras e Tabelas}

Figura 1.1: Esquema da vista microscópica de uma rede capilar. Figura retirada da página: http//: www.corpohumano.hpg.ig.com.br.

Figura 1.2: Estrutura complexa do suprimento sangüíneo cerebral (Huettel et al.,2004)......04

Figura 1.3: Artérias da base do encéfalo. Círculo arterial do cérebro (polígono de Willis). (Figura retirada do Atlas de Anatomia Humana, Netter, 2003)

Figura 1.5: (a) Artérias da face súpero-lateral do cérebro (b). Artéria da face medial e inferior do cérebro. (Figuras retiradas de Ângelo Machado, 2005).

Figura 2.1: Descrição geral dos termos usados para descrever os compartimentos do tecido

Figura 2.2: Ilustração dos quatro compartimentos: o plasma sangüíneo, as células vermelhas do sangue (RBC), o espaço estracelular extravascular (EEE) e o espaço intracelular extravascular. O plasma e o EEE são separados por uma membrana, no cérebro esta é chamada de barreira hematoencefálica.

Figura 2.3. Figura da estrutura do Gd-DTPA, o agente de contraste mais comumente usado. O íon gadolínio está ligado a um composto orgânico [Lauffer, 1996].....

Figura 2.4. A cinética do agente de contraste no tecido. $\frac{d n_{a}}{d t}$ e $\frac{d n_{0}}{d t}$ são as taxas das molécula do agente de contraste que entra e que sai, respectivamente, do compartimento vascular devido ao fluxo. $\frac{d n_{e} p}{d t}$ e $\frac{d n_{e}}{d t}$ descrevem o transporte do agente de contraste dos capilares ao EEE. Se a membrana for simétrica, este transporte é completamente caracterizado por uma única taxa. Para um traçador intravascular, não existe transporte através da membrana dos capilares. 32

Figura 2.5. Três diferentes curvas de concentração e entrada (linhas tracejadas) estão mostradas em a), c) e e). A quantidade de traçador correspondente no plasma está descrita com linhas cheias em b), d) e f), sendo que a curva a curva mais clara corresponde ao fluxo rápido e a curva mais escura ao fluxo mais lento. a) a função Delta resulta numa saída (wash out) exponencial (b). Em c) a constante de infusão resulta na concentração do plasma alcançando o equilíbrio, se a infusão terminar o traçador decai exponencialmente. E em e) uma função de entrada do tipo gama variada resulta em curvas do plasma que também têm a forma da gama variada 
Figura 2.6 A IRF reflete o transporte e agente de contraste através do tecido. Em a se o agente de contraste não está misturado no compartimento, a IRF é uma função da forma caixa. Em b se o bolus tem um grau limitado de mistura, a IRF deve ter a forma de uma função de Fermi. E em c A mistura instantânea é modelada por uma função exponencial. A função na forma de caixa é artificial desde que sempre existirá alguma mistura. Então, a IRF é sempre uma função suave.

Figura 2.7: Ilustração da conversão de uma curva sinal-tempo numa curva concentraçãotempo. Levando em consideração a proporcionalidade entre a queda do sinal de RM e a concentração de agente de contraste num tecido normalmente pefundido. A quantidade de agente de contraste, bolus, está representada na cor verde. Ilustração retirada e modificada da referência [Womg et al, 1999]. .38

Figura 2.8: Típica forma de uma curva concentração-tempo com os vários parâmetros que podem ser usados para a estimação do MT'T.

Figura 3.1: Exemplo de minimização usando o Método gradiente descendente.

Figura 3.2: Esquema de um Algoritmo Genético básico.

Figura 3.3: Exemplo do Método da Roleta .62

Figura 3.4: Cruzamento de um ponto de corte. .64

Figura 3.5: Cruzamento de dois pontos. .65

Figura 3.6: Cruzamento Uniforme. 66

Figura 4.1: Conversão das curvas intensidade-tempo para curvas concentração-tempo de um determinado ponto da imagem 72 Figura 4.2: Ilustração da obtenção dos dados do CBV feito através da integral debaixo da curva ajustada (pintado em vermelho). A curva sólida á a curva gama variável usada e os pontos representados por bolinhas abertas são os dados obtidos a partir das imagens de RM.

Figura 4.3: a) a área debaixo da curva concentração-tempo é definida como o rCBV. b) TPB é o tempo entre a injeção do agente de contraste e a concentração máxima do agente dentro da região de interesse. c) Tc é o tempo entre a injeção do agente de contraste e a chegada das primeiras moléculas do agente de contraste dentro da região de interesse. d) é chamado de primeiro momento da curva, dá uma estimativa do valor do MTT, ou seja, o tempo em que o agente de contraste permanece na região de interesse.. 
Figure 5.1. Resultado da comparação entre os mapas de rCBV usando: a) o programa da GE, b) o método de Levenberg-Marquardt (LM) e c) o método com Algoritmo Genético $(\mathrm{AG})$...... .79

Figure 5.2: A figura mostra os valores de qui-quadrado versus os valores de Tc, de modo a verificar a sensibilidade do valor de qui-quadrado em relação ao Tc utilizado. .82

Figure 5.3: Construção de mapas de CBV usando $\mathrm{Tc}=17 \mathrm{~ms}$, para ambos os métodos. a) Levenberg-Marquardt e; (b) Algoritmo.Genético

Figure 5.4: Mapas hemodinâmicos de 2 pacientes a) CBV, b) MTT e c) mapa de CBF.....83

\section{Tabelas}

Tabela 5.1: Mostra os valores iniciais de qui-quadrado e o número de iterações necessárias para encontrar o valor mínimo usando tanto o método LM quanto o método AG .81

Tabela 5.2: Mostra os resultados do laudo feito através do Doppler Transcraniano, no HCRP. Legenda: ACM (artéria cerebral média), representado a letra e (esquerda) e d

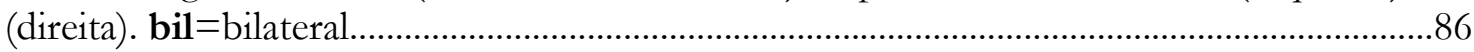

Tabela 5.3: Resultados observados por um neuroradiologista do HCRP-USP . .8 


\section{Capítulo 1}

\section{Introdução}

\subsection{Circulação Sangüínea}

O sistema circulatório é dedicado ao fornecimento de oxigênio, substâncias nutritivas e hormônios aos tecidos; além de exercer a função de levar os produtos residuais do metabolismo $\left(\mathrm{CO}_{2}\right.$ e uréia) até os órgãos responsáveis por sua eliminação.

O alcance do sangue a todas as regiões do nosso organismo se dá através dos o sangue, divididos em três tipos principais: as artérias, as veias, e os capilares [Guyton, 2002].

As artérias têm como função transportar o sangue oxigenado sob uma pressão elevada aos tecidos, por esta razão as artérias têm paredes vasculares fortes e o sangue flui rapidamente nelas.

Pela presença do tecido elástico, as artérias respondem de forma ativa à pressão do sangue. Contudo, o tecido elástico perde a sua flexibilidade com o passar do tempo, tornando suas paredes tortas e endurecidas, o que faz com que a pressão se modifique.

As artérias, à medida que chegam à periferia do corpo humano, vão diminuindo seu diâmetro (arteríolas), até que o seu calibre se torna microscópico (capilares). É justamente nesse nível que ocorre as trocas entre sangue e células. O sangue circula muito lentamente nos capilares (0,8 de milímetro por segundo). Suas paredes se compõem de uma só capa celular, o endotélio, sendo extremamente delgadas, de 1 a 2 milésimos de milímetro; o que as torna permeáveis às moléculas pequenas. Embora sejam extremamente pequenos, os capilares são extremamente numerosos e fazem o intercâmbio entre o sangue e o tecido 
(figura 1.1). Desse modo, o sangue pode ceder às células substâncias nutritivas e delas receber substâncias rejeitadas ou excretadas pelo corpo.

Os capilares confluem para pequenas veias (vênulas), que aos poucos vão se unindo umas com outras, tornando-se maiores (veias propriamente ditas), que por sua vez trazem de volta o sangue ao coração.

As paredes das veias também são formadas por camadas, porém muito mais finas, quando comparada às artérias. Possuem um calibre maior que as artérias, sendo seu fluxo muito mais lento, pois devolvem o sangue dos tecidos ao coração.

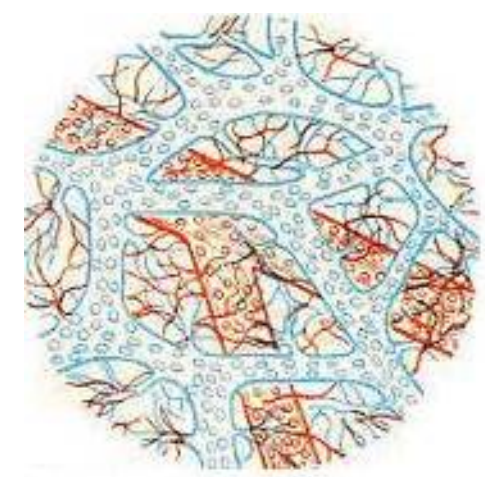

Figura 1.1: Esquema da vista microscópica de uma rede capilar. Figura retirada da página: http//: www.corpohumano.hpg.ig.com.br

\subsection{Circulação do Sistema Nervoso Central}

Da mesma forma, no sistema nervoso central (SNC) as artérias que levam o sangue para o encéfalo e a medula se abrem em vasos cada vez mais finos, que por fim se ramificam em uma extensa rede de capilar capaz de irrigar todas as regiões neurais.

No entanto, a rede vascular arterial do SNC apresenta algumas especializações morfofuncionais engenhosas muito peculiares. Uma característica funcional importante das arteríolas do SNC é a capacidade de sofrer uma regulação local do seu diâmetro, seja para manter o fluxo sangüíneo constante, seja para alterá-lo em resposta às necessidades funcio- 
nais. No sistema nervoso é prioritário controlar o fluxo. Então, o mecanismo de autoregulação atua no sentido de manter constante o aporte de sangue para o encéfalo e medula independentemente das variações sistêmicas. Para tanto, quando há uma elevação da pressão sistêmica, o diâmetro vascular do sistema nervoso se contrai (vasoconstrição); e quando se diminui a pressão o inverso ocorre, ou seja, uma vasodilatação.

O encéfalo representa apenas cerca de $2 \%$ da massa corporal de uma pessoa, mas recebe $15 \%$ do fluxo sanguíneo e consome aproximadamente $20 \%$ do oxigênio disponível na circulação, refletindo, assim, uma alta taxa metabólica do tecido nervoso. A glicose também é intensamente consumida pelos neurônios, que a utilizam como fonte anaeróbica de energia. Como o tecido nervoso não armazena nem glicose nem oxigênio, é necessário que haja um fluxo continuo desses componentes através do sangue arterial. Quando ocorre anóxia ou isquemia de poucos segundos, o indivíduo pode apresentar sintomas neurológicos que dependem da região atingida, e se essas ocorrências se prolongarem por alguns minutos ocorre morte cerebral irreversível. A parada da circulação por mais de sete segundos leva o indivíduo à perda de consciência. Após cerca de cinco minutos começam a aparecer lesões que são irreversíveis, pois como se sabe, as células nervosas não se regeneram [Lent, 2004].

\subsubsection{Anatomia da Circulação Cerebral}

O sistema nervoso central (SNC) não está em contato com o ar. Muito ao contrário, flutua em um ambiente líquido especial que o protege mecanicamente e favorece trocas metabólicas. Esse ambiente líquido é delimitado externamente pelas meninges (dura-máter, aracnóide e pia-máter). Abaixo da aracnóide fica o espaço subaracnóideo, que se comunica com as cavidades internas do SNC (ventrículos e canais). O líquido que preenche esse sistema de compartimento é o líquor ou o líquido cefalorraquidiano, produzido por estruturas especializadas chamadas plexos coróides. A partir dos plexos coróides, o líquor circula pe- 
los ventrículos, passa ao espaço subaracnóideo e é finalmente drenado para o sangue venoso. Esse ambiente líquido que banha o exterior do sistema nervoso e o interior de suas cavidades não é suficiente para garantir a nutrição e o aporte de oxigênio para o tecido nervoso. Para isso é necessária uma rede vascular bastante ramificada e extensa. A rede capilar do tecido nervoso fornece uma superfície de troca de substâncias estimada em cerca de 180 $\mathrm{cm}^{2}$ por grama de substância cinzenta. Isso significa, grosseiramente, algo em torno de 20 $\mathrm{m}^{2}$ de superfície endotelial para prover o SNC humano com as substâncias de que ele necessita [Lent, 2004].

A figura 1.2 ilustra o sistema vascular do cérebro humano. Os vasos vermelhos são contribuintes da artéria cerebral média, os vasos verdes são constituintes da artéria cerebral anterior e os vasos azuis da artéria cerebral posterior. As veias estão mostradas em preto. Como se pode observar o sistema vascular cerebral possui uma infinidade de caminhos pelo qual o sangue chega aos tecidos. Para se ter uma idéia, o cérebro de um humano adulto consome aproximadamente $54 \mathrm{~mL}$ de sangue para cada 100 gramas de tecido, a cada minuto. Isto significa aproximadamente $750 \mathrm{~mL}$ por minuto para um cérebro médio de 1400 gramas e representa cerca de 15 a 20\% do fluxo sangüíneo corpóreo total [Huettel et al.,2004].

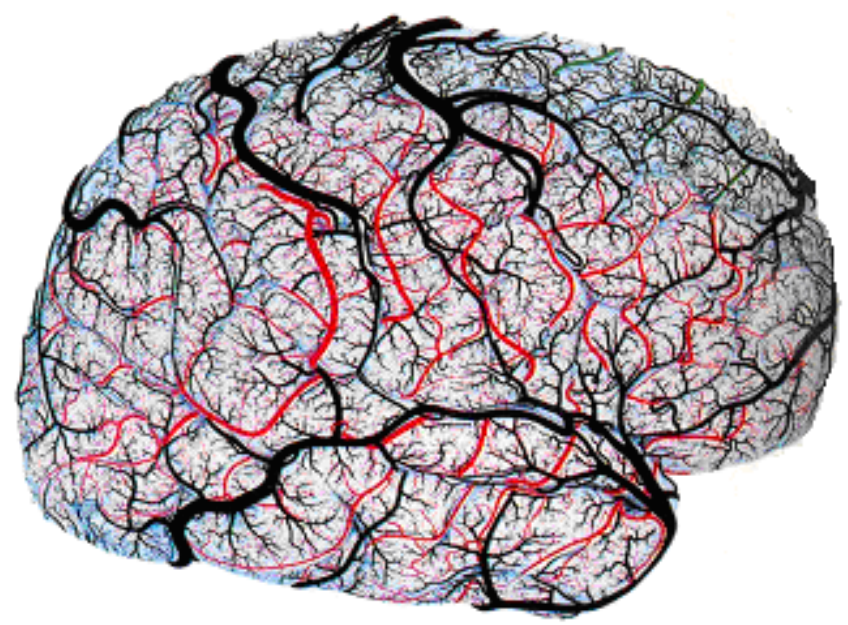

Figura 1.2: Estrutura complexa do suprimento de sangue no cérebro [Huettel et al.,2004]. 


\subsubsection{Vascularização Arterial do encéfalo}

O sistema de irrigação do SNC consiste de três vias de entrada: (1) via anterior ou carotídea, que irriga os hemisférios cerebrais e o tronco encefálico; (2) via posterior ou vértebro-basilar, que compartilha com as carótidas a irrigação do tronco encefálico e se encarrega também da medula espinhal; e (3) via sistêmica, que irriga a medula por anastomose com a via posterior. As grandes artérias que constituem essas três vias têm trajetos similares entre os indivíduos e ao longo desse trajeto emitem numerosos ramos. Alguns deles são superficiais, isto é, cobrem a superfície externa do encéfalo e da medula, gerando finalmente arteríolas penetrantes que se aprofundam no tecido e se abrem na rede capilar. Outros ramos são profundos, orientando-se para as estruturas internas do encéfalo, como os núcleos da base, o diencéfalo e outras [Lent, 2004].

Como pode se visto na figura 1.3, as artérias vertebrais, direita e esquerda, vêm juntas na base do cérebro para formar uma única artéria basilar. A artéria basilar se junta ao suprimento de sangue da artéria carótida interna em um círculo da base do cérebro, chamado de Polígono de Willis, que é uma estrutura de anastomose. As vias de irrigação arterial do sistema nervoso apresentam poucas anastomoses, em relação às que ocorrem em outros órgãos. Estas poucas anastomoses representam as únicas alternativas para manter irrigada uma região, mesmo que apenas parcialmente, quando sua artéria principal sofre algum tipo de obstrução.

A seguir, será visto a descrição e localização das artérias carótidas internas e vertebrais, que constituem, com as artérias basilares, os dois sistemas de irrigação encefálica, sistema carotídeo interno e o sistema vértebra-basilar [Machado, 2005]. 


\section{Artéria carótida interna}

Ramo da bifurcação da carótida comum, a artéria carótida interna, após um trajeto mais ou menos longo no pescoço, penetra na cavidade craniana pelo canal carotídeo do osso temporal, atravessa o seio cavernoso, no interior do qual descreve em um plano vertical uma dupla curva, formando um S, o sifão carotídeo. A seguir perfura a dura-máter e aracnóide e, no inicio do sulco lateral, próximo a substância perfurada anterior, divide-se em dois ramos terminais: as artérias cerebrais médias e anterior (figura 1.3). Além de seus dois ramos terminais, a artéria carótida interna dá os seguintes ramos mais importantes: artéria oftálmica, artéria comunicante posterior e artéria carotídea anterior.

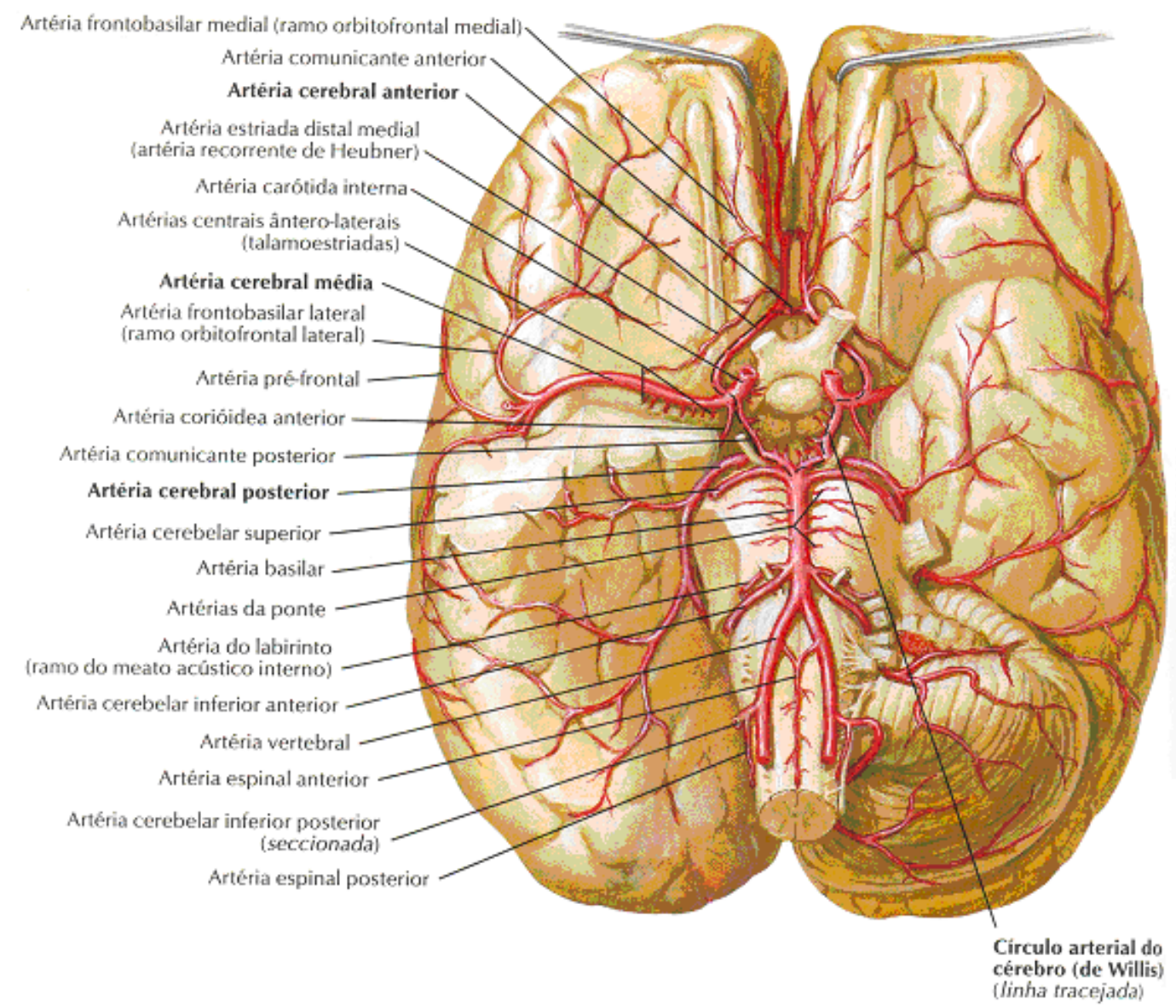

Figura 1.3: Artérias da base do encéfalo. Círculo arterial do cérebro (polígono de Willis). (Figura retirada do Atlas de Anatomia Humana, Netter, F, H. 3a ed., 2003, Porto Alegre). 


\section{Artérias vertebral e basilar.}

As artérias vertebrais, direita e esquerda, destacam-se das artérias subclávias, direita e esquerda correspondentes, sobem no pescoço dentro dos forames transversos das vértebras cervicais, perfuram a membrana atlanto-occipital, a dura-máter e a aracnóide penetrando no crânio pelo forame magno. Percorrem a seguir a face ventral do bulbo e, aproximadamente ao nível do sulco bulbo-pontino, fundem-se para constituir um tronco único, a artéria basilar (figura 1.3). As artérias vertebrais dão origem às duas artérias espinhais posteriores e à artéria espinhal anterior. Originam ainda as artérias cerebelares inferiores posteriores, que irrigam a porção inferior e posterior do cerebelo, bem como a área lateral do bulbo. A artéria basilar percorre geralmente o sulco basilar da ponte e termina anteriormente, bifurcando-se para formar as artérias cerebrais posteriores direita e esquerda. Neste trajeto a artéria basilar emite os seguintes ramos importantes: artéria cerebelar superior, artéria cerebelar inferior anterior e a artéria do labirinto.

\section{O Círculo Arterial do Cérebro}

O círculo arterial do cérebro, ou polígono de Willis, é uma anastomose arterial de forma poligonal situado na base do cérebro, sendo formado pelas porções proximais das artérias cerebrais anterior, média e posterior, pela artéria comunicante anterior e pelas artérias comunicantes posteriores, direita e esquerda (figura 1.3). Esse círculo, em casos desfavoráveis, permite a manutenção de um fluxo sangüíneo adequado em todo o cérebro, em caso de obstrução de uma ou mais das quatro artérias que irrigam o cérebro. Isso acontece pelo fato de que se o suprimento de sangue for interrompido, as células do cérebro morrem. Sendo as células cerebrais altamente especializadas, o cérebro tem prioridade superior para o sangue; ou seja, mesmo se outros órgãos necessitarem de sangue, o corpo tenta fornecer prioritariamente ao cérebro um fluxo constante do sangue [Lent, 2004]. 
Entretanto, o Círculo de Willis tem muitas variações, que torna inesperado o seu comportamento diante de um determinado quadro de obstrução vascular. Em muitos indivíduos, o círculo é incompleto, faltando uma ou mais artérias comunicantes, apesar de não haver qualquer prejuízo funcional Além disso, o estabelecimento de uma circulação colateral adequada depende de outros fatores, tais como a rapidez com que se instala o processo obstrutivo e o estado da parede arterial, o qual, por sua vez, depende da idade do paciente.

\section{Os territórios de irrigação cerebral}

O conhecimento detalhado dos territórios de irrigação das principais artérias do SNC é importante, já que doenças agudas e crônicas desses vasos podem provocar sintomas muito específicos, que dependem da área do tecido nervoso irrigada por cada uma delas. Os hemisférios cerebrais são irrigados pelas artérias cerebrais anteriores, médias e posteriores (Figura 1.4) [Machado, 2005].

\section{Artéria Cerebral Anterior:}

Um dos ramos de bifurcação da carótida interna, a artéria cerebral anterior dirige-se para diante e para cima, ganha a fissura longitudinal do cérebro (figura 1.4b), curva-se diante do joelho do corpo caloso e ramifica-se na face medial de cada hemisfério desde o lobo frontal até o sulco parieto-occipital. Distribui-se também à parte mais alta da face súperolateral de cada hemisfério, onde se limita com o território da artéria cerebral média (figura 4a). A obstrução de uma das artérias cerebrais anteriores causa, entre outros sintomas, paralisia e diminuição da sensibilidade no membro inferior do lado oposto, decorrente da lesão de partes das áreas corticais motoras e sensitiva, que correspondem à perna e que se localizam na porção alta dos giros pré e pós-central. 


\section{$\underline{\text { Artéria Cerebral Média }}$}

Ramo principal da carótida interna, a artéria cerebral média percorre o sulco lateral em toda sua extensão, distribuindo ramos que vascularizam a maior parte da face súperolateral de cada hemisfério (figura 1.4a). Este território compreende áreas corticais importantes, como a área motora, área somestésica o centro da palavra falada e outras. Obstruções da artéria cerebral média, quando não são fatais, determinam sintomatologia muito rica, com paralisia e diminuição da sensibilidade do lado oposto do corpo (exceto no membro inferior), podendo haver ainda graves distúrbios da linguagem. O quadro é especialmente grave se a obstrução atingir também ramos profundos da artéria cerebral média (artérias estriadas), que vascularizam os núcleos da base e a cápsula interna.

\section{Artéria Cerebral Posterior}

Ramos de bifurcação da artéria basilar (figuras 1.4a e 1.4b), as artérias cerebrais posteriores dirigem-se para trás, contornam o tronco encefálico e, se ramifica profundamente por toda a superfície medial e lateral do lobo occipital. A artéria cerebral posterior irriga a área visual situada no lobo occipital e a sua obstrução causa cegueira em uma parte do campo visual.

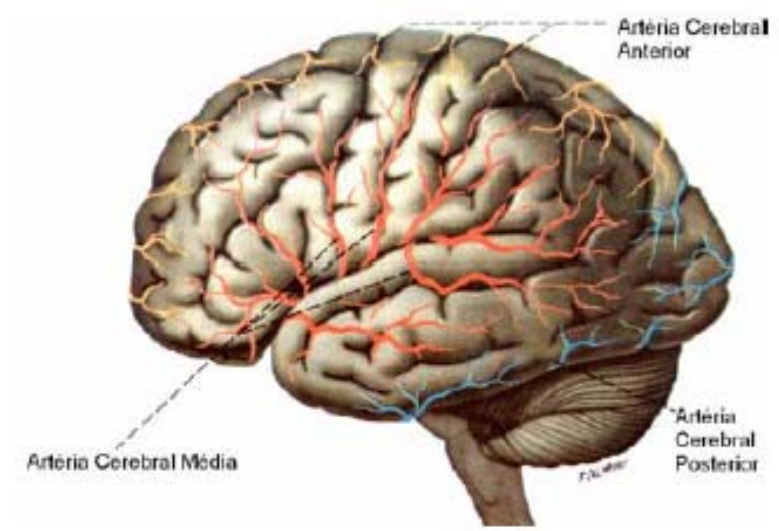

a)

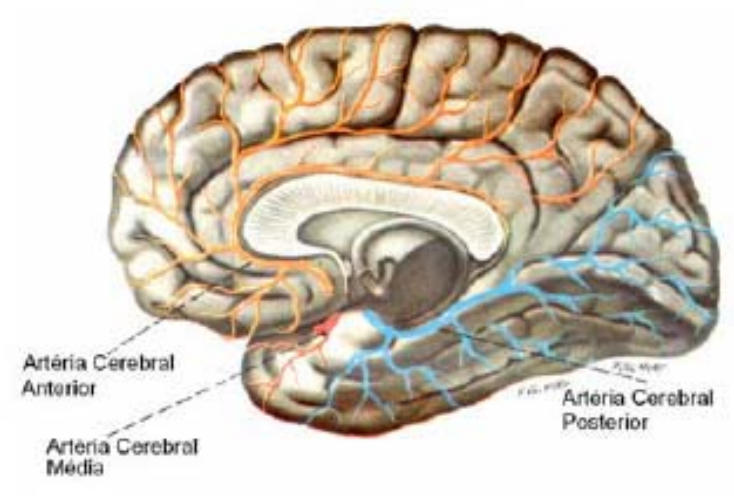

b)

Figura 1.4: (a) Artérias da face súpero-lateral do cérebro (b). Artéria da face medial e inferior do cérebro. (Figuras retiradas de Ângelo Machado, 2005) 
Os núcleos da base e o diencéfalo são irrigados pelos ramos profundos das três artérias cerebrais e por um ramo que emerge diretamente da carótida interna, a artéria coróidea anterior, que também irriga parte do hipocampo. Outro ramo da carótida e a artéria oftálmica irrigam a retina e o nervo óptico. A nutrição do mesencéfalo e do tronco encefálico é feita pelas artérias que constituem a via posterior.

\subsubsection{A Barreira Hematoencefálica}

A primeira noção de que os capilares do Sistema Nervoso Central (SNC) teriam uma permeabilidade diferente dos demais foi obtida através de experiências com animais realizadas no fim do século 19 . Verificou-se que, injetando certos tipos de corantes vitais na corrente sangüínea, todos os órgãos se coravam, com exceção do cérebro, o que indicava que estes corantes não atravessam as paredes dos capilares cerebrais. Entretanto, quando o mesmo corante era injetado no líquido cefalorraquidiano (LCR), ou líquor, havia coloração do tecido nervoso cerebral. Isso sugeria a existência de uma espécie de "barreira", que evitava a entrada de algumas substâncias no SNC [Machado, 2005]. Surgiu assim, a idéia de que qualquer substância que penetrasse no líquor já estaria em contato com o tecido nervoso, mas que existia um tipo de dispositivo que impedia ou inibia a passagem de substâncias do sangue para o tecido nervoso. Esse dispositivo de bloqueio recebeu o nome de "Barreira Hematoencefálica” (BHE).

\section{Características e funções}

A Barreira Hematoencefálica (BHE) é formada por células endoteliais que constituem a parede dos capilares (vasos sanguíneos muito finos), fortemente unidas umas as outras por junções oclusivas, isto é, as membranas das células endoteliais adjacentes estão estreitamente justapostas umas com as outras. Geralmente, na maioria dos outros capilares 
do corpo, o tecido endotelial possui poros ou fendas (também chamadas de fenestrações), para que substâncias possam se mover de um lado para o outro, entrando e saindo dos capilares. Porém, no cérebro, as células endoteliais são posicionadas de maneira que apenas as menores substâncias possam entrar no Sistema Nervoso Central. Moléculas maiores, como a glicose, só podem entrar através de mecanismos especiais, específicos para cada molécula.

Assim, a barreira é extremamente seletiva, permitindo a passagem de algumas substâncias e bloqueando outras. Esse mecanismo seletivo é capaz de garantir aos neurônios e gliócitos o aporte de substâncias nutricionais, além dos gases respiratórios, e ao mesmo tempo bloquear algumas substâncias tóxicas ou neuroativas nocivas, tal como venenos, toxinas, bilirrubina, e inibir a presença de hormônios e neurotransmissores, como a adrenalina, noradrenalina e acetilcolina, que possam estar circulando pelo corpo e danificar o cérebro [Kandel, 2003].

O rígido controle dessa barreira é necessário visto que a maior parte das funções neurais se baseia na comunicação por sinais elétricos gerados pelas membranas dos neurônios e sinais químicos transmitidos de um neurônio a outro. Ambos devem estar protegidos de quaisquer interferências externas que possam perturbar a precisão das mensagens. Além disso, a restrição à transição de certas substâncias constitui um mecanismo de proteção do encéfalo contra agentes que poderiam causar algum tipo de lesão ou alterar seu funcionamento.

Portanto, podemos concluir que entre as funções da barreira hematoencefálica estão: garantir o equilíbrio iônico do compartimento intersticial do tecido nervoso; mediar a entrada controlada de substâncias de importância fisiológica e possibilitar a saída de substâncias que se acumulam no tecido nervoso com potencial risco de neurotoxicidade. Toda essa proteção para manter um ambiente químico constante e protegido para os neurônios funcionarem de maneira estável e eficaz [Lent, 2004]. 


\subsection{Microcirculação Cerebral}

Da mesma forma como nos outros tecidos do corpo, o número de capilares sangüíneos do cérebro é maior onde as necessidades metabólicas são maiores. O metabolismo global da substância cinzenta do cérebro, onde estão localizados os corpos celulares neuronais, é quatro vezes maior do que o da substância branca; de modo correspondente, o número de capilares e a intensidade do fluxo sangüíneo também são cerca de quatro vezes maiores na substância cinzenta [Guyton, 2002].

\section{Metabolismo Cerebral}

Como já foi visto, o cérebro requer oxigênio e nutrientes para suprir as suas necessidades metabólicas. Entretanto, sob condição de repouso, porém em vigília, o metabolismo do cérebro é responsável por cerca de 15\% do metabolismo total do corpo, ainda que a massa do cérebro corresponda a somente $2 \%$ da massa corporal total. Portanto, sob condições de repouso, o metabolismo do cérebro por unidade de massa de tecido é cerca de 7,5 vezes maior do que o metabolismo médio em tecidos extra-sistema nervoso.

A maior parte desse excesso metabólico do cérebro ocorre nos neurônios, e não nos tecidos gliais de sustentação. A maior necessidade do metabolismo nos neurônios é para bombear íons através de suas membranas, principalmente para transportar os íons sódio e cálcio para o lado externo da membrana neuronal e os íons potássio e cloreto para o interior. Cada vez que um neurônio conduz um potencial de ação, esses íons movem-se através da membrana em direções opostas, aumentando a necessidade de transporte adicional, no nível da membrana, para restaurar as diferenças de concentrações iônicas apropriadas através das membranas neuronais. Portanto, durante a atividade cerebral excessiva, o metabolismo neuronal pode aumentar por até 100 a $150 \%$. 
A maioria dos tecidos do corpo pode sobreviver sem oxigênio durante vários minutos, e alguns por até 30 minutos. Durante esse tempo, as células dos tecidos obtêm sua energia pelos processos do metabolismo anaeróbico, o que significa a liberação de energia pela degradação parcial da glicose e do glicogênio, porém sem a participação do oxigênio. Contudo, o metabolismo anaeróbico mantém os tecidos vivos.

O cérebro não é capaz de manter um metabolismo anaeróbico significativo. Uma das razões para tal é a alta intensidade metabólica dos neurônios, uma vez que é necessária muito mais energia para cada célula cerebral do que na maioria dos outros tecidos. Razão adicional é que a quantidade de glicogênio armazenada nos neurônios é pequena, de tal modo que a degradação anaeróbica do glicogênio não está disponível para suprir muita energia. As reservas adicionais de oxigênio nos tecidos cerebrais também são pequenas, portanto, a maior parte da atividade neuronal depende da distribuição, segundo a segundo, de glicose e de oxigênio pelo sangue.

Colocando juntos todos esses fatores, podemos compreender por que a cessação súbita o fluxo sangüíneo no cérebro ou a falta total súbita de oxigênio no sangue podem causar inconsciência dentro de 5 a 10 segundos. Mais que isso, o encéfalo é extremamente vulnerável a alterações do seu suprimento sangüíneo. Anoxias e isquemias que duram apenas alguns segundos causam sintomas neurológicos e, quando duram minutos podem causar dano neuronal irreversível [Guyton, 2002].

\subsubsection{Doenças e Desordens Cerebrais}

A IRM é uma ferramenta poderosa de diagnóstico clínico, inicialmente usada para adquirir imagens morfológicas de vários tecidos para a identificação de estruturas patológicas. Nos últimos anos, sua aplicação tem se expandido para a avaliação da função cerebral através de alguns métodos funcionais ou metabólicos, tal como a perfusão cerebral. A quantificação de parâmetros que caracterizam a microcirculação cerebral com IRM é de 
grande importância na avaliação da irrigação cerebral, em especial nas doenças cerebrovasculares. De fato, as medidas de perfusão podem ser usadas para diagnosticar e avaliar uma série de doenças [Guyton, 2002], que ocasionam um decréscimo ou acréscimo focalizado da perfusão, que serão descritas a seguir.

\section{Acidente Vascular Cerebral -AVC}

Quase todas as pessoas idosas têm pelo menos algum bloqueio do suprimento de sangue arterial para o cérebro, e até 10\% das pessoas acabam apresentando um bloqueio tal, que pode causar distúrbio da função cerebral, a condição chamada Acidente Vascular cerebral. Os efeitos neurológicos do AVC são determinados pela área cerebral afetada.

A maioria dos AVC é causada por placas arterioscleróticas que ocorrem em uma ou mais artérias que alimentam o cérebro. As placas podem ativar o mecanismo de coagulação do sangue que bloqueia o fluxo sangüíneo da artéria, levando, assim, à perda aguda da função cerebral em área localizada. Em cerca de um quarto das pessoas que desenvolvem AVC, a alta pressão arterial faz com que haja ruptura de um dos vasos sangüíneos; ocorre então a hemorragia, comprimindo o tecido cerebral local, e a subseqüente coagulação do sangue também levam ao bloqueio do vaso sangüíneo [Kandel, 2003].

Os AVCs podem ser oclusivos (por obstrução de um vaso sangüíneo) ou hemorrágicos (por extravasamento de sangue dos vasos). A insuficiência de suprimento sangüíneo é chamada de isquemia. Se for temporária, os sinais e os sintomas melhoram, deixando pouco ou nenhuma evidência patológica de dano tecidual, se não, dependendo da área afetada pode ocorrer desde disfunções cerebrais até morte tecidual (zona enfartada). Nestas áreas de derrame, após a ruptura da veia, há um decréscimo do volume de sangue, como também uma diminuição do fluxo sanguíneo e por conseqüência um aumento no tempo de trânsito (tempo médio que o sangue demora em atravessar uma dada região cerebral) e uma redução na perda do sinal (induzido pelo agente). 


\section{Tumores cerebrais e avaliação histológica}

Várias situações patológicas estão associadas com alteração da função da barreira hematoencefálica. Muitos tumores encefálicos contêm vasos com uma barreira hematoencefálica pobre ou incompletamente desenvolvida. A permeabilidade anormal dos vasos é responsável pelo acúmulo excessivo de líquido intersticial (chamado edema vasogênico) comumente associado aos tumores cerebrais.

As variações no fluxo de sangue ocorrem, pois o crescimento dos tumores acima de um determinado tamanho depende do desenvolvimento de um tecido vascular "complementar" para suprir as necessidades metabólicas do tecido neoplásico (tumoral). Isso porque, uma vez que o tumor alcança uma certa massa crítica (equivale a 1 milímetro cúbico ou aproximadamente 1 milhão de células), a difusão metabólica torna-se insuficiente e o crescimento de novos vasos deve ocorrer para continuar o crescimento. Avaliando essa neovascularidade em tumores, pode se correlacionar com o grau de malignidade do tumor [Selch et al, 1998, kremer et al, 2002].

As imagens de perfusão podem também ajudar na avaliação precoce de novos agentes terapêuticos. Isso pode ser feito avaliando a influência dos medicamentos que tem o objetivo de impedir o crescimento dos vasos. Freqüentemente é realizada uma análise das imagens de perfusão cerebral dos pacientes que usam medicamentos para tratar doenças neurodegenerativas, de modo a estimar a eficácia dos medicamentos usados nos tratamentos destas doenças.

\section{$\underline{\text { Epilepsia }}$}

Uma aplicação importante é a investigação da atividade cerebral em pacientes que sofrem de epilepsia. Em algumas formas de epilepsia que não respondem bem à medicação anticonvulsivante, a cirurgia pode ser indicada. Esse procedimento é caracterizado pela 
remoção do tecido epileptogênico, causador da atividade anormal. Infelizmente, os métodos de diagnóstico e localização das fontes das descargas anormais ainda são muito imprecisos e invasivos. Técnicas tradicionais de diagnóstico envolvem a intervenção cirúrgica para o registro direto de sinais na superfície cerebral através de eletrocorticogramas. Dado o número de pacientes que sofrem desse mal, cujos surtos são provenientes de uma área específica do cérebro, existe a necessidade de aperfeiçoamento de métodos de detecção e localização de eventos anormais.

Algumas formas de epilepsia são acompanhadas por distorções anatômicas, evidentes em técnicas de neuroimagens de alta resolução anatômica, como a MRI. No entanto, outros casos exibem alterações neurofisiológicas que não são combinadas a deformações anatômicas. Conseqüentemente, sua caracterização passa pela análise dos traçados da atividade elétrica cerebral, em busca da localização do tecido epileptogênico. Outra alternativa seria a localização através das imagens de perfusão, já que as zonas responsáveis pelos ataques epiléticos requerem uma demanda grande de sangue.

\section{$\underline{\text { Anemia falciforme }}$}

O nosso sangue é formado de células vermelhas chamadas de hemácias. As hemácias são células redondas repletas de um pigmento chamado de hemoglobina, que dá a cor vermelha ao sangue. A hemoglobina e o ferro são responsáveis por levar o oxigênio do pulmão para todo o corpo, para que todos os órgãos funcionem bem.

A anemia é a diminuição da hemoglobina no sangue. Na maioria das vezes, essa diminuição ocorre por falta de ferro no sangue, razão pela qual os órgãos não recebem a quantidade suficiente de oxigênio e não podem desempenhar bem suas funções. Ao contrário da anemia comum, a anemia falciforme (AF) não possui tratamento definitivo. Assim, há indivíduos portadores de uma forma branda e de uma forma severa da mesma 
doença. De qualquer forma, a rigidez das hemácias prejudica a circulação sangüínea normal, visto que essas células presentes no sangue, já não têm mais uma capacidade maleável de passar através das veias mais finas. Deste modo, não só um prejuízo no transporte de sangue, mas possíveis entupimentos e rupturas das veias se tornam mais freqüentes e propício [Ohene-Frempong et al, 1998].

Complicações neurológicas são muito comuns em pacientes portadores de anemia falciforme. Para se ter uma idéia, o derrame cerebral é uma das complicações mais sérias em pacientes com Anemia Falciforme (AF), ocorrendo em 5 a 8\% dos pacientes, representando $12 \%$ das mortes pediátricas dos portadores desta doença [Crowley and Sarnaik, 1999]. Esse número é tão grande, que o derrame cerebral em pacientes com AF é 250 vezes mais comum do que em outras crianças não portadoras da doença [Earley et al, 1998], o que torna esses dados são similares ao da população idosa em geral.

Os pacientes falcêmicos recebem terapia de transfusão crônica para prevenir derrames recorrentes, que é o tratamento padrão para a prevenção de infartos secundários cerebrais, e esta terapia consegue prevenir o risco de derrames recorrentes e reduzí-los de 10 a 15\% [Pegelow, et al, 1995]. Entretanto, O risco da terapia de transfusão inclui entre outras coisas, excesso de ferro no organismo e possíveis a infecções virais.

Apesar de não haver um tratamento efetivo, a prevenção tem sido uma das ferramentas aliadas nesta doença. A imagem por perfusão, usando RM, vem justamente para ajudar, como uma ferramenta adicional, em casos onde possa haver problemas cerebrais envolvidos. Isso pode ser dar através da monitorização periódica dos pacientes a fim de encontrar possíveis regiões com perfusão alterada. 


\section{Capítulo 2}

\section{Perfusão Cerebral}

A identificação do cérebro como um órgão central que controla as sensações, a atividade motora, as emoções e a razão tem sido questionada desde o século 18 [Clarke et al., 1968, Zanchin at al., 1989]. Enquanto que grandes pensadores como Pitágoras, Hipocrates e Platão acreditavam nesse ponto de vista, Aristóteles adotava a visão de que o coração era o órgão mais importante. Ele atribuía ao cérebro a função de resfriar o calor produzido pelo coração e conduzido através do sangue. Desse modo, ele identificou a vasculatura da superfície cerebral e ainda percebeu que estes vasos eram bem pequenos e numerosos. $\mathrm{O}$ conhecimento sobre a função e a anatomia cerebral foi limitado até o Renascimento. Antes disso, muito do conhecimento era baseado na dissecação de animais, o que conduzia a identificação errônea com relação à regulação sangüínea. Com o passar do tempo o conhecimento anatômico foi gradualmente crescendo, o que acarretou a descoberta do Círculo de Willis, que estabelecia a idéia de fluxo colateral de modo a suprir uma região de perfusão deficiente. Nesse momento, começam a surgir os primeiros indícios de uma mudança de foco da anatomia para a fisiologia da circulação cerebral.

No final do século 19 e começo do século 20 surgiram dois métodos de medida de fluxo de sangue cerebral, os quais formam a base das medidas de perfusões atuais. O primeiro método é baseado na injeção ou inalação de um agente de contraste difusível. Tal agente, como o xenônio ou água, pode atravessar livremente a barreira sangue-cérebro. A primeira aplicação desta técnica foi através da injeção de óxido nitroso, o que forneceu a primeira medida de fluxo sangüíneo do cérebro. Este método também permitiu a investigação da influência de medicamentos e doenças (ou desordens) no fluxo de sangue cerebral. 
Com o advento de novas modalidades de imagem, como o SPECT (Single Photon Emission Computer Tomography) e PET (Positron Emission Tomography), métodos novos de medidas de perfusão foram desenvolvidos, sendo estes baseados no mesmo princípio de traçadores.

O desenvolvimento mais recente a respeito de medidas de perfusão se refere às medidas feitas utilizando Imagem por Ressonância Magnética. Várias técnicas de medidas têm sido usadas, entre as mais comuns estão as que envolvem os traçadores que se difundem livremente, chamada de arterial spin labelling (ASL), e aquelas que medem o rastreamento de um agente intravascular. Este último método é baseado na injeção de um traçador intravascular e o monitoramento de sua primeira passagem através do tecido. Embora a primeira aplicação deste método date do final do século 19, seu uso generalizado começou apenas nas últimas décadas. Atualmente, a aplicação de ambas as técnicas tem provocado um crescente conhecimento sobre a regulação hemodinâmica do tecido cerebral e a sua influência nas doenças e desordens cerebrais.

\subsection{A importância da Imagem de Perfusão}

Como já foi visto no Capítulo 1, os metabólitos se difundem a partir do sangue e passam através das membranas dos capilares para dentro dos tecidos. Esse suprimento, contínuo, de metabólitos do sangue ao tecido, e vice-versa, é essencial para as células teciduais. A perfusão está, portanto, intimamente relacionada ao estado fisiológico do tecido.

Especialmente, em três áreas da medicina, a aplicação das medidas de perfusão cerebral tem produzido resultados promissores. Primeiro, as medidas de perfusão têm aumentado visivelmente o conhecimento sobre a hemodinâmica deficiente em algumas regiões, por exemplo, em pacientes com doenças na artéria carótida ou demência. Powers et al. propuseram um importante modelo que descrevia as várias fases da deficiência hemodinâmica [Powers, et al. 1991]. De acordo com esse modelo, a diminuição na pressão de perfusão resulta, primeiramente, em um aumento no volume de capilares. Em seguida, em uma 
combinação de fluxo sangüíneo diminuído e extração de oxigênio aumentada, ocorre uma substituição do metabolismo aeróbico pelo anaeróbico, que eventualmente conduza a danos isquêmicos. A segunda maior área de aplicação é na pesquisa de AVCs agudos. Como será visto adiante, a perfusão é o fluxo de sangue nos menores capilares do tecido. Em pacientes que sofreram AVC, o nível de perfusão é significantemente alterado, já que o nível de perfusão está intimamente relacionado à sobrevivência do tecido. As pesquisas nessa área têm tido um papel importante em estudos na predição do crescimento de infartos e na avaliação de intervenções terapêuticas [Ueda et al., 1999]. A última, e maior área que tem empregado a pesquisa de perfusão, é a graduação de tumores cerebrais. Casos em que a perfusão poderia fornecer informações sobre a angiogênese do tumor [Aronen et al., 1994; Griebel et al., 1997; Roberts et al., 2000, Jackson et al., 2002].

Naturalmente, qualquer variação significativa da perfusão cerebral pode fornecer informações relevantes sobre uma área específica, seja ela hipo e/ ou hiper-perfundida. Ademais, os níveis de perfusão variam em um grande número de doenças. Ganong [Ganong, 1993] lista vários exemplos incluindo foco epiléptico, que é hiper-perfundido durante as crises, enquanto que o fluxo é reduzido em outras partes do cérebro. Outros exemplos interessantes incluem a demência senil, em que há diminuições do fluxo, que parece estar relacionado ao grau de demência, a esquizofrenia, a depressão e a doenças menos comuns, como a de Huntington [Marstrand et al; 2001], e a anemia falciforme, que será tratada em mais detalhes neste trabalho.

As doenças cerebrovasculares em pacientes com AF são normalmente estudas usando angiografia por ressonância magnética (Magnetic Resonance Angiography-MRA) [Kandeel et al, 1996] ou Doppler Transcraniano (Transcranial Doppler-TCD) [Adams et al, 1992, Seibert et al, 1993, Verhac et al, 1995, Adams et al, 1997 e 1998, Crowley and Sarnaik, 1999].

Alguns estudos usando novas técnicas de imagem têm sido realizados no intuito de investigar as doenças neurológicas de origem circulatória, principalmente no que se refere 
às diferenças entre doenças de vasos largos e de vasos pequenos, além de suas manifestações clínicas [Tzika et al, 1993, Baird et al, 1998, Calamante et al, 1999, Kirkham et al, 2001]. A análise das imagens ponderada por perfusão vem sendo investigada, de modo a verificar sua capacidade em fornecer informação sobre a perfusão cerebral regional em pacientes falcêmicos [Calamante et al, 2001, Moritania et al, 2004].

Este espectro amplo é bastante fértil para novas pesquisas que envolvem o cérebro, de modo a contribuir não só para o entendimento da sua fisiologia, mas também para auxiliar no diagnóstico, prevenção ou tratamento de doenças ou disfunções cerebrais.

\subsection{Conceitos de Perfusão Cerebral}

O termo perfusão é usado em um grande número de descrições de processos de fornecimento de oxigênio e nutrientes para o tecido cerebral, como o fluxo de sangue nas carótidas, o fluxo de sangue nos capilares e na extração de oxigênio do sangue. Nesta tese o termo será usado em todo o processo que envolva o fornecimento de oxigênio e nutrientes ao tecido cerebral. Há vários termos que podem ser usados para descrever partes específicas desse processo:

$\checkmark$ Fluxo de sangue cerebral (CBF): é definido como a quantidade de sangue fornecido aos capilares por massa de tecido, por unidade de tempo; sendo expresso em $[\mathrm{ml} / 100 \mathrm{ml}$ de tecido/min] ou $[\mathrm{ml} / 100 \mathrm{~g}$ de tecido/min]. Ele descreve o suprimento de oxigênio e nutrientes, apesar de não refletir o transporte através da barreira hematoencefálica ou a quantidade de oxigênio e nutrientes dissolvidos no sangue;

$\checkmark$ Volume de Sangue Cerebral (CBV): O volume relativo dos capilares é descrito pelo CBV (dado em $[\mathrm{ml} / 100 \mathrm{~g}$ de tecido]). É um indicador da vasodilatação, que faz um importante papel garantindo um fluxo de sangue suficiente para o tecido quando o fluxo é inversamente relacionado à resistência da microvasculatura; 
$\checkmark$ Tempo de Trânsito Médio (MT'T): é definido como o tempo médio que o sangue leva para atravessar o leito capilar. Estudos demonstraram que o recíproco do TTM é proporcional à pressão da perfusão [Ferrari et al 1992];

$\checkmark$ Fração de Extração de Oxigênio (OEF - Oxigen Extraction Fraction): a diferença na oxigenação do sangue nas arteríolas e do sangue nas veias é dada pela OEF e está, portanto, relacionada ao uso local de oxigênio;

Taxa Metabólica Cerebral de Consumo de Oxigênio $\left(\mathrm{CMRO}_{2}-\right.$ Cerebral Metabolic Rate of Oxygen): é conhecido como o produto do CBF com a OEF, que reflete o uso local de oxigênio e logo a quantia de energia produzida pelo metabolismo aeróbico;

Tempo de Pico do Bolus (TPB) e tempo de chegada (Tc): Esses dois parâmetros de tempo indicam o tempo que o sangue leva para fluir da artéria carótida até o tecido cerebral. Esses parâmetros de tempo produzem, portanto, pouca informação sobre a microvasculatura, mas conseguem descrever a eficiência do transporte sangüíneo aos capilares;

\subsection{Medidas de Perfusão}

Várias técnicas têm sido usadas para medidas de perfusão e de fluxo de sangue. Uma delas é chamada de Doppler Transcraniano (TCD), que usa o ultra-som para realizar medidas de fluxo de sangue. A tomografia computadorizada (CT - Computer Tomography) usa raios-X e é também disponível na maioria dos hospitais. A tomografia computadorizada por emissão de único fóton (SPECT), e a tomografia por emissão de pósitron (PET), usam traçadores metabólicos radioativos de modo a medir a perfusão. A SPECT é mais usada que a PET, já que a segunda requer um cíclotron (acelerador de partículas sub- 
atômicas) e um pessoal dedicado à produção de traçadores radioativos, os chamados radiofármacos (radioisótopos que servem de marcadores). No entanto, a SPECT apenas adquire medidas de perfusão relativas, enquanto que a PET tem sido considerada como método padrão para a quantificação da perfusão no cérebro.

Uma subdivisão dos métodos de perfusão pode ser feita dependendo do tipo de traçador utilizado. Se esse traçador for livremente difusível, o CBF é calculado usando o princípio de Fick. Já nos casos em que o traçador é intravascular, se aplica à diluição de indicadores. Neste trabalho, entraremos em mais detalhes apenas nos processos que envolvem a imagem por ressonância Magnética.

\subsubsection{Medidas usando traçadores não-difusíveis}

Os primeiros experimentos que envolveram a diluição de indicadores foram realizados no final do século 19 [Stewart et al, 1894], que utilizava a injeção intra-arterial de um traçador para medir o tempo de trânsito através de um órgão de interesse. Contudo, a significância clínica desses tempos de trânsito, no órgão como um todo, é limitada pelo fato de não haver nenhuma informação sobre o percurso que o traçador percorre no órgão, ou seja, apenas conseguimos medir a conexão mais rápida entre a artéria e a veia. Zierler estendeu a base teórica do método para superar essa desvantagem e calcular os mapas de perfusão a partir da primeira passagem de um traçador intravascular [Zierler, 1962]. A idéia geral do método é que a cada junção da árvore vascular o agente de contraste se dividirá de acordo com a proporção do fluxo. Como traçador não atravessa a barreira hematoencefálica, a quantidade de traçador em um vaso é proporcional ao fluxo naquele vaso.

Os agentes de contraste têm sido usados nos últimos dez anos para obter a informação sobre diferentes parâmetros fisiológicos relacionados ao fluxo de sangue cerebral $(\mathrm{CBF})$, volume de sangue cerebral (CBV) e ao tempo de trânsito médio (MTT) do sangue [Rosen et al, 1991; Buxton, 2000; Petrella et al., 2000]. Agentes de contraste endógenos são 
referidos a contrastes pertencentes ao próprio corpo ou órgão que utiliza sangue marcado para monitoração da perfusão, já os agentes exógenos são aqueles que possuem sua origem externa ao corpo ou órgão, como materiais paramagnéticos.

Embora o espaço vascular seja uma fração pequena do volume total do tecido (cerca de 5\% no cérebro humano), a compartimentalização do agente de contraste dentro do espaço intravenoso conduz a uma significativa perda do sinal, conforme o contraste se movimenta. O que esse agente de contraste paramagnético faz é alterar a susceptibilidade magnética local, de modo a alterar os tempos de relaxação e por conseqüência a intensidade do sinal de RM. Por esta razão tais técnicas são chamadas de contraste por susceptibilidade dinâmico (Dynamic Susceptobility Contrast - DSC-MRI) [Villringer, et al., 1988; Rosen et al., 1990]. Se o suprimento arterial para qualquer região do cérebro está comprometido, isto deve ser detectado como uma anormalidade (por exemplo, um atraso ou atenuação) na variação da intensidade do sinal. Modelos matemáticos [Belliveau et al., 1990; Rosen et al., 1990, Pickens, 1992] permitem mapas para ser dados a partir de variações nas intensidades dos sinais, refletindo o fluxo de sangue cerebral relativo (CBF), volume de sangue cerebral relativo (CBV) e o tempo de trânsito médio (MTT) do agente de contraste. Os modelos que permitem a obtenção desses parâmetros serão discutidos a seguir.

\subsection{Modelos para a Obtenção dos Parâmetros de Interesse}

O modelo do tecido é apresentado como um sistema simplificado, cujo foco principal é a perfusão cerebral. Para tanto, grosso modo, o tecido apresentado aqui consiste do sangue presente nos capilares, e nos tecidos adjacentes. O sangue consiste de duas partes. Uma, são as células sangüíneas, principalmente as células vermelhas, (Red Blood Cells RBC). A outra parte é o plasma, que é justamente o fluido que transporta estas células vermelhas. Juntos, chamaremos, neste caso, de espaço vascular. Os tecidos vizinhos também consistem de duas partes. Uma contendo as células do tecido, e a outra o espaço interstici- 
al. Juntos eles formam o espaço extravascular. O espaço intersticial é também chamado de espaço extracelular extravascular, EEE, que será o termo usado aqui por diante. Os termos estão apresentados a seguir na figura 2.1. O sistema que consiste de quatro compartimentos está esboçado na figura 2.2.

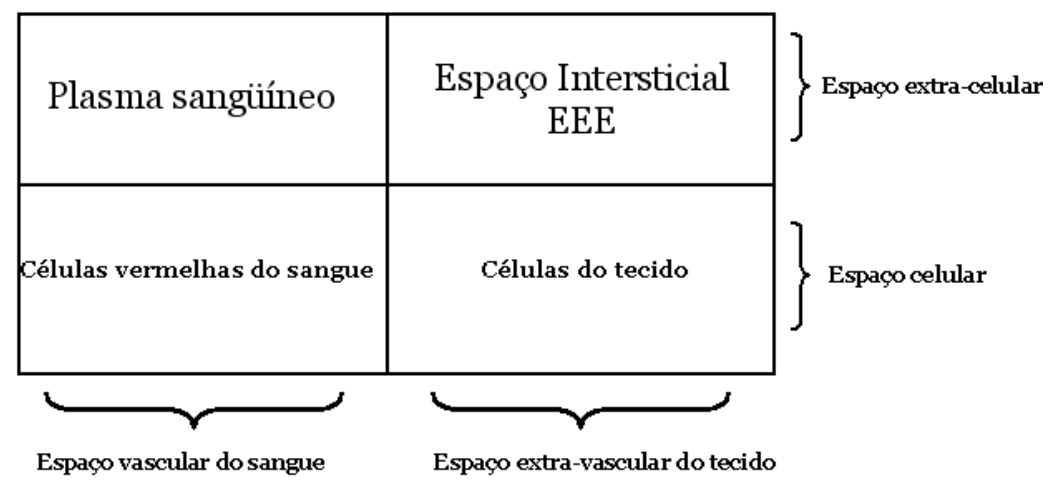

Figura 2.1: Descrição geral dos termos usados para descrever os compartimentos do tecido.

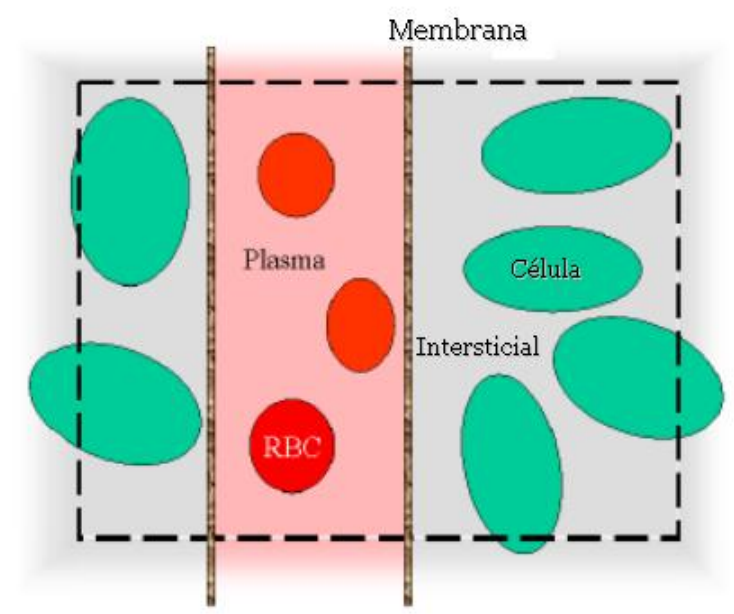

Figura 2.2: Ilustração dos quatro compartimentos: o plasma sangüíneo, as células vermelhas do sangue (RBC), o espaço estracelular extravascular (EEE) e o espaço intracelular extravascular. $\mathrm{O}$ plasma e o EEE são separados por uma membrana, no cérebro esta é chamada de barreira hematoencefálica.[Cho et al, 1993]. 
Cada um dos quatro compartimentos individuais e do tecido como um todo, são descritos pelos parâmetros listados a seguir:

$\checkmark \quad$ O tecido, de uma maneira geral, o tem um volume $\mathrm{V}_{\mathrm{bt}}[\mathrm{ml}]$; uma massa $\mathrm{m}_{\mathrm{bt}}[\mathrm{g}]$; uma densidade $\rho=\frac{m_{b t}}{V_{b t}}[\mathrm{~g} / \mathrm{ml}]$; e uma concentração de agente de contraste médio $C_{b t}=\frac{n_{b t}}{V_{b t}}[$ mmoles $/ \mathrm{ml}]$, sendo que $n_{b t}$ é a quantidade de traçador em mmoles no tecido total. A concentração do $\mathrm{k}$ tecido é freqüentemente calculada como $C_{b t}=\frac{n_{b t}}{m_{b t}}$ com unidades de $[$ mmoles $/ g]$

$\checkmark \quad$ O plasma sangüíneo tem volume $\mathrm{V}_{\mathrm{p}}[\mathrm{ml}]$, volume específico $v_{p}=\frac{V_{p}}{V_{b t}}$, a concentração do contraste $C_{p}=\frac{n_{p}}{V_{p}}[\mathrm{mmole} / \mathrm{ml}]$ e densidade $\rho_{p}=\frac{m_{p}}{V_{p}}[\mathrm{~g} / \mathrm{ml}]$

$\checkmark$ As células vermelhas do sangue, $\mathbf{R B C}$ com volume $\mathrm{V}_{\mathrm{r}}$, a concentração de agente de contraste $C_{\mathrm{r}}$ e a densidade $\rho_{\mathrm{r}}$. O hematócrito, Hct, é definido como a fração de volume RBC para o volume vascular, $H c t=\frac{V_{r}}{V_{r}+V_{p}}$

$\checkmark$ O espaço extracelular extravascular, EEE com volume $V_{e}$, volume específico $V_{e}=\frac{V_{e}}{V_{b t}}$, concentração do contraste $\mathrm{C}_{\mathrm{e}}$ e a densidade $\rho_{\mathrm{e}}$

$\checkmark$ As células de tecido com volume $V_{c}$, a concentração de agente de contraste $C_{c}$ e densidade, $\rho_{c}$. 
Os compartimentos extravasculares (EEE e células do tecido) juntas são referidas como tecido com concentração $C_{t}[$ mmoles $/ \mathrm{ml}$ ] seguindo a notação [Tofts et al, 1999]. Eles usam a concentração arterial, $C_{a}[\mathrm{mmoles} / \mathrm{ml}]$, como a função de concentração de entrada ao tecido. A concentração vascular do sangue todo, aqui chamada de $\mathrm{C}_{\mathrm{b}}[\mathrm{mmoles} / \mathrm{ml}]$, é normalmente considerada igual à concentração da artéria. Ainda, o tamanho dos compartimentos é de aproximadamente: espaço intravascular tem $V_{b}=5 \% V_{b t}$, EEE possui $\mathrm{V}_{\mathrm{e}}=15 \% \mathrm{~V}_{\mathrm{b}}$, e espaço intracelular, $\mathrm{V}_{\mathrm{c}}=80 \% \mathrm{~V}_{\mathrm{bt}}$ [Lauffer, 1996].

O modelo esboçado na figura 2.2 parece muito simples, em especial quando se tem a noção de que os capilares constituem uma vasta rede de vasos. Esse modelo é descrito por uma única entrada, que é uma suposição razoável, desde que muitas das entradas para o voxel cheguem a partir das artérias próximas.

Uma vez que a RM é um método de detecção residual, ela mede a concentração de contraste remanescente no tecido. Então, ela não tem nenhuma influência, em qual direção o traçador deixa o voxel, apenas o tempo de entrada é relevante. Além disso, deve ser dito que o tempo de transito médio, MTT [s], de um traçador através de um órgão ou tecido está relacionado ao fluxo, $\mathrm{F}[\mathrm{ml} / \mathrm{s}]$, e o volume de distribuição do agente de contraste, $\mathrm{V}_{\mathrm{D}}$ [ml], pela razão [Lassen et al, 1984]:

$$
\mathrm{F}=\mathrm{V}_{\mathrm{D}} / \mathrm{MT} \mathrm{T}
$$

A equação 2.1 deve ser dividida pela massa de tecido, $m_{b}$ em ambos os lados. Isto conduz ao teorema do volume central, que será mais amplamente discutido adiante, expressado em termos da perfusão:

$$
f=\lambda / M T T,
$$

sendo que, 


$$
\lambda=\frac{V_{D}}{m_{b t}}
$$

é o volume de distribuição do agente de contraste medido em $[\mathrm{ml} / \mathrm{g}]$.

Por simplicidade, o sistema deve então ser exclusivamente considerado como representado na figura 2.2, mas deve ter-se em mente que a área de superfície da BHE (barreira hematoencefálica) é muito mais extensa do que como foi esboçada e que a direção de fluxo é isotrópico como será descrito mais adiante.

\subsection{O Agente de Contraste}

O traçador mais comumente usado em imagens de RM é o gadolínio (III) ácido dimetilenotriaminapenaacético, Gd-DTPA, (Magnevist, Scheering) [Lauffer, 1996]. Embora tóxicos, os átomos de gadolínio são altamente magnéticos. A sua ligação com um quelato forte, DTPA, elimina sua toxidade tornando o agente apto para uso clínico. A figura 2.3, mostra a ligação do gadolínio com o DTPA. [Felix et al, 1998a]. Esse complexo é excretado pela via renal com uma constante de formação muito elevada, e teve seu uso aprovado pela FDA americana, para o uso em diagnóstico, em meados dos anos 80.

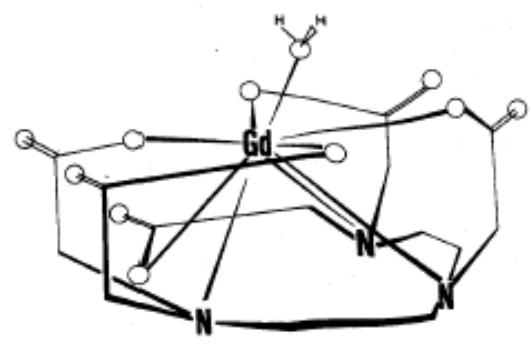

Figura 2.3. Figura da estrutura do Gd-DTPA, o agente de contraste mais comumente usado. O íon gadolínio está ligado a um composto orgânico [Lauffer, 1996]. 
O Gd-DTPA se distribui dentro de todo o espaço extracelular em muitos corpos. No cérebro, o agente fica intravascular desde que ele não possa passar pela barreira hemato-encefálica (BHE). Se ocorrer uma ruptura desta barreira, o Gd-DTPA entra no tecido extravascular, mas permanece extracelular, ou seja, nem entra nas células vermelhas sangüíneas (RBC) nem nas células do tecido [Felix et al, 1998b]. A concentração nos capilares, $C_{b}$, é então a razão da quantidade de traçador no plasma e o volume vascular, $C_{b}=n_{p} / V_{b}$. Do mesmo modo, a concentração no tecido é $C_{t}=n_{e} / V_{t}$

Quando um agente de contraste é injetado em um paciente, admite-se, como modelo, considera-se que o traçador é bem misturado dentro do compartimento, ou seja, não existe nenhum gradiente de concentração, desde que a mistura seja instantânea [Tofts et al; 1999].

Existem dois mecanismos de contraste básicos. Um mecanismo induz a um aumento das taxas de relaxação transversal, $R_{2}$ e $R_{2}^{*}$, das moléculas da água. O outro induz a um aumento das taxas de relaxação longitudinal, $R_{1}$. Desde que as variações em $R_{1}$ estão confinadas no compartimento vascular, a troca de água sobre os capilares influenciam a medida do sinal [Donahue et al., 1994, Dobahue et al., 1997]

Os íons paramagnéticos não geram qualquer sinal por si só; eles somente afetam os núcleos vizinhos, e o mecanismo de interação dipolo-dipolo entre elétron e próton só é efetivo quando as duas espécies estão muito próximas [Solomon, 1955]. Por outro lado, a diminuição dos tempos de relaxação $\mathrm{T}_{1}$ e $\mathrm{T}_{2}$, resultantes da presença de substâncias paramagnéticas, é proporcional à concentração desta. Em concentrações baixas e médias, íons paramagnéticos afetam predominantemente $T_{1}$. $\mathrm{O}$ aumento na eficiência da relaxação longitudinal faz aumentar a intensidade do sinal em imagens de $\mathrm{T}_{1}$. Em concentrações mais altas, o efeito de $\mathrm{T}_{2}$ começa a dominar, mesmo quando tempos de eco curtos são usados. Pelo aumento na defasagem dos spins, o resultado é uma forte diminuição de sinal em imagens ponderadas por $T_{2}$. 
Desse modo, o agente de contraste tem um mecanismo de contraste secundário. Isto induz a uma variação no campo magnético vizinho aos vasos devido à diferença de susceptibilidade entre a solução de Gd-DTPA no vaso e na água do tecido. A susceptibilidade alterada cria gradientes de campos magnéticos dentro e ao redor dos vasos, conduzindo a atenuação do sinal de RM. Embora o agente de contraste esteja confinado no espaço intravascular, o sinal de RM total é afetado pelo fato dos gradientes microscópicos de campo magnético penetrarem no espaço extravascular. Como resultado, as variações nos sinais podem ser bastante grandes $(30-50 \%)$ e quanto maior for o volume de sangue, maior será o efeito sobre o sinal de RM. Seguindo uma injeção de um bolus de contraste, o sinal de RM local no cérebro cai transitoriamente quando o agente passa pela vasculatura. Este efeito dura apenas um breve tempo (em torno de 10s) e imagens dinâmicas rápidas são requeridas pra medi-lo. Para um mesmo bolus, a queda do sinal será mais pronunciada nas áreas com um volume de sangue maior, ou seja, com uma concentração maior do agente.

A diferença de susceptibilidade induz a uma variação na taxa de relaxação efetiva, $R_{2}^{*}$, desde que esta taxa seja mais sensível as inomogeneidades do campo magnético local. Isto é dado como:

$$
R_{2}^{*}=R_{2}+\gamma \Delta B_{0} / 2
$$

sendo que $\gamma$ é a razão giromagnética da água, e $\Delta B_{0}$ á a variação no campo magnético devido as inomogeneidades do campo [Webb, 1988].

Contudo, não apenas as medidas ponderadas em $R_{2}^{*}$ são sensíveis aos distúrbios de campo local. Quando as moléculas de água extravascular se difundem num campo magnético local não-homogêneo, a defasagem dos spins não deve ser totalmente recuperada num experimento de ecos de spin. Então isso aparecerá como se $R_{2}$ extravascular também variasse durante a passagem do bolus. 
A variação no sinal foi detectada por Villringer e colaboradores, que estimou que aproximadamente $60 \%$ dos prótons da água estariam expostos a um gradiente significante em seus experimentos [Villringer et al., 1988]. Medidas ponderadas em $R_{2}$ e $R_{2}^{*}$ também são chamadas de imagens por ressonância magnética (IRM) realçadas por susceptibilidade dinâmica (DSC-MRI). Outro resultado encontrado no mesmo estudo foi que a razão de relaxação longitudinal, $R_{1}$, no compartimento extravascular, não é afetado por pequenas variações no campo induzidas pela passagem do bolus [Villringer et al., 1988].

Pode-se, ainda, modelar a diferença de susceptibilidade, $\Delta \chi$, como sendo proporcional à concentração de gadolínio. A suposição chave é que a variação na diferença de susceptibilidade é proporcional a variação em $R_{2}$ e $R_{2}^{*}$ :

$$
\Delta R_{2}^{*}=K[C A],
$$

em que $\mathrm{K}$ a constante de proporcionalidade [Boxerman et al., 1995].

A validade da equação (2.5) pode ser questionada, uma vez que a variação em $\Delta R_{2}^{*}$ não é apenas dependente da concentração do contraste, mas também depende do valor da difusão e geometria do vaso [Kiseley, 2001]. Contudo, embora limitados, alguns outros estudos têm encontrado regimes de proporcionalidade [Weisskoff et al., 1994].

A cinética do traçador é esquematizada na figura 2.4. O traçador entra via artérias numa taxa de $\frac{d n_{0}}{d t}$. As moléculas de traçador instantaneamente se misturam com as moléculas de água dentro do compartimento vascular. A quantidade de traçador, $n_{0}$, que sai devido ao fluxo por tempo é dada por: $\frac{d n_{0}}{d t}=C_{b} F=n_{p} / V_{b} \cdot F$, em que $F$ é o fluxo e $C_{b}$ é a concentração de contraste no compartimento vascular. Se a membrana não for permeável, então $n_{e}=0$ e, 


$$
\frac{d n_{p}(t)}{d t}=\frac{d n_{a}(t)}{d t}-\frac{F}{V_{b}} n_{p}(t)
$$

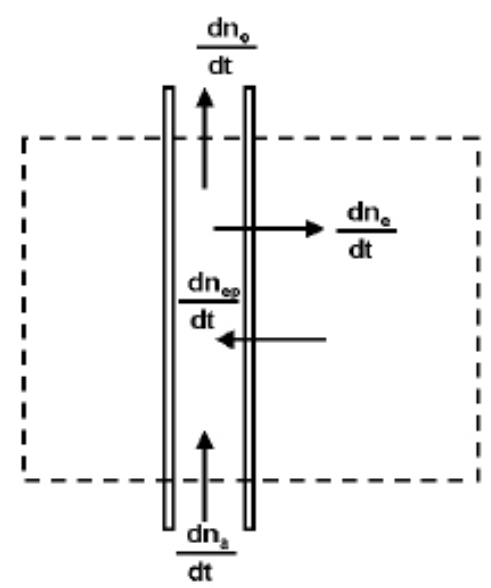

Figura 2.4. A cinética do agente de contraste no tecido. $\frac{d n_{a}}{d t}$ e $\frac{d n_{0}}{d t}$ são as taxas das molécula do agente de contraste que entra e que sai, respectivamente, do compartimento vascular devido ao fluxo. $\frac{d n_{e} p}{d t}$ e $\frac{d n_{e}}{d t}$ descrevem o transporte do agente de contraste dos capilares ao EEE. Se a membrana for simétrica, este transporte é completamente caracterizado por uma única taxa. Para um traçador intravascular, não existe transporte através da membrana dos capilares.

Com a ruptura da barreira hematoencefálica, o traçador extravasa do espaço vascular e entra no EEE. Desde que o fluxo de agente de contraste sobre a barreira hematoencefálica seja proporcional à diferença de concentração entre os dois compartimentos, o transporte do agente de contraste do EEE para o plasma é descrito por uma equação diferencial de primeira ordem:

$$
\frac{d n_{p e}(t)}{d t}=k_{e p} n_{e}(t) \frac{V_{p}}{V_{e}}-k_{e p} n_{p}(t),
$$

sendo que $k_{e p}[1 / \mathrm{min}]$ é a taxa constante entre os compartimentos de plasma e EEE, e $n_{p e}$ é a quantidade de traçador que entra no plasma a partir do EEE. A constante depende da permeabilidade da membrana e da área de superfície. É esperado que a membrana seja si- 
métrica. A variação total na concentração do traçador no plasma é a soma das entradas e saídas (Princípio de Fick),

$$
\begin{gathered}
\frac{d n_{p}(t)}{d t}=\frac{d n_{a}(t)}{d t}+\frac{d n_{p e}(t)}{d t}-\frac{d n_{0}(t)}{d t} \ldots \ldots . \\
\frac{d n_{p}(t)}{d t}=\frac{d n_{a}(t)}{d t}+k_{e p} \frac{V_{p}}{V_{e}} n_{e}(t)-\left(k_{e p}+\frac{F}{V_{b}}\right) n_{p}(t)
\end{gathered}
$$

Com as equações acima é possível modelar a distribuição do contraste como uma função do tempo para uma dada função de entrada para a concentração, $C_{a}(t)$. A figura 2.5 mostra o resultado da quantidade de traçador (linhas cheias) no plasma para três funções de entrada (linhas tracejadas).

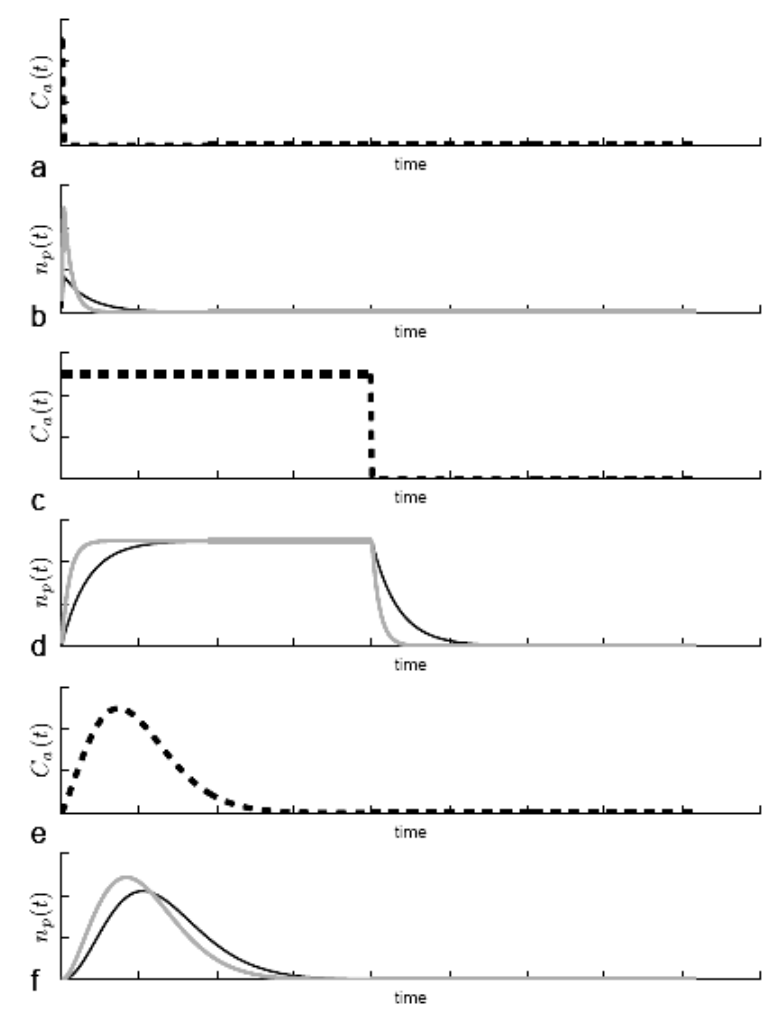

Figura 2.5. Três diferentes curvas de concentração e entrada (linhas tracejadas) estão mostradas em a), c) e e). A quantidade de traçador correspondente no plasma está descrita com linhas cheias em b), d) e f), sendo que a curva a curva mais clara corresponde ao fluxo rápido e a curva mais escura ao fluxo mais lento. a) a função Delta resulta numa saída (wash out) exponencial (b). Em c) a constante de infusão resulta na concentração do plasma alcançando o equilíbrio, se a infusão terminar o traçador decai exponencialmente. E em e) uma função de entrada do tipo gama variada resulta em curvas do plasma que também têm a forma da gama variada. 
Se um bolus instantâneo de agente de contraste for colocado no compartimento vascular em um tempo $t=0$, então para calcular o tempo de trânsito médio, cada tempo de trânsito, $t_{t}$ deve ser ponderado com a porcentagem de traçador que passa com aquele tempo de trânsito, $r\left(t_{t}\right)$. A função freqüência, $r(t)$, descreve o fluxo de saída por unidade de dose do traçador a partir do compartimento por unidade de tempo. O tempo de trânsito médio é então dado como [Lassen et al., 1984]:

$$
\bar{t}=\int_{0}^{\infty} t_{t} r\left(t_{t}\right) d t .
$$

A porcentagem de traçador que deixa o compartimento em qualquer tempo é a integral da função freqüência até aquele tempo. A porcentagem remanescente no compartimento como uma função do tempo, o resíduo, é descrito por uma função de resposta do impulso residual (IRF), $\mathrm{R}(t)$ :

$$
R(t)=1-\int_{0}^{t} r(t) d t
$$

No tempo $t=0$, a integral é zero e todo o traçador está ainda dentro do compartimento. Em $t=\infty$, a integral é um (1) e todo o traçador deixou o compartimento. Note que $r(t)$ tem a unidade de tempo, enquanto que a IRF ( ou $\mathrm{R}(t)$ )é adimensional. Isso para um bolus ideal.

Se o bolus não é um impulso ideal, a concentração de contraste que permanece dentro do compartimento, num dado ponto no tempo, é uma soma ponderada das concentrações de entrada com $\mathrm{R}(t)$,

$$
C_{b t, W}(t)=f \int_{0}^{t} C_{a}(T) R(t-T) d T,
$$

em que $C_{b t, W}(t)$, é então a concentração no volume de tecido em unidades de quantidade por massa como denotado por $W$. Na equação (2.11), a concentração de contraste no tecido foi expressa como a convolução da função de entrada e a $R(t)$ multiplicada pela perfu- 
são. As curvas de concentração devem ser obtidas com realce de contraste usando IRM. O produto da $\mathrm{R}(t)$ e a perfusão é chamado de kernel, $h(t)$. O kernel deve ser obtido pela deconvolução das curvas do tecido e a função de entrada. Desde que $\mathrm{R}(t)$ tenha um máximo por definição, equação (2.10), a perfusão é encontrada ser máxima para o kernel.

A figura 2.6 mostra alguns exemplos das funções impulso de reposta. A IRF reflete o grau de mistura da função de entrada. A parte superior da figura mostra três situações de mistura: em a sem mistura, $\mathbf{b}$ alguma mistura e em $\mathbf{c}$ mistura instantânea total. Em todas as situações, a função de entrada foi um impulso ideal. As IRFs correspondentes estão mostradas na parte inferior: em $\mathbf{a}$ uma função na forma de caixa, em $\mathbf{b}$ uma função Fermi, e em c uma função exponencial. As funções de freqüência das partículas que deixam o compartimento, $r(t)$, são dadas como a uma função delta, b uma função da forma gaussiana e c uma função exponencial, visto pela resolução da equação $r(t)=1 / \bar{t} \exp (-t / \bar{t})$.

A situação de nenhuma mistura e a de mistura instantânea são situações artificiais. Situações reais estão num intervalo entre a figura 2.6 b e c. Sempre haverá alguma mistura dentro do compartimento, então a IRF é sempre uma função suave [Lassen et al., 1984].
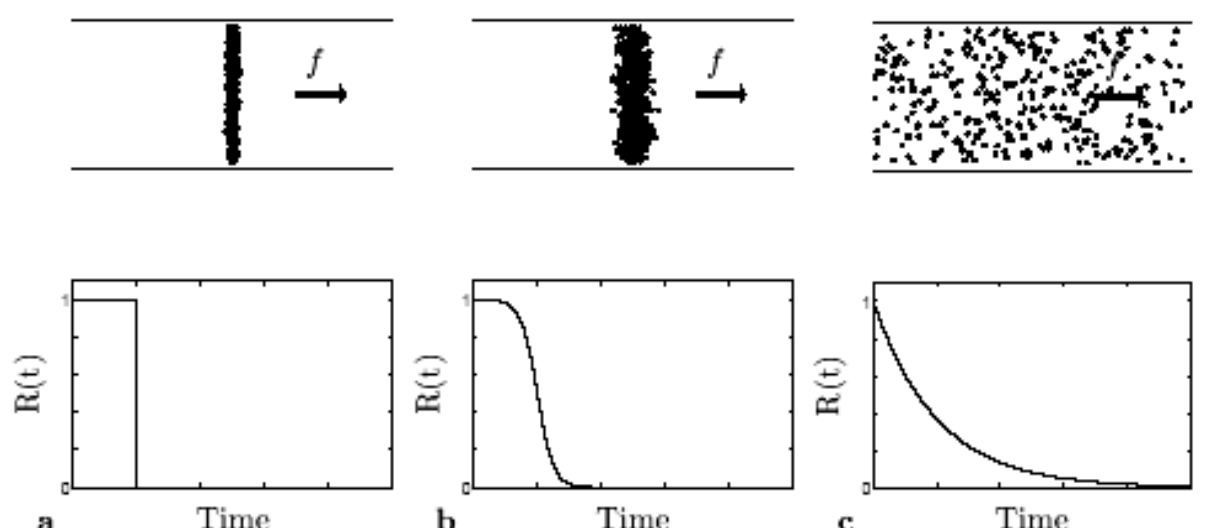

Figura 2.6 A IRF reflete o transporte e agente de contraste através do tecido. Em a se o agente de contraste não está misturado no compartimento, a IRF é uma função da forma caixa. Em b se o bolus tem um grau limitado de mistura, a IRF deve ter a forma de uma função de Fermi. E em c A mistura instantânea é modelada por uma função exponencial. A função na forma de caixa é artificial desde que sempre existirá alguma mistura. Então, a IRF é sempre uma função suave. A saber: (\{função Fermi: $[1+\exp (-\mathrm{ab})] /(1+\exp [(\mathrm{a}(\mathrm{t}-\mathrm{b})])\})$. 
Se o traçador sai fora do EEE, o volume de distribuição do traçador é consideravelmente aumentado. Normalmente, a contribuição do compartimento vascular é então omitido das equações [Larsson et al., 1996, Tofts, 1997].

\subsection{Medidas Hemodinâmicas}

O uso de uma substância traçadora para estudar o fluxo de sangue depende de uma variedade de suposições sobre a substância utilizada, seu meio de administração e de medida, além de sua interação com o espaço extravascular. Outras suposições devem também ser exigidas com respeito ao leito vascular ao qual essa substância percorrerá [Lassen et al, 1979]. Desse modo, as considerações mais gerais são de que o fluxo deve permanecer estável e não alterado pela presença do traçador, ou seja, o traçador não afeta a circulação e possui um volume considerado desprezível para causar variações de fluxo, mas ao mesmo tempo possui uma amostra representativa o suficiente para se ter medidas confiáveis. Outra suposição importante é que a recirculação do traçador deve ser desprezível ou capaz de ser corrigida Assim, dentro dos limites impostos por estas implicações, os traçadores podem fornecer informações quantitativas úteis sobre o volume e o fluxo sangüíneo [Petrella and Provenzale, 2000]. A escolha da técnica de depende de muitos fatores, tais como a região do cérebro, da cobertura regional, da resolução do tempo e das especificações do hardware [Gillis and Koenig 1987, Villringer et al, 1988].

Conforme visto anteriormente, baseado nas equações anteriormente vista, uma série de medidas podem ser realizadas para estimar os parâmetros de interesse, como o CBV, CBF e MTT. A seguir entraremos em mais detalhes sobre a maneira como esses mapas podem ser obtidos, a partir de exames de DSC-MRI. 


\subsubsection{Volume de Sangue Cerebral (CBV)}

Do ponto de vista prático, um exame de DSC-MRI envolve a injeção intravenosa de um agente de contraste e subseqüente monitoração da sua passagem através da rede vascular cerebral [Villringer et al, 1988, Rosen $e t$ al, 1989]. Para tanto, as variações na intensidade do sinal, provocadas por alterações da susceptibilidade magnética local, pela presença do agente, são observadas a partir da aquisição de uma série de imagens rápidas de RM, conhecidas por imagens eco-planares (EPI - Echo Plannar Imaging). Logo, em um exame de perfusão por MRI, o valor de $\mathrm{C}(\mathrm{t})$ não é medido diretamente. Logo, em primeiro lugar, é necessário que se converta a variação da intensidade desse sinal em concentração do agente de contraste.

Se considerarmos que há, como visto anteriormente, uma relação linear entre a concentração de agente paramagnético $C_{m}$ e as variações na taxa de relaxação transversal $\Delta \mathrm{R}_{2}^{*}$, isto é, $\Delta \mathrm{R}_{2}^{*}=\mathrm{kC}$, então a concentração durante a passagem do bolus pode ser escrita como[Rosen et al, 1989]:

$$
S(t)=S_{0} e^{\frac{-k C(t)}{T E}}
$$

sendo TE o tempo ao eco e $S_{0}$ o valor de brilho durante a linha de base, i.e., antes da passagem do agente de contraste. A constante de proporcionalidade é normalmente, igualada a um (1), já que se considera que a quantidade da concentração do contraste é igual à queda provocada do sinal de RM. Resolvendo a equação 2.12, temos [Villriger et al 1988, Rosen et al, 1989, Rosen et al 1990, Belliveau et al, 1990]:

$$
C_{m}(t)=-\frac{1}{k T E} \ln \frac{S(t)}{S_{0}} .
$$

sendo $C_{m}(t)$ a concentração do agente de contraste, que é a equação usada para encontrar o volume de sangue cerebral nesta tese. 
Estudos anteriores [Thompson et al, 1964, Rosen et al, 1990, Bahn, 1995] demonstraram que o CBV é proporcional a área debaixo a curva concentração-tempo, $C_{m}$, referentes à primeira passagem do bolus, não considerando os efeitos de recirculação ou vazamento do agente de contraste utilizado, como pode ser visto na figura 2.7.

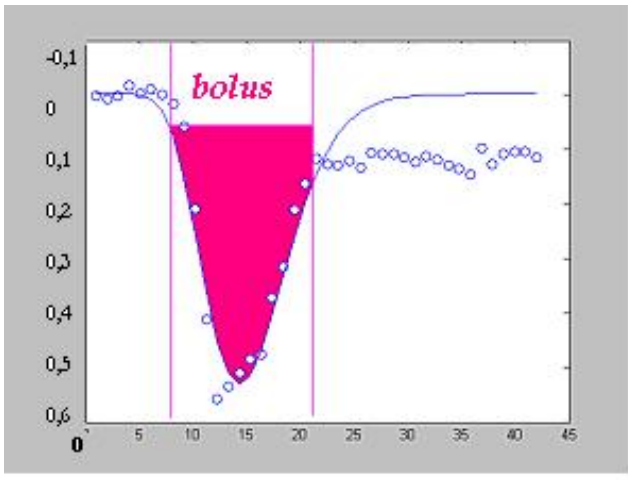

curva sinal-tempo

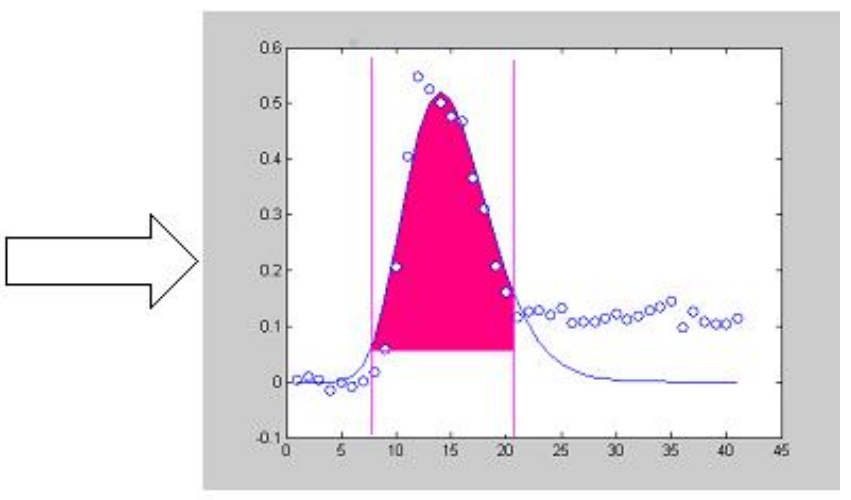

curva concentração-tempo

Figura 2.7: Ilustração da conversão de uma curva sinal-tempo numa curva concentração-tempo. Levando em consideração a proporcionalidade entre a queda do sinal de RM e a concentração de agente de contraste num tecido normalmente pefundido. A quantidade de agente de contraste, bolus, está representada na cor vermelha.

Os esses efeitos de recirculação podem ser reduzidos através do ajuste de uma função gama variável aos dados da curva concentração-tempo do agente [Thompson et al, 1964, Starmer et al., 1970 e Berninger et al., 1981]. Apesar dessa correção, CBV é superestimado em regiões com rupturas da BHE. Portanto, o valor do CBV obtido com esta metodologia não é uma medida absoluta, e na prática clínica, a comparação entre pacientes requer um padrão de referência interno, que pode ser o valor de CBV obtido contralateralmente na matéria branca normal. Então, o volume de sangue cerebral relativo (rCBV) pode ser calculado da seguinte forma:

$$
r C B V=\frac{C B V_{p}}{C B V_{n}}
$$

sendo CBVp é o valor do CBV no tecido patológico. 
Várias considerações devem ser feitas para que se possa fazer uso do método descrito acima: primeiro, o fluxo sanguíneo deve permanecer estável durante a medida, segundo o agente de contraste deve possuir volume desprezível e não afetar a CBF; terceiro, a mudança do tempo de relaxação $T_{1}$ deve ser desprezível; quarto, a recirculação do sangue é negligenciada ou eliminada.

Mas de fato, o que vem a ser a recirculação e o que este efeito provoca nos dados, de modo que seja indispensável a sua eliminação? A recirculação é um efeito que pode superestimar os valores do CBV, fornecendo, portanto, valores de volume de sangue maiores do que realmente são. Ela pode ocorrer de duas maneiras. Primeiro, quando há um refluxo do agente de contraste, ou seja, o agente volta no sentido oposto ao seu trajeto; e segundo, pode ser devido a uma segunda passagem do bolus.

O segundo motivo pode ser contornado usando imagens rápidas, do tipo ecoplanares que conseguem mapear todo o cérebro em questão de poucos segundos. Já o primeiro é algo intrínseco e que não nos permite ter um controle total, já que um refluxo pode ocorrer, variações cardíacas, diferentes estruturas microcirculatórias, etc...

Uma alternativa, que tem sido empregada para eliminar esses efeitos é tentar promover um ajuste da curva de $C(t)$ por meio de uma função gama variável, que tem justamente a mesma forma da curva de diluição de traçadores, mas sem a recirculação.

Várias formulações teóricas foram propostas para explicar a forma das curvas de diluição de traçadores [Stephenson, 1948, Newman et al, 1951, Sheppard, 1952]. Uma das aproximações matemáticas mais utilizadas tem sido a integral de convolução, na qual a curva de concentração-tempo do indicador é manuseada como uma função do tempo desconhecida e inespecífica, $C(t)$. A generalização do uso desse método, contudo, é limitada devido às manipulações matemáticas requeridas, quando aplicadas à curvas obtidas in vivo, os quais envolvem cálculos mais complicados [Gonzáles, 1962, Grodins et al, 1962]. 
Esse tipo de análise seria simplificado se a concentração do indicador pudesse ser convenientemente expressada por uma função específica do tempo [Zierler, 1962.]. Se essa função fosse disponível, seria também possível caracterizar mais precisamente as curvas de diluição de indicadores normais e anormais, e até talvez conseguir uma percepção de alguns dos fatores determinantes na forma das curvas.

Uma expressão para $C(t)$, proposta por Evans em 1959 [Evans, 1959] possui uma representação gráfica que conduz a uma semelhança extraordinária com as curvas de diluição sem a recirculação. Com apenas uma pequena variação na notação, essa função pode ser expressa da seguinte forma:

$$
C(t)=K(t-A T)^{\alpha} e^{-(t-A T) / \beta}
$$

Sendo: $t=$ tempo após a injeção;

$$
\begin{gathered}
C(t)=\text { a concentração do indicador no tempo, } t \\
K=\text { fator de escala constante; } \\
A T=\text { tempo de aparecimento, de chegada; que chamaremos de Tc. } \\
\alpha, \beta=\text { são parâmetros arbitrários. }
\end{gathered}
$$

Nos estudos de Thompson e colaboradores [Thompson et al, 1964], as curvas de diluição foram obtidas a partir de um corante verde usado intravenosamente no auxílio de diagnósticos de funções hepáticas. Em geral, seus resultados demonstraram que os valores de $\alpha$ e $\beta$ variavam em direções opostas. Para curvas curtas com picos altos foram associados com os maiores valores de $\alpha$, e os menores valores de $\beta$. Agora, para curvas anormais, mais alongadas normalmente tiveram baixos valores de $\alpha$ com valores altos para $\beta$.

Os valores de $\beta$ variaram num intervalo extenso entre 1,08 a 8,48 (80\% dos valores estavam entre 1,21 e 5,1), enquanto que os valores de $\alpha$ variaram entre 1,69 e 6,24 (80\% dos valores estavam entre 1,69 e 4,17), exceto para uma curva com um tempo de 
chegada muito rápido e uma descida acentuada. A constante de escala $K$, que reflete as diferenças quanto fatores de calibração e compensa nas variações dos parâmetros $\alpha$ e $\beta$, mostrou uma vasta variabilidade.

Relembrando a equação 2.14, e com algumas modificações, a constante K pode ser expressa em termos de $C_{\text {pico }}, \alpha$ e $\beta$ das curvas de diluição, da seguinte forma:

$$
K=C_{\text {piсo }}(e / \alpha \beta)^{\alpha}
$$

Substituindo essa expressão (2.15) na equação 2.14, temos a seguinte relação:

$$
C(t)= \begin{cases}C_{\text {pico }}\left(\frac{e}{\alpha \beta}\right)^{\alpha}\left(t-T_{c}\right)^{\alpha} \exp \left(\frac{-\left(t-T_{c}\right)}{\beta}\right), & \mathrm{t}>\mathrm{T}_{\mathrm{c}} \\ 0, & \mathrm{t} \leq \mathrm{T}_{\mathrm{c}}\end{cases}
$$

que é a nossa função gama variável usada nesta tese para o ajuste das curvas de concentração-tempo do agente de contraste usado, e, portanto usada para o cálculo dos nossos mapas de volume de sangue cerebral (CBV).

De maneira formal, a concentração $C_{v o l}(t)$ do traçador em um dado volume de interesse (VOI) pode ser descrita em termos de três funções [Axel 1995, Østergaard et al, 1996b]. Além da função resíduo, R(t), esse cálculo deve levar em conta uma função de entrada arterial, conhecida do inglês por AIF (Arterial Input Function). Do ponto de vista prático, medidas da AIF são baseadas nas curvas de $\mathrm{C}(\mathrm{t})$ feitas sobre a artéria carótida interna. Existem artefatos de volume parcial que distorcem a AIF, reduzindo a exatidão das medidas de imagem de perfusão cerebral e conduzindo a erros substanciais na determinação da concentração do contraste [van Osch, et al, 2001]. Embora existam maneiras de corrigir esse efeito de volume parcial proveniente dos tecidos vizinhos aos vasos, a conclusão desse estudo é que medidas quantitativas de uma AIF pode se tornar viável se dados complexos e completos forem usados. Além desse efeito, já foi verificado que quando um vaso não está 
orientado paralelo ao campo magnético principal, o material de contraste também induzirá variações no campo magnético próximo a este vaso [Akbudak et al, 1994].

Normalmente se escolhe a AIF de 7 a 15 pixels adjacentes à artéria que tenha uma queda mais rápida e larga na intensidade do sinal (de 3 a 10 vezes da substância cinzenta e branca). Então, depois de escolhida a região, é feita uma média das curvas de concentraçãotempo destes pixéis, para produzir uma boa representação dos níveis de contraste arterial. A determinação de uma AIF exata é uma exigência muito importante, e como vimos pode ser obtida diretamente dos dados da imagem. Isso também pode ser feito pela escolha de uma pequena quantia de voxeis, usando um algoritmo automático que seja capaz de pesquisar o volume inteiro da imagem e escolher justamente os vóxeis cujas curvas de concentração-tempo satisfaçam a critérios de características pré-estabelecidas das artérias, tais como um pico largo, um tempo de chegada rápido e um tempo de trânsito médio curto [Rempp et al, 1994, Petrella et al, 1997]. O uso de um algoritmo aumenta a reprodutibilidade pelo fato de exigir menos interação com o usuário. Deve-se notar, contudo, que a confiança exclusiva em uma aproximação automática pode levar a seleções errôneas de uma AIF.

Comparado a outros métodos, os quais muitas vezes são completamente automáticos, essa dependência da escolha certa para cada pessoa pode vir a se tornar bastante problemática num cenário clínico grave. No entanto, o procedimento de seleção da AIF é bastante direto e leva de 2 a 3 minutos para uma pessoa bem treinada encontrar a melhor região. De acordo com um estudo realizado por [Yamada, et al, 2001] a diferença na escolha da AIF entre inter-observadores foi relativamente baixa, não afetando a qualidade dos mapas de perfusão calculados, o que os levou a concluir que essa técnica é viável, embora aja algumas complicações no seu cálculo.

Dessa forma, a partir da AIF, a $\mathrm{C}_{\mathrm{VOI}}(\mathrm{t})$ pode ser escrita em termos de uma convolução entre a função resíduo, $\mathrm{R}(\mathrm{t})$, e a AIF: 


$$
C_{V O I}(t)=\left(\frac{\rho}{k_{H}}\right) F_{V O I}\left(C_{a}(t) \otimes R(t)\right)=\left(\frac{\rho}{k_{H}}\right) F_{V O I} \int_{0}^{t} C_{a}(t) R(t-\tau) d \tau,
$$

sendo que $\mathrm{F}_{\mathrm{VOI}}$ é o CBF no VOI, $\rho$ é a densidade do tecido do cérebro e $\mathrm{k}_{\mathrm{H}}=\left(1-\mathrm{H}_{\mathrm{art}}\right) /(1$ $\mathrm{H}_{\text {cap }}$ ) dá a diferença de hematrócitos $\mathrm{H}$ (Volume percentual de hemácias presentes em amostra de sangue total) entre capilares e vasos grandes. Esta expressão pode ser interpretada considerando a AIF como sendo uma superposição de consecutivos bolus ideais $C_{a}(\tau) d \tau$ injetados em um tempo $\tau$. Para cada bolus ideal, a concentração ainda presente no VOI, no tempo t, será proporcional a $C_{a}(t) R(t-\tau) d \tau$. A concentração ideal $\mathrm{C}_{\mathrm{VOI}}(\mathrm{t})$ será dada pela soma (integral) de todas estas contribuições. Em termos matemáticos, podemos dizer que esse cálculo envolve a convolução entre $\mathrm{C}_{\mathrm{a}}(\mathrm{t})$ e $\mathrm{R}(\mathrm{t})$, ponderada pelo $\mathrm{CBF}_{\text {voir }}$.

Desse modo, partindo-se desse modelo, podemos, então, determinar o CBF, como sendo a amplitude resultante da operação de deconvolução entre a AIF e o CBV medido.

\subsubsection{Fluxo de Sangue Cerebral (CBF)}

O fluxo de sangue cerebral $(\mathrm{CBF})$ abaixo de certo limite conduz a disfunções $(<20$ $\mathrm{mL} / 100 \mathrm{~g} / \mathrm{min})$ ou morte $(<10-12 \mathrm{~mL} / 100 \mathrm{~g} / \mathrm{min})$ de células neurais [Guyton, 2002]. Para uma função cerebral normal, o ajuste (a adaptação) do CBF de acordo com a demanda (exigência) real, determinado pelo nível de ativação dos neurônios, e a manutenção do CBF acima do limiar isquêmico durante as variações da pressão sanguínea sistêmica são cruciais. Esta autoregulação do CBF é controlada por mecanismos celulares e metabólicos complexos [Kandel, 2003]. Então, a estimativa (e a avaliação) do CBF e a sua autoregulação podem ser usadas para investigar a fisiologia normal e a natureza de várias doenças do cérebro.

A determinação voxel a voxel do CBF, na teoria, requer a determinação de uma única entrada arterial para cada voxel. Pelo fato disso ser impossível, muitos métodos consi- 
deram que a AIF é praticamente uniforme em todo o cérebro, e aplicam uma única AIF para o cérebro inteiro. Embora esse fato possa ser verdadeiro em alguns casos, vários outros o violam, como em problemas da artéria cerebral média unilateral [Petrella and Provenzale, 2000]. Além disso, a AIF também depende do rendimento cardíaco, da geometria vascular e da resistência vascular cerebral [Thomas et al, 2000], que são medidas inerentes do paciente e diferentes para cada indivíduo. Outra variável importante é a velocidade da injeção. Geralmente ela é escolhida para ser a mais rápida o possível para criar a melhor forma do perfil do bolus. Normalmente se usa uma taxa de injeção de $5 \mathrm{ml}$ por segundo, com o auxílio de uma bomba injetora, uma vez que velocidades menores a $3 \mathrm{ml} / \mathrm{seg}$ conduzem a uma subestimação do CBF [van Osch, 2002].

Por fim, a determinação do CBF envolve uma operação matemática de deconvolução, que nada mais é do que a inversa da operação convolução. Contudo, exatamente por ser um processo inverso tem alguns problemas, tais como o problema da matriz inversa, que produz oscilações nos dados da resposta [Østergaard et al, 1996a]. Existem alguns algoritmos para a deconvolução das curvas de passagem do contraste, tais como transformada de Fourier [Rempp et al, 1994], algoritmo de maximização através da estimação da máxima vizinhança (Maximum Likelihood Estimation Maximization Algorithm-ML-EM) [Volken et al, 1999] e, o mais comumente usado, o método de decomposição de valor singular (SVD) [Østergaard et al., 1996a].

\section{Decomposição de Valor Singular (SVD)}

A análise do deconvolução baseada em decomposição em valor singular (SVD) tem sido extensamente aceita para a quantificação de fluxo de sangue cerebral usando imagem de ressonância magnética baseada em contraste por susceptibilidade (DSC-MRI) [Østergaard et al, 1996a]. 
De modo bem sucinto, as curvas da $\mathrm{AIF}$ e $\mathrm{C}_{\mathrm{m}}$ (obtida através do Gadolínio) pode ser escritas na notação vetorial como $\mathbf{C}=\mathbf{A I F}^{-1} \cdot \mathbf{C}_{\mathrm{m}}$, sendo que $\mathbf{C}$ representa a matriz da curva $C(t)$ deconvoluída. Essa equação pode ser resolvida usando a técnica de SVD, por meio da decomposição da matriz da AIF em três outras: $\mathbf{A I F}=\mathbf{U} \cdot \mathbf{W} \cdot \mathbf{V}^{\mathbf{T}}$ [Press et al, 1992]. A inversa da AIF pode ser calculada como $\mathbf{A I F}^{-1}=\mathbf{V} \cdot\left[\operatorname{diag}\left(1 / w_{j}\right] \cdot \mathbf{U}^{\mathbf{T}}\right.$, sendo que $\left[\operatorname{diag}\left(1 / w_{j}\right]\right.$ representa o recíproco dos elementos diagonais de W. Quando se calcula $\mathbf{A I F}^{-1}$, problemas aparecem quando $\mathbf{W}$ contem valores singulares (isto é, $w_{j}=0$ ou próximo de zero) e isto causa oscilação na curva de $C(t)$. Assim, Østergaard [Østergaard et al, 1996a] usou em seu método um conjunto de valores de corte, variando de 15-20\% do valor máximo na diagonal da matriz W. Para mais detalhes da técnica, ver os trabalhos de Press [Press et al, 1992] e Van Huffell e colaboradores [van Hueffel, et al, 1987].

\subsubsection{Tempo de Trânsito Médio (MTT)}

Um último parâmetro muito usado em DSC-MRI é o tempo de trânsito médio (MT'T). Essa variável caracteriza o tempo médio que uma molécula de agente leva para passar pela vascularização do tecido. Para sua obtenção é necessário, novamente, que se obtenha a AIF. Podemos notar, ainda, que um bolus real de contraste é sempre de duração finita, e a curva de concentração-tempo medida $C_{m}(t)$ é, então, a convolução da resposta da concentração-tempo no tecido para um bolus idealizado $\mathrm{C}(\mathrm{t})$ e a $\operatorname{AIF}(\mathrm{t})$ :

$$
C_{m}(t)=C(t) \otimes A I F(t)
$$

Do ponto de vista prático, uma vez obtido o $\mathrm{CBF}$, o MTT pode como sendo a razão entre o CBV e o CBF, seguindo às argumentações que levaram à equação 2.1.

As imagens resultantes do MTT tendem a superestimar a região de fluxo anormal, resultando numa especificidade menor. Inversamente, quando a AIF é escolhida a partir de 
uma artéria peri-infato, uma maior especificidade é obtida para o fluxo local, por que a AIF corrige para o contraste o atraso e a dispersão que ocorre distalmente à estenose vascular. Assim, na presença de tais doenças vasculares, essa técnica acaba por delinear áreas com prolongações reais do MTT [Thacker, et al., 2000].

Em adição a esses métodos de cálculo, outros parâmetros conhecidos podem ser úteis para as estimativas de perfusão. Esses parâmetros incluem o tempo de chegada, Tc, tempo ao pico do bolus (TPB), tempo relativo ao pico (rTPB- que é TPB menos Tc), e o chamado FWHM (full-width at half-maximum), que é o tempo calculado na largura máxima da curva a meia altura. A figura 2.8 ilustra esses parâmetros com relação à curva de concentração-tempo do agente de contraste.

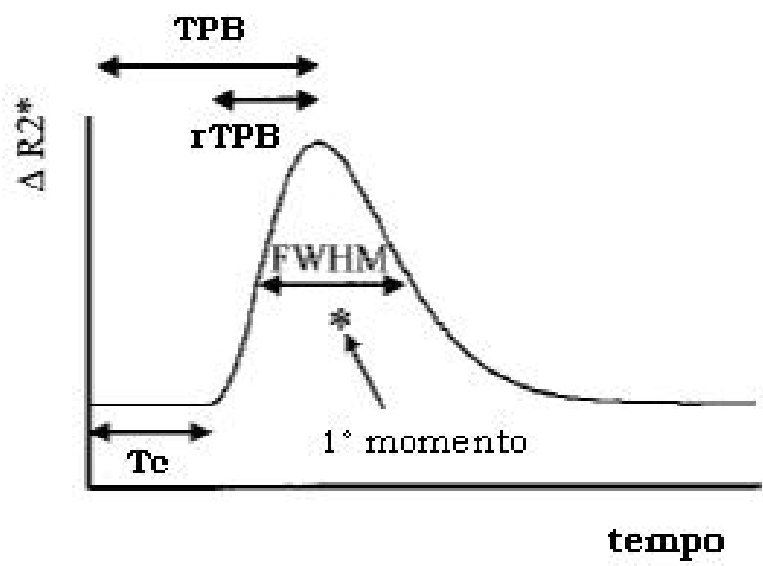

Figura 2.8: Típica forma de uma curva concentração-tempo com os vários parâmetros que podem ser usados para a estimação do MTTT.

O TPB é uma medida simples que calcula o tempo necessário para que o bolus chegue à sua concentração máxima. Por ser um parâmetro cujo cálculo é direto, ele tem despertado um grande interesse na prática clínica [Thacker, et al., 2000]. Apesar de tais benefícios, essa técnica tem se mostrado altamente vulnerável quando se trata de doenças estenooclusivas. Um método que utiliza um limiar tem sido proposto nestes casos, para que o cálculo do TPB possa ser útil, aumentando a precisão da técnica. 


\subsubsection{Atraso e Dispersão}

Se o bolus fosse um impulso ideal, quando ele entrasse no tecido de interesse, a perfusão seria simplesmente o pico da curva concentração do tecido, desde que essa curva fosse então a função resposta do impulso ponderada. Contudo, como o bolus de entrada nunca é ideal, a curva do tecido tem que ser corrigida para curvas de entrada de atraso (delay) e dispersão. Sendo a curva do tecido a convolução da curva de entrada e da IRF, a IRF é obtida pela deconvolução da curva tecido e a curva de entrada.

Calamante e colaboradores [Calamante et al, 2000] investigaram o efeito do atraso e da dispersão sobre a AIF, usando parâmetros exatos de perfusão obtidos pela análise de deconvolução baseada em SVD com um valor de limiar (threshold) fixo em 0,15- 0,20. Foi observado que houve uma subestimação dos valores do CBF para atrasos em torno de 1,5 a 2 segundos, e que esta subestimação oscilava ao redor de 35\%. A máxima subestimação obtida do CBF ficou em torno de 40\% para um atraso de aproximadamente 2 segundos.

Ainda, Murasse e colaboradores [Murase et al., 2001] se propuseram a investigar o efeito deste limiar no método SVD, a fim de avaliar a sua exatidão sobre os dados do CBF. Segundo os resultados adquiridos, o valor de corte deve ser cuidadosamente considerado quando se quer quantificar o CBF, em termos absolutos, usando SVD. E mais, seus resultados mostraram que uma subestimação equivalente ao atraso é muito rapidamente alcançada com uma dispersão de valores próximos a 1,5 a 2 segundos, mas no caso da dispersão, este valor continuava a aumentar mais e mais, à medida que a dispersão aumentava. Alguns dos resultados de Murase [Murase et al., 2001] foram similares aos resultados relatados por Calamante [Calamante et al, 2000], com o adicional de que o efeito da dispersão foi muito maior do que o atraso quando se usou um valor de limiar fixo como uma constante.

Como apontado por Calamante [Calamante et al, 2000], enquanto o erro introduzido pelo atraso pode ser corrigido usando informação a respeito do tempo de chegada do bolus, a correção da dispersão é muito mais difícil e requer um modelo para a vasculatura 
percorrida pelo agente de contraste. Alguns modelos de vasculatura foram estudados [Kroll et al, 1996, Østergaard et al, 1999, van Osch et al, 2003] na tentativa de diminuir os erros provocados pelo atraso e pela dispersão na AIF, mas ainda não necessárias suas validações.

Como pôde ser visto neste capítulo e em especial nas últimas seções, existem várias aproximações, tais como as vistas na obtenção da AIF, na análise de deconvolução, nos efeitos de atraso e dispersão, que tornam a medida do CBF um valor aproximado e não exato, em vista de ser sistema complexo de irrigação e circulação sangüínea, tanto corpórea quanto cerebral. 


\section{Capítulo 3}

\section{Métodos de ajuste de curva}

Existem vários métodos de ajuste de curvas que podem ser usados de acordo com a situação e o problema a ser analisado. No nosso caso, temos curvas de concentraçãotempo que são criadas a partir de imagens sucessivas de RM, de modo a rastrear o caminho percorrido pelo agente de contraste. Como já foi visto no capítulo 2, mais precisamente na seção 2.6.1, existe uma queda do sinal quando o agente passa por uma determinada região e que essa queda no sinal é mais pronunciada quanto maior for a quantidade de agente passando naquele momento, naquele tecido. A área debaixo da curva de concentração-tempo fornece uma estimativa do volume de sangue cerebral daquela região.

O que na verdade temos é uma medida indireta, pois avaliamos essa quantidade de volume de sangue em relação ao volume que o sangue ocuparia caso o bolus, nosso marcador, não estivesse presente na corrente sangüínea. Portanto, é muito importante calcular de maneira exata esse valor do volume de sangue, que é dado pela área debaixo da curva concentração-tempo. É claro que existem suposições, tal como que a relação entre a concentração do agente de contraste é diretamente proporcional à queda de sinal.

Além disso, nesses tipos de curvas há a presença da recirculação, também vista no Capítulo 2, um efeito bastante desconcertante, pois interfere nas medidas de modo a superestimar o valor do CBV. Assim sendo, tendo em vista a obtenção de um valor mais próximo possível do real, o ajuste da curva de concentração tem sua importância em garantir um resultado o mais exato possível do real, já que a diminuição ou o aumento do volume de 
sangue em determinada região e em determinados casos, pode indicar algum tipo de anormalidade mais preocupante.

Felizmente, podemos dizer que existem vários métodos de ajuste de curvas, para minimizar a função gama variável. O método mais usado para imagens de perfusão é o método de Levenberg-Marquardt, que será descrito neste capítulo de maneira simplificada. Além disso, vários outros métodos de otimização têm sido motivo de bastante estudos.

Este trabalho trata da otimização de curvas concentração-tempo de imagens por perfusão usando IRM, utilizando Algoritmos Genéticos (AGs). A proposta de tal algoritmo foi inspirada no principio da seleção natural de indivíduos, sendo que o considerado 'mais apto' tende a permanecer na população e se reproduzir, passando seu código genético para a próxima geração. Em alguns casos, esse método pode alcançar melhores soluções se comparados aos métodos tradicionais de otimização.

O principal objetivo do trabalho é investigar o uso do AG como uma técnica para a minimização da função gama variável no ajuste das curvas de concentração-tempo, e poder usar os mapas de perfusão na avaliação de pacientes falcêmicos. O trabalho de pesquisa compara os resultados obtidos utilizando AGs com aqueles obtidos utilizando o método de otimização convencional conhecido como Método de Levenberg-Marquardt (LM).

Atualmente existem inúmeros estudos usando os AGs, quase sempre com o objetivo de desenvolver melhores métodos para representar de maneira eficiente o problema analisado e buscar sua rápida solução (ótima, quando possível). Em geral, em um problema de otimização há a necessidade de identificar as variáveis envolvidas e seus limites de variação, bem como as constantes relevantes ao problema, de maneira a poder equacioná-las em relações matemáticas, com o objetivo de representar formalmente o problema e suas restrições para então buscar a solução. A solução do problema consiste, basicamente, em encontrar uma solução (ótima) que identifica um ponto de máximo ou de mínimo de uma função objetivo, sujeita a algumas restrições. 
Existe uma grande variedade de algoritmos matemáticos avançados que implementam métodos de minimização do erro, sendo classificados pela informação que usam, aqui citaremos brevemente apenas algum destes:

- Métodos de $1^{a}$ ordem (usam a $1^{a}$ derivada-Jacobiana), tal como:

- Método do Gradiente Descendente (GD).

- Métodos de $2^{\mathrm{a}}$ ordem (usam a $2^{\mathrm{a}}$ derivada-Hessiana), tais como:

- Método de Gauss-Newton (GN).

- Método de Levenberg-Marquardt (LM).

Estes métodos são métodos de otimização, ou minimização, de uma função. A condição para minimizar uma função (ou seja, encontrar seu valor mínimo) é que a derivada parcial com respeito a cada parâmetro, desapareça (isto é seja igual a zero).

$$
\frac{\partial f}{\partial a_{i}}=0, \quad i=1,2,3, \ldots
$$

As derivadas parciais de $1^{a}$ ordem formam o vetor de gradiente, chamado de Jacobiano $(J)$.

$$
J=\nabla f=\left[\begin{array}{lll}
\frac{\partial f}{\partial a_{1}} & \frac{\partial f}{\partial a_{2}} & \frac{\partial f}{\partial a_{n}}
\end{array}\right]
$$

As derivadas parciais de segunda ordem formam a matriz chamada de Hessiana $(H)$, dada por:

$$
H=\left[\begin{array}{cccc}
\frac{\partial^{2} f}{\partial a_{1}^{2}} & \frac{\partial^{2} f}{\partial a_{1} a_{2}} & \cdots & \frac{\partial^{2} f}{\partial a_{1} a_{N}} \\
\frac{\partial^{2} f}{\partial a_{2} a_{1}} & \frac{\partial^{2} f}{\partial a_{2}^{2}} & \cdots & \frac{\partial^{2} f}{\partial a_{2} a_{N}} \\
\vdots & \vdots & \ddots & \vdots \\
\frac{\partial^{2} f}{\partial a_{N} a_{1}} & \frac{\partial^{2} f}{\partial a_{N} a_{2}} & \cdots & \frac{\partial^{2} f}{\partial a_{N}^{2}}
\end{array}\right]
$$




\subsection{Método do gradiente descendente (GD)}

Primeiramente é bom lembrar que métodos de otimização utilizando gradientes são baseados na expansão de Taylor:

$$
f(x+\Delta x)=f(x)+J^{T} \Delta x+1 / 2 \Delta x^{T} H \Delta x+\ldots
$$

Os termos de terceira ordem e superiores são considerados desprezíveis. Caso os termos de segunda ordem sejam também desprazíveis, a equação anterior, 3.1, pode ser simplificada como:

$$
f(x+\Delta x) \approx f(x)+J^{T} \Delta x=F+\Delta F
$$

Os métodos baseados em gradiente são mais eficientes quando a função $\boldsymbol{f}$ tem derivadas contínuas, de segunda ordem, que podem ser obtidas analiticamente. Em certos casos, porém, as derivadas somente podem ser obtidas por métodos numéricos. Lembrando que $F$, é a função objetivo.

Este é um método [Adby et a, 1982, Chong et al 1996, Kelley, 1999] utiliza apenas a derivada de $1^{a}$ ordem, ou seja o Jacobiano, para determinar uma direção adequada de movimento em direção a suposta solução final, usando a aproximação de primeira ordem, a equação 3.2. O termo de primeira ordem pode ser reescrito como:

$$
\Delta F=J^{T} \Delta x=\sum_{i=1}^{n} \frac{\partial f(x)}{\partial x_{i}} \Delta x_{i}
$$

Esta equação pode ser analisada como o produto escalar de dois vetores. Assim, pode ser reescrita como:

$$
\Delta F=J^{T} \Delta x=|J||\Delta x| \cos \theta
$$


Observa-se que, para valores fixos de $|J|$ e $|\Delta x|, \Delta F$ varia em função de $\theta$. Como a redução máxima em $\mathrm{F}$ ocorrera quando $\cos \theta$ atingir seu valor mínimo, isto é, para $\theta=\pi$, tem-se que a variação ótima correspondente em $\Delta x$ ocorrerá na direção do gradiente negativo -J.

O vetor unitário na direção de -J é dado por:

$$
u=-\frac{J}{|J|}
$$

de forma que a variação $\Delta x$ seja proporcional a x:

$$
\Delta \mathrm{x}=\lambda \mathrm{u} \quad \lambda \in \mid \mathrm{R}^{+}
$$

$\mathrm{Na}$ minimização usaremos a negativa do gradiente, por isso o nome "gradiente descendente" (GD). Portanto no método do GD a direção de busca é igual à negativa do gradiente Esse método pesquisa na forma de passos para se chegar aos melhores valores da estimativa. Freqüentemente, o procedimento desse método é uma aproximação linear da função em cada passo e aperfeiçoar esta aproximação através de correções sucessivas.

O problema do método de gradiente descendente é similar ao mostrado na figura 3.1. O método é realizará pequenos passos rumo ao vale (mínimo), como se este tivesse a forma quadrática perfeita, como está ilustrado pelo caminho feito pela seta.

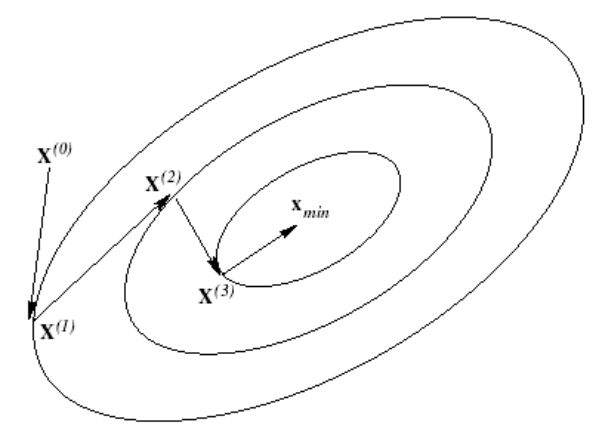

Figura 3.1: Exemplo de minimização usando o Método gradiente descendente. 
Uma busca linear da função dada por $f(x+\lambda u)$ determina o valor ótimo de $\lambda$ .Esta busca produz o mínimo da função na direção de $u$. O processo e repetido iterativamente até atingir-se o mínimo $\mathrm{F}_{\min }$.

Observa-se que a minimização segue uma trajetória em zigzag. Caso o ponto inicial esteja localizado próximo ao mínimo, o progresso torna-se muito lento, em virtude do elevado número de passos requerido. Para um ponto inicial distante o progresso é mais rápido, porém depende de um escalamento apropriado para obter melhores resultados.O método gradiente descendente apresenta algumas dificuldades. É eficiente nas primeiras iterações, quando o ponto encontra-se afastado do ponto ótimo, porém sua taxa de convergência diminui drasticamente à medida que se aproxima da solução ótima. O seu problema maior é que tem grandes possibilidades de cair em mínimos locais e não globais.

\subsection{Método de Gauss-Newton}

Uma desvantagem do método de Newton é a necessidade de usar informação de segunda ordem e a possibilidade de existência de singularidades, que dificulta, ou mesmo impossibilita o cálculo da inversa. O método de Quasi-Newton tenta, em certa medida, ultrapassar o problema, estimando o valor da Hessiana com base apenas em informação de primeira ordem. No método Gauss-Newton é calculada uma aproximação da Hessiana, $\mathrm{H}_{a}$, tendo em conta apenas o cálculo do gradiente, desprezando-se o termo de segunda ordem. A função é presumida ser bem-comportada com respeito aos seus parâmetros (seja contínua e diferenciável em qualquer ponto).

É um método eficiente apenas quando o ponto encontra-se próximo do ponto ótimo. Portanto, o método não deve convergir a menos que o "chute" inicial seja bom. Outra característica é que a rapidez de convergência do método de Gauss-Newton decresce à 
medida que a não-linearidade ou o tamanho residual relativo do problema aumentam. Se uma destas medidas for demasiado grande, o método não converge [Press et al, 1988].

- Vantagens

1. Tem convergência quadrática local em problemas de resíduos nulos.

2. Tem convergência linear local rápida em problemas com não linearidades muito fortes ou com resíduos razoavelmente pequenos.

3. Resolve problemas de mínimos quadrados lineares numa iteração.

- Desvantagens

1. Tem convergência linear local lenta em problemas razoavelmente não lineares ou com resíduos moderadamente grandes.

2. Não converge localmente em problemas acentuadamente não lineares ou com grandes resíduos.

3. Não tem necessariamente convergência global.

No método de Gauss-Newton a direção é sempre de descida, se o método for bem definido. No entanto, um dos problemas que pode surgir na aplicação desse método de é que o passo muitas vezes é errado, apesar de a direção ser correta, ou seja, este método dá muitas vezes passos exageradamente longos.

A definição do passo (mais adequado) a dar ao longo da direção, pode resolver a limitação relacionada com a convergência local, o que sugere a inclusão de uma técnica de globalização no algoritmo. Esta globalização pode ser feita através de uma procura unidimensional ou usando uma estratégia de regiões de confiança 


\subsection{Método de Levenberg-Marquardt}

Como vimos, cada método possui sua limitação, então pensando nisso, Levenberg [Levenberg, 1944, Marquardt, 1963] propuseram, inicialmente separadamente, um método conveniente que combinasse as melhores características do método de Gauss-Newton com o gradiente descendente. Para tanto, tal técnica utiliza, em cada iteração, uma combinação ponderada do passo Gauss-Newton e do Gradiente Descendente.Esse algoritmo, que faz a correção de pesos através da aproximação do método de gradiente descendente e do método de Gauss-Newton, ficou conhecido como Método de Levenberg-Marquardt, ou simplesmente método LM. Resumidamente a equação de correção de pesos pode ser escrita como:

$$
\Delta w=\left(J^{T} . J+\alpha \cdot I\right)^{-1} \cdot J^{T} \cdot \varepsilon
$$

Em que: $-\Delta w$ representa a diferença entre os pesos inicial e final;

- $\alpha$ é um escalar que controla a derivação dos erros, permitindo que o termo $\left(J^{T} J\right)$ possa ser invertido;

- J é chamado de jacobiano da matriz derivada dos erros. Cada elemento desta matriz representa uma derivada parcial de um elemento da matriz de erros com o seu correspondente peso;

- I é a matriz identidade. Como ela é multiplicada pela constante $\alpha$, pode-se gerar uma nova matriz contendo como elementos apenas valores de $\alpha$;

- $\quad \varepsilon$ é um vetor de erros calculados.

A seguir temos um resumo simplificado dos passos do método: 
1 Calcula-se o valor do qui-quadrado;

2 Fornece um valor para o passo inicial, normalmente, $\lambda=0,001$;

3 Calcula-se o valor do qui-quadrado com uma pequena variação;

4 Compara esse novo valor com o primeiro valor do qui-quadrado;

Se esse novo valor do qui-quadrado for maior que o primeiro:

diminui o valor do passo, $\lambda$, por um fator de 10 .

Caso contrário, se o novo valor de qui-quarado for menor:

aumenta o valor de do passo, $\lambda$, por um fator de 10 .

O procedimento é então repetido até que o valor de qui-quadrado pare de diminuir, ou seja, quando o valor não se reduzir mais, após um certo número de iterações ter transcorrido.

Se $\lambda$ é muito pequeno, o método vai para o método de Gauss-Newton. Agora, se $\lambda$ é um valor muito grande, o método de Levenberg-Marquardt se ajusta e trabalha na faixa do método do gradiente descendente. Assim, o Método LM utiliza o melhor de ambos os métodos para encontrar o melhor valor de ajuste.

No entanto, o método de LM é limitado por um certo número definido de parâmetros a ser estimado, como também o fato de ser preciso dar um "chute" inicial e tais variáveis. No caso na construção dos mapas de rCBV, tem-se que estimar a priori o valor de Tc, que permanece fixo durante o procedimento da construção dos mapas hemodinâmicos. Sendo assim, foi necessária a busca por outro método, no nosso caso o Algoritmo Genético, que fosse capaz de produzir valores melhores, com um número maior de parâmetros a ser ajustados, como o Tc, sem a necessidade de "chutar valores" ou escolher valores pré-determinados, escolhidos a priori, mais próximos dos valores considerados ótimos. 


\subsection{O Algoritmo Genético}

Os algoritmos genéticos (AGs) são métodos de busca e otimização que utilizam conceitos da Genética e são baseados nos mecanismos de evolução de populações de seres vivos. Este algoritmo foi baseado no princípio da seleção natural e sobrevivência do "mais apto", estabelecido por Charles Darwin em seu livro The Origin of Species em 1859 [Darwin, 1859, Coley, 1999]. De acordo com esse princípio, em uma população de indivíduos, aqueles com "boas" características genéticas (portanto considerados "mais aptos") apresentam maiores chances de sobrevivência e reprodução, enquanto que indivíduos menos "aptos" tendem a desaparecer durante o processo evolutivo.

O Algoritmo Genético (AG) simula o processo de evolução biológica por meio de uma busca multidirecional no espaço de soluções potenciais do problema. Geralmente mantém constante um número de soluções potenciais (população) e, a cada geração, a população é modificada de maneira que as soluções "boas" possam se "reproduzir" e passar a geração seguinte, enquanto que as consideradas "ruins" são eliminadas. O AG normalmente usa regras de transição probabilística para selecionar algumas soluções para a reprodução e outras para serem descartadas. Para fazer a distinção entre diferentes soluções é empregada uma função-objetivo (de avaliação ou de adaptabilidade) que simula o papel da pressão exercida pelo ambiente sobre o indivíduo.

A criação de uma nova geração pode ser feita de três maneiras básicas distintas: a Reprodução, onde os melhores indivíduos da geração atual são simplesmente copiados para a nova geração, com o objetivo de não se descartar os melhores indivíduos; o Cruzamento, em que são escolhidos dois indivíduos (pais) bem adaptados, dos quais são criados dois descendentes que vão estar na próxima geração - o objetivo é um novo indivíduo seja criado usando o que há de melhor de uma geração, com alguma variação; e finalmente a Mutação, em que um indivíduo é modificado com o objetivo de melhorá-lo, contudo, a mutação pode causar perda de desempenho e eliminação do indivíduo. 
Os princípios básicos dos AGs foram rigorosamente estabelecidos por Holland, publicado em seu livro Adaptaton in Natural and Artificial System em 1975, e podem ser encontrados em muitas referências bibliográficas [Goldberg (1989), Michalewicz (1996), Coley (1999)].

A idéia básica do Algoritmo Genético pode ser descrita de maneira sucinta: O primeiro passo é a geração de uma população inicial, que é formada aleatoriamente de possíveis soluções do problema a ser resolvido. Durante o processo evolutivo, esta população é avaliada e cada membro da população é avaliado de acordo com sua aptidão, refletindo a qualidade da solução que ele representa. Os membros selecionados podem sofrer modificações em suas características fundamentais através dos operadores de cruzamento e mutação, gerando descendentes para a próxima geração. A figura 3.2 a seguir ilustra este procedimento. Nas próximas seções cada etapa será descrita com maiores detalhes.

Seja $\mathbb{P}_{k}$ a população de cromossomos na geração $k$.

$k \leftarrow 0$

iniciar $\mathbb{P}_{k}$

avaliar $\mathbb{P}_{k}$

Enquanto o critério de parada não for satisfeito faça

$k \leftarrow k+1$

selecionar $\mathbb{P}_{k}$ a partir de $\mathbb{P}_{k-1}$

aplicar cruzamento sobre $\mathbb{P}_{k}$

aplicar mutação sobre $\mathbb{P}_{k}$

avaliar $\mathbb{P}_{k}$

Fim enquanto

Figura 3.2: Esquema de um Algoritmo Genético básico 


\subsubsection{População e seleção.}

Primeiramente uma população inicial é criada, geralmente de maneira aleatória, composta por indivíduos nos quais o algoritmo irá se basear para criar novas populações até encontrar a solução. Esta população deve ter uma diversidade grande o suficiente para que características necessárias estejam presentes em algum indivíduo da população, pois características não existentes na população inicial dificilmente aparecem durante o processo evolutivo. Com o intuito de aumentar a diversidade, pode-se desejar a unicidade dos indivíduos, ou seja, garantir que cada indivíduo na população seja único; para tanto, é necessário comparar os novos indivíduos com todos os indivíduos criados anteriormente.

Após isso, a população é avaliada, associando-se a cada indivíduo um valor de fitness (ou "adaptação") que irá indicar o quão próximo da solução o indivíduo está (ou seja, mede o quanto o indivíduo é uma boa solução). A função de fitness depende do problema que está sendo resolvido. Depois que a população for avaliada, um subgrupo dela é selecionado para que possam ser aplicados os operadores genéticos (reprodução, cruzamento e mutação). Como conseqüência, há a eliminação dos considerados menos "aptos".

Inspirado no processo de seleção natural dos seres vivos, o processo de seleção escolhe os melhores indivíduos (indivíduos mais adaptados têm melhores chances de sobreviver) da população para determinar quais indivíduos podem participar da próxima fase e contribuir na formação da geração seguinte. Existem vários métodos de seleção. As principais formas são: método por rank, o método da roleta e método por torneio [Koza, 1992].

Os algoritmos genéticos pertencem à classe dos algoritmos probabilísticos, mas eles não são métodos de busca puramente aleatórios, pois combinam elementos de procura direcionada e estocástica. De acordo com Mitchel [Mitchel, 1997], a popularidade dos AGs se deve, entre outros, ao fato: tais como: a evolução ser um método de adaptação reconhecidamente bem sucedido e robusto em sistemas biológicos e de poderem realizar buscas em espaços com hipóteses (soluções candidatas). 
- Método por rank.

Na Seleção rank, os indivíduos são classificados pelos seus valores de aptidão. Deste modo, mantendo-se a população ordenada em valores decrescentes de aptidão, a probabilidade de seleção de um indivíduo para a etapa de cruzamento, cresce com o seu "ranking". Ou seja, os melhores indivíduos possuem as melhores posições (ranking) e, conseqüentemente, maiores chances de reprodução [Bennett (1997)].

\section{- Método da Roleta.}

Este método de seleção é um dos mais utilizados, sendo que a analogia com uma roleta é utilizada porque se imagina que os indivíduos da população estão dispostos numa “roleta virtual”, onde cada indivíduo é alocado numa seção desta roleta que é proporcional ao seu valor de aptidão. Assim, os indivíduos com alta aptidão recebem uma porção maior da roleta, enquanto que os de baixa aptidão ocuparão uma porção relativamente menor. Assim, os indivíduos com alta aptidão terão uma maior probabilidade de serem escolhidos.

Para escolher um individuo para reproduzir, usa-se um gerador de números aleatórios que simula o giro de uma roleta. O procedimento da roleta é repetido tantas vezes quanto o número de indivíduos da população, escolhendo-se assim aqueles que darão origem à próxima geração. Em alguns casos, esse esquema de seleção pode gerar problemas de convergência prematura quando a função de avaliação atribui valores altos a um indivíduo, levando este indivíduo a monopolizar toda a geração. A figura 3.3 mostra um exemplo de utilização deste método.

- Método por torneio.

Neste método de seleção n indivíduos (geralmente dois) são escolhidos aleatoriamente (com probabilidades iguais) da população atual. Os indivíduos escolhidos são com- 
parados entre si, caracterizando um torneio, e aquele com maior valor da função de aptidão (Fitness) é escolhido para reprodução [Back, 2000]. O indivíduo vencedor do torneio pode ser ou não removido da população corrente. Se não for removido ele poderá competir no próximo torneio. É importante ressaltar que uma seleção baseada na aptidão não garante a seleção de qualquer indivíduo em particular, mesmo daquele que é o mais apto.

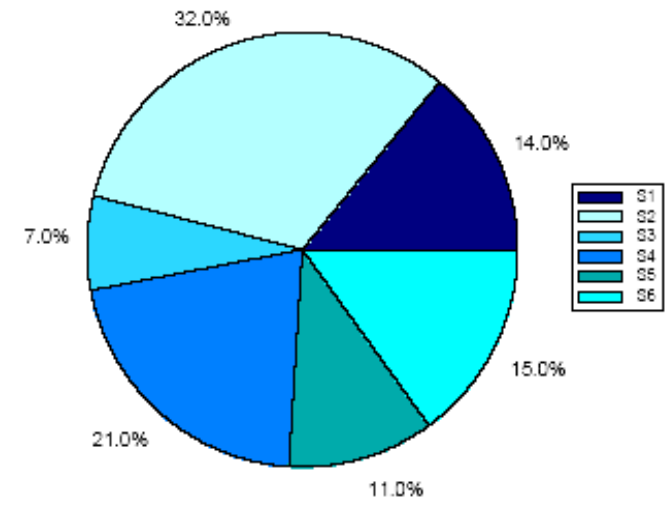

Figura 3.3: Exemplo do Método da Roleta.

Como comentado em Coley (1999), “A menos que o indivíduo mais apto seja o muito, mas muito mais apto do que qualquer outro, ocasionalmente ele não será selecionado. Não ser selecionado é 'morrer'. Assim, com uma seleção baseada em aptidão, a melhor solução do problema descoberta até um determinado momento, pode ser descartada. Embora isto pareça contra-produtivo, pode ser vantajoso em alguns problemas, porque permite explorar mais o espaço de busca, antes da convergência”.

O torneio se repete uma quantidade de vezes suficiente até que toda a população esteja completa. O processo de seleção não introduz novos indivíduos na população temporária, apenas os chamados progenitores, que servirão como pais para nova geração, composta pelos filhos. Nas etapas seguintes, o algoritmo tenta criar novas e melhores soluções (indivíduos mais aptos). 


\subsubsection{Operadores genéticos}

O princípio básico dos operadores genéticos é transformar a população através de sucessivas gerações, estendendo a busca, ou seja, explorar outras regiões do espaço de busca até chegar a um resultado satisfatório. Os operadores genéticos são necessários para que a população mantenha a diversidade, além das características de adaptação adquiridas pelas gerações anteriores.A escolha dos operadores genéticos, juntamente com a determinação da função de Fitness (aptidão) e da representação apropriada dos indivíduos, é determinante para o sucesso de um AG. Os operadores genéticos de seleção, cruzamento e mutação fornecem o mecanismo básico de busca e são usados para criar novas soluções baseadas nas melhores soluções existentes na população atual do AG. A seguir, os principais operadores são cruzamento (crossover) e mutação.

\subsubsection{Cruzamento}

De maneira análoga ao papel da reprodução de organismos biológicos, o algoritmo genético tenta combinar elementos das soluções (pode ser indivíduos) existentes a fim de criar uma solução nova, com algumas das características de cada "pai".

Os elementos das soluções existentes são combinados em uma operação chamada de "cruzamento", inspirada pelo processo de reprodução das espécies vivas. Uma vez que os indivíduos já foram selecionados, é possível aplicar então este operador, que realiza a troca de material genético entre pares de indivíduos selecionados para reprodução.

O operador de cruzamento é considerado o operador genético predominante e é aplicado com uma dada probabilidade a cada par de cromossomos selecionados. Usualmente esta probabilidade, denominada de taxa de cruzamento, varia entre $60 \%$ e $90 \%$. Não ocorrendo o cruzamento, os filhos serão iguais aos pais (isto permite que algumas soluções sejam preservadas). Isto pode ser implementado, gerando números aleatórios no intervalo 
$[0,1]$. Assim, o cruzamento só é aplicado se o número gerado for menor que a sua taxa de cruzamento.

No entanto, uma taxa alta permite uma explotação maior do espaço de solução e reduz as chances de convergência para um ótimo local. Entretanto, se essa taxa for muito alta pode resultar na perda de tempo computacional devido a explotação de regiões não promissoras dentro do espaço de soluções. Há muitas maneiras possíveis executar uma operação de cruzamento. A seguir são apresentados os principais tipos de cruzamento:

Este operador pode ser utilizado de várias maneiras. A seguir são apresentados os principais tipos de cruzamento:

- Cruzamento de um ponto;

- Cruzamento de multipontos;

- Cruzamento uniforme.

\section{$\underline{\text { Cruzamento de um ponto }}$}

O operador de cruzamento é aplicado a um par de indivíduos escolhidos aleatoriamente na população. Para isto, aleatoriamente é escolhido um ponto de corte (ou ponto de cruzamento), sendo que as informações posteriores a este ponto são concatenadas as informações anteriores, conforme ilustra a figura 3.4.

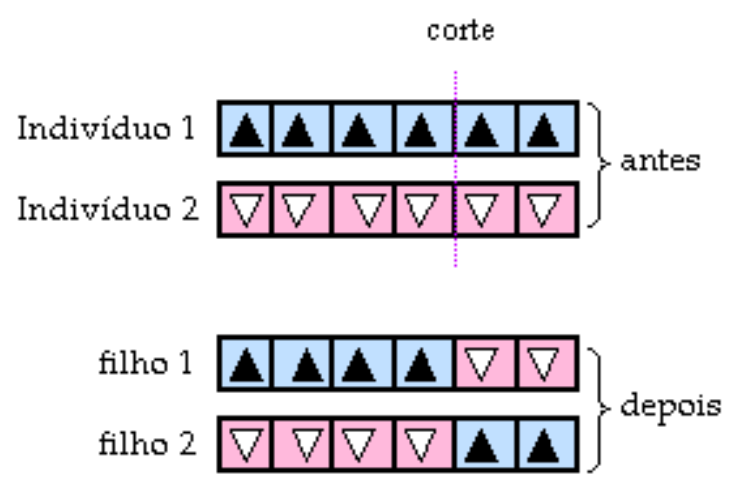

Figura 3.4: Cruzamento de um ponto de corte. 


\section{Cruzamento de multipontos.}

É uma generalização desta idéia de troca de material genético através de pontos, onde muitos pontos de cruzamento podem ser utilizados. Na ilustração a seguir, figura 3.5, os dois pontos de cortes são escolhidos aleatoriamente e as seções entre os pontos são trocadas entre os indivíduos 1 e 2.

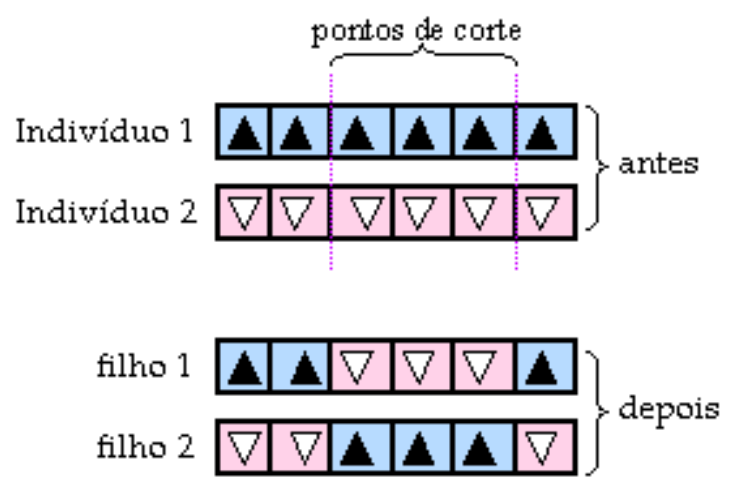

Figura 3.5: Cruzamento de dois pontos.

$\mathrm{O}$ cruzamento de $\mathrm{N}$ pontos tende a manter juntos os genes que são codificados próximos um do outro. Existe um operador denominado Inversão (Holland, 1975) que busca o ordenamento ideal dos genes no cromossomo. Dois pontos aleatórios são escolhidos no cromossomo e os genes entre eles são invertidos. Vale notar que a inversão não é um tipo de mutação brutal. De fato, cada gene é associado um número para identificar quem é quem após a troca de posição. No entanto, tem sido raramente utilizado na prática.

\section{Cruzamento uniforme.}

O cruzamento uniforme utiliza uma máscara de bits aleatórios ao invés de pontos de cruzamentos. Essa máscara é gerada para cada par de indivíduos (também chamado de pais) e determina quais genes de cada indivíduo serão herdados por cada um dos filhos. 
Este tipo de cruzamento é ilustrado na Figura 3.6. Se o primeiro bit da máscara possuir o valor 1, então o primeiro bit do indivíduo 1 é copiado para o primeiro bit do filho 1; caso contrário, o primeiro bit do indivíduo 2 é copiado para o primeiro bit do filho1. O processo se repete para todos os bits restantes do filho 1. Na geração do filho 2 , o procedimento é invertido, ou seja, se o bit da máscara for 1, então será copiado o bit do indivíduo 2; se for igual a 0 , então será copiado o bit do indivíduo 1.

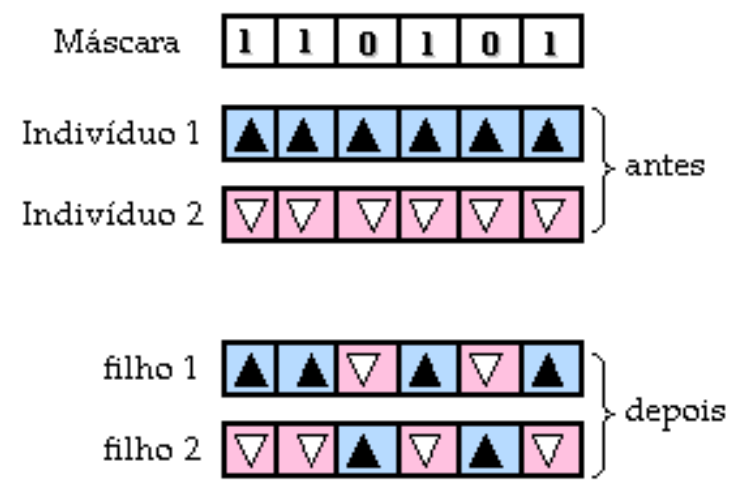

Figura 3.6: Cruzamento Uniforme.

\subsubsection{Mutação}

Inspirado pelo papel da mutação do DNA de um organismo na evolução natural -um algoritmo genético faz periodicamente variações, ou mutações aleatórias, em um ou mais membros da população atual, produzindo uma solução nova de candidatos (que pode ser membros melhores ou piores do que os existentes na população). Sendo assim, os operadores de mutação têm como objetivos a introdução e a manutenção da diversidade genética da população, assegurando uma maior varredura do espaço de busca e evitando possíveis perdas de características genéticas valiosas, que possam ter ocorrido durante as operações de cruzamento. 
A operação de mutação é utilizada, portanto, para garantir que a probabilidade de examinar qualquer ponto do espaço de busca nunca será nula, além de evitar que o algoritmo genético convirja prematuramente para mínimos locais, pois com esta operação alterase levemente a direção de busca. Deste modo, a mutação introduz novas informações, no âmbito da população, permitindo que novos pontos sejam testados, aumentando assim, a probabilidade de se encontrar o ótimo global.

O operador de mutação é aplicado aos indivíduos com uma probabilidade dada pela taxa de mutação $P_{\mathrm{m}} ;\left(0,0001 \leq \mathrm{p}_{\mathrm{m}} \leq 0,1\right)$. Na maioria das vezes a mutação é aplicada após a operação de cruzamento e geralmente se utiliza uma taxa de mutação pequena, da ordem de $2 \%$ ou menos [Coley, 1998]. Contudo, se $P_{\mathrm{m}}$ for muito baixa pode haver um comprometimento da diversidade da população; por outro lado, se $P_{\mathrm{m}}$ for muito alta, acontecerão muitas permutações aleatórias e os filhos provavelmente começarão a perder suas semelhanças com os pais, o que pode comprometer a convergência.

Há muitas maneiras possíveis de executar uma "mutação". A mais simples é a chamada mutação randômica, que consiste na substituição (alteração) de um gene de um indivíduo escolhido aleatoriamente no intervalo permitido pelo problema. Esta probabilidade de mutação, como a probabilidade de cruzamento, e também o tamanho da população, são elementos muito importantes nos AGs. Eles podem controlar todo o processo de busca, influenciando diretamente a velocidade de convergência, e evitando que aconteça a supremacia de uma determinada sub-população, o que geraria o chamado Elitismo [DeJong, 1993]. Em contrapartida, em muitas aplicações a velocidade de busca pode ser melhorada consideravelmente quando o melhor indivíduo de uma geração (elite) é transferido para a seguinte, sem qualquer modificação. Esta estratégia é muito comum nos AGS tradicionais. 


\subsubsection{Parâmetros genéticos}

Os parâmetros genéticos representam características relacionadas ao algoritmo que influenciam fortemente o seu desempenho. A escolha do valor desses parâmetros é essencial para o melhor comportamento desses algoritmos e, conseqüentemente, é determinante na obtenção de uma solução ótima ou quase ótima para o problema. Os principais parâmetros são descritos a seguir:

- Tamanho da população: o tamanho da população afeta o desempenho global e a eficiência dos AGs, influenciando a identificação de soluções ótimas. Com uma população pequena o desempenho pode cair, pois a cobertura do espaço de busca do problema é limitada e pode resultar na convergência para uma solução subótima (convergência prematura). Uma população grande geralmente fornece uma cobertura representativa do domínio do problema, além de prevenir convergências prematuras para soluções locais ao invés de globais. Contudo, para se trabalhar com grandes populações, são necessários maiores recursos computacionais, ou então tempos maiores de processamento. No entanto, normalmente o AG investe tempo no processamento de indivíduos redundantes.

- Taxa de cruzamento: representa a probabilidade de ocorrer o cruzamento entre indivíduos selecionados na população. Quanto maior for esta taxa, mais rapidamente novos indivíduos serão introduzidos na população. Porém, se esta taxa for muito alta, os indivíduos com boas aptidões poderão ser retirados mais rapidamente da população, provocando perda de bons indivíduos. Se esta taxa for muito baixa, a busca pode tornar lenta a convergência do algoritmo. Na prática, a taxa de cruzamento varia entre 0.60 e 0.90 , sendo que estes números apenas indicam uma ordem de grandeza, pois existem vários tipos possíveis de cruzamento e com taxas distintas, determinadas pelo usuário (pesquisador). 
- Taxa de mutação: indica a probabilidade de mutação de indivíduos nas populações ao longo da evolução. Uma baixa taxa de mutação previne que uma dada posição fique estagnada em um valor, além de possibilitar uma maior varredura do espaço de busca. Já com uma taxa muito alta, a busca se torna essencialmente aleatória. Assim como os demais parâmetros, a taxa ideal de mutação depende essencialmente da aplicação a ser resolvida. A maioria das taxas se encontra entre os valores de 0.0001 e 0.1 .

\subsubsection{Critérios de parada}

$\mathrm{Na}$ natureza o processo evolutivo não tem término. Todavia, estamos tratando de um algoritmo que deve ter um tempo finito de execução, de forma que seus resultados possam ser aproveitados. Para que isso seja possível, deve existir uma condição de parada. O algoritmo termina a execução quando for encontrada a solução ou quando o número máximo de iterações tiver sido alcançado. O número total de iterações é também chamado de número de gerações.

Sendo assim, alguns dos critérios de parada para os AGs são:

- quando se atinge um dado número de gerações ou um tempo-limite,

- quando o valor ótimo da função objetivo é conhecido, o critério de parada é a obtenção deste valor, definido a priori;

- convergência, isto é, quando não ocorrer melhoramento significativo no indivíduo de maior aptidão por um dado número de gerações;

- quando um alto percentual da população (por exemplo $90 \%$ ou 95\%) possuir o mesmo valor da função aptidão. 


\subsubsection{Restrições e Vantagens}

As principais diferenças entre os algoritmos genéticos da maioria das outras técnicas de otimização convencionais são [Goldberg, 1989]:

- Trabalham com uma codificação do conjunto (combinação dos parâmetros de ajuste) de parâmetros e não com os próprios parâmetros individuais;

- Trabalham com uma população de soluções candidatas simultâneas e não com uma única solução;

- Utilizam informações de custo ou recompensa e não derivadas das funções;

- Utilizam regras de transição probabilísticas e não determinísticas.

Os três aspectos mais importantes do uso de algoritmos genéticos são:

(1) definição da função objetiva,

(2) definição e execução da representação genética, e

(3) definição e execução dos operadores genéticos.

Uma vez que estes três aspectos foram definidos, o algoritmo genético deve trabalhar razoavelmente bem. Além de que você pode tentar muitas variações diferentes para melhorar o desempenho, encontrar ótimos múltiplos (espécie - se existem), ou paralisar o algoritmo.

Para usar um algoritmo genético, você deve representar uma solução a seu problema como um genoma (ou o cromossomo). O algoritmo genético então cria uma população de soluções e aplica operadores genéticos tais como a mutação e o cruzamento para evoluir as soluções a fim encontrar a melhor delas.Portanto, há uma maior possibilidade de encontrar a solução ótima, já que se trabalha com várias soluções simultaneamente. 


\section{Capítulo 4}

\section{Material e Métodos}

\subsection{Aquisição das Imagens}

As imagens ponderadas por perfusão foram feitas usando um tomógrafo de ressonância magnética de 1.5 T (Signa Excite II, General Electric Healthcare, Milwawkee, EUA). Imagens eco-planares foram obtidas continuamente através de uma injeção intravenosa de Gd-DTPA (0.2 mmol $/ \mathrm{kg})$. Os exames consistiram de 42 aquisições de volume cerebral, as quais foram utilizadas na construção das curvas de concentração $C(t)$. Os parâmetros das imagens foram: espessura da fatia $=5 \mathrm{~mm}$, tamanho da matriz $=128 \times 128, \mathrm{TR}=1$ segundo, $\mathrm{TE}=60 \mathrm{~ms}, \mathrm{FOV}=220 \mathrm{~mm}^{2}$, tamanho do pixel=1,7 e o número de fatias $=16$.

\section{Formação do sinal e conversão para medidas de concentração}

As curvas de sinal x tempo foram convertidas em curvas de concentração x tempo (Figura 4.1) de acordo com a equação vista anteriormente:

$$
C(t)=\frac{-1}{k T E} \log \frac{S(t)}{S_{0}}
$$



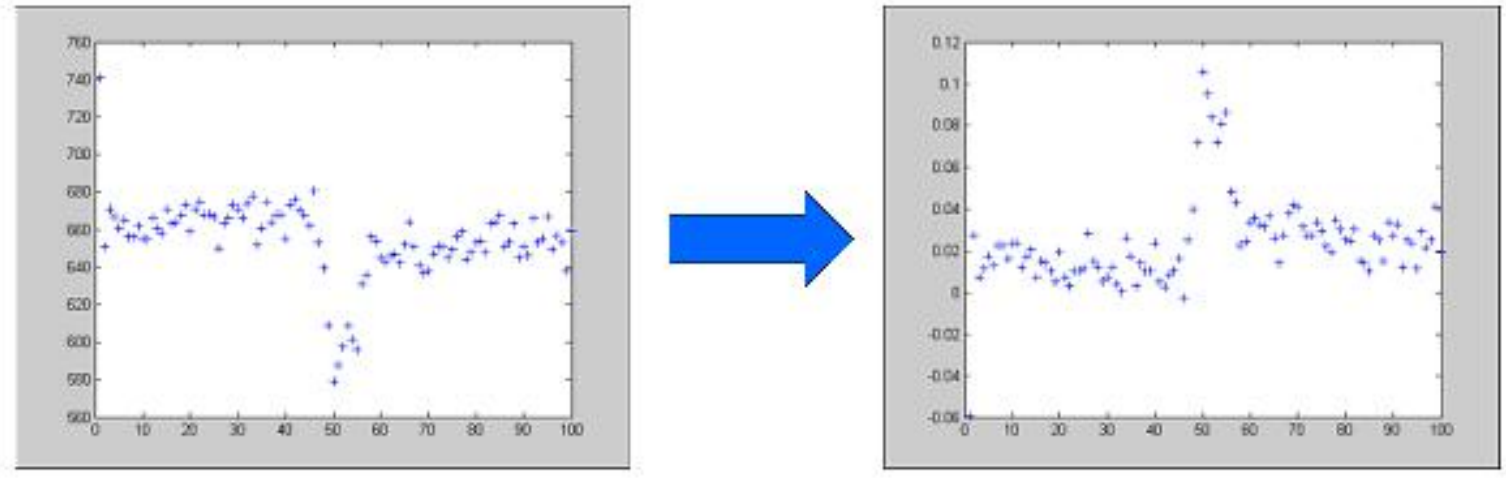

Figura 4.1: Conversão das curvas intensidade-tempo para curvas concentração-tempo de um determinado ponto da imagem.

\subsection{Processamento das imagens}

Para criar os mapas de perfusão foi desenvolvido um programa computacional, baseado na plataforma Matlab (versão 6.5, Mathworks, Sherborn, MA). Os níveis de intensidade do agente de contraste no tecido foram determinados supondo de antemão uma relação linear entre a taxa de relaxação transversal $\left(\Delta \mathrm{R}_{2}{ }^{*}\right)$ e a concentração intravascular do GdDTPA [Villriger et al 1988, Rosen et al, 1989, Rosen et al 1990, Belliveau et al, 199].

Uma série de testes foi realizada para comparar a performance dos métodos Levenberg-Marquardt (LM) e Algoritmo Genético. Os programas normalmente disponíveis nos hospitais utilizam rotineiramente o método LM, quando se trata de mapas perfusionais.

Primeiro, nós comparamos os mapas de perfusão obtidos por nossos programas computacionais, usando ambos os métodos LM e AG, com os mapas obtidos através de programas comerciais. Isso foi necessário para demonstrar que nossos programas eram capazes de gerar mapas aceitáveis à análise clínica. Para tanto, valores ótimos dos parâmetros foram usados no método que utiliza LM. Também se estimou o número de iterações que cada método exigiu para encontrar o valor mínimo do qui-quadrado. 
Foi verificada a sensibilidade dos valores de Tc (tempo de chegada do bolus) com relação aos valores mínimos do qui-quadrado e subseqüentemente os mapas foram obtidos de maneira a observar a influencia do valor de Tc na qualidade da imagem.

Em todos os casos, os seguintes parâmetros do AG foram: população inicial=100, probabilidade de cruzamento de 0.9 e 550 iterações. Uma função gama variável do tipo foi usada e com isso o efeito da recirculação foi eliminado.

\subsubsection{Mapas de CBV}

A área sob a função gama variável é analiticamente calculada pela equação abaixo (equação 4.2) a partir dos parâmetros estimados da curva ajustada. Com o auxílio dessa equação é possível construir os mapas de CBV de cada região que se queira.

$$
C B V \propto C_{0}=\int_{0}^{\infty} C(t) d t=C_{\text {pico }}\left(\frac{e}{\alpha \beta}\right)^{\alpha} \beta^{(\alpha+1)} \Gamma(\alpha+1)
$$

sendo $\mathrm{C}_{0}$ é a área sob a curva concentração x tempo (representada em vermelho), e $\Gamma$ é a função gama. Esse processo é ilustrado na figura 4.2.

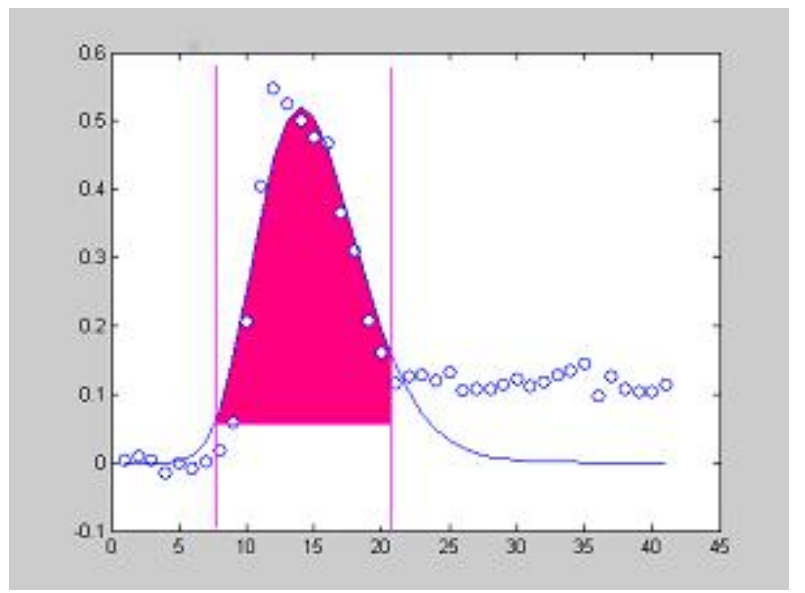

Figura 4.2: Ilustração da obtenção dos dados do CBV feito através da integral debaixo da curva ajustada (pintado em vermelho). A curva sólida á a curva gama variável usada e os pontos representados por bolinhas abertas são os dados obtidos a partir das imagens de RM. 


\subsubsection{Mapas de MT'T}

O tempo de trânsito médio (MTT), como vimos também pode ser calculado pelo primeiro momento, ou seja, a largura da curva ajustada (gama), a meia altura da curva (FWHM). É claro que o ajuste da função gama é importantíssimo para eliminar a recirculação e garantirmos que estamos analisando apenas os dados da primeira passagem do bolus pelo tecido. E isso é de vital importância para garantirmos um valor exatos para os mapas de rCBV.

A aproximação padrão é considerar que a FWHM (full-width at half-maximum) da curva gama variável, gerada pela passagem do bolus, é representativa quanto ao tempo de passagem do contraste através de uma região de interesse. Sabemos que essa aproximação é altamente dependente da forma da curva, mas segundo os ajustes fornecidos com o uso do algoritmo genético (AG), a curva gama variável se ajusta bem tanto nas curvas pronunciadas, como nas mais alargadas. Por esse algoritmo ter essa flexibilidade em se ajustar nas curvas das mais variadas formas, acreditamos que ele também nos forneça uma boa estimativa dos tempos de trânsito médio.

O nosso algoritmo genético nos fornece além dos parâmetros de ajuste da função gama variável, $\alpha$ e $\beta$, também nos dá os valores de $C_{\text {pico }}$ (o valor da concentração máxima do agente), e Tc, o tempo de chegada do bolus.

Como sabemos, vários parâmetros cerebrovasculares podem ser calculados a partir das curvas de concentração-tempo do agente de contraste. A figura 4.3 mostra os parâmetros que podem ser encontrados com o uso do Algoritmo Genético e a representação de como se calcular o MTT, a partir dos dados que dispomos. 
a

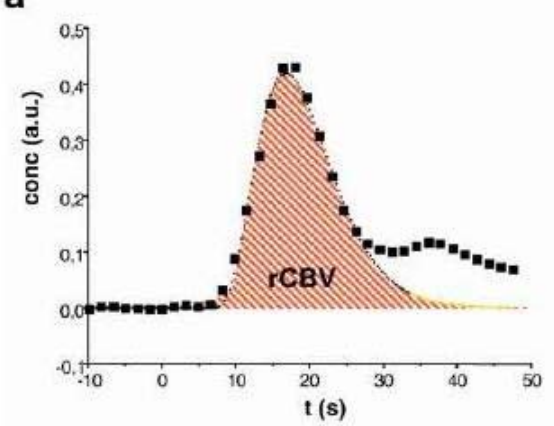

c

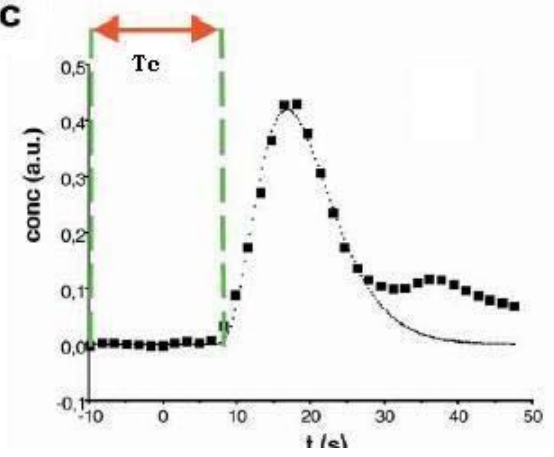

b

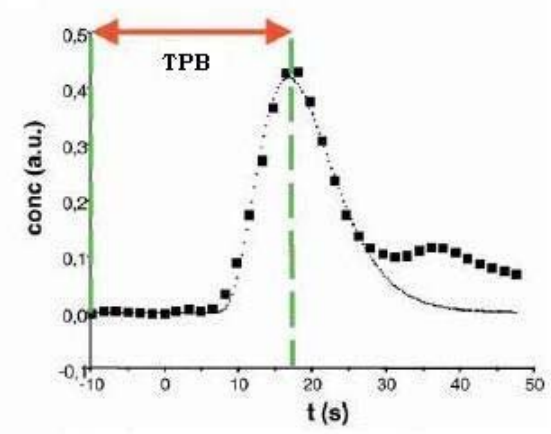

d

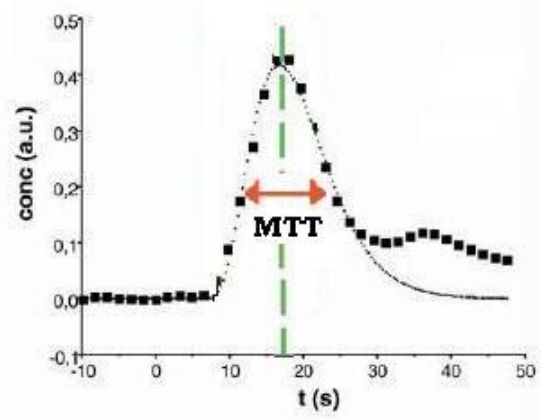

Figura 4.3: a) a área debaixo da curva concentração-tempo é definida como o rCBV. b) TPB é o tempo entre a injeção do agente de contraste e a concentração máxima do agente dentro da região de interesse. c) Tc é o tempo entre a injeção do agente de contraste e a chegada das primeiras moléculas do agente de contraste dentro da região de interesse. d) é chamado de primeiro momento da curva, dá uma estimativa do valor do MTT, ou seja, o tempo em que o agente de contraste permanece na região de interesse.

\subsubsection{Mapas de CBF}

A maioria dos cálculos de fluxo de sangue cerebral (CBF) usa uma AIF para obter uma função de resposta, através da deconvolução como já vimos, e com base nesta função de resposta encontram o valor de fluxo sangüíneo cerebral. O que se faz normalmente é calcular a altura dessa função de resposta, como sendo uma boa estimativa do valor do CBF e após isto se calcula a área desta curva sobre sua altura para dar o valor de MTT. Essa é apenas uma das possibilidades de se encontrar o valor do CBF, e também do MTT, como pode ser visto no esquema da figura 4.3. No geral, de uma forma ou de outra, essas aproximações se baseiam no teorema do volume central [Meier e Zierler, 1954], em que:

$$
C B F=\frac{C B V}{M T T} .
$$


A maneira de se estimar esses valores também depende muito do que se deseja observar. No nosso caso, o uso da AIF, ao invés de ajudar a dar um valor mais preciso, poderia ser uma fonte de erro, visto que nosso objetivo neste trabalho é aplicar estes mapas de perfusão na avaliação de pacientes com anemia falciforme, que infelizmente, já possuem na maioria das vezes algum déficit em um dos hemisférios. Como vimos, se a AIF for obtida a partir dos dados da artéria pertencente a esse hemisfério comprometido, isso conduziria a um resultado mais exato do que se a AIF fosse derivada a partir do hemisfério contralateral. Foi daí que se pensou em determinar um critério que satisfizesse melhor a idéia de uma artéria "normal", ou seja, um tempo de chegada rápido, um pico pronunciado e um tempo de transito médio curto.

Sendo assim, nesta tese, calculamos os valores do MTT e do CBF sem o uso da AIF. Já dispondo do valor do CBV, e através o princípio do volume central, é possível encontrar bons resultados do MT'T e do CBF.

\subsection{Voluntários e Pacientes}

Este estudo constituiu-se inicialmente de quatro pacientes do Hospital das Clínicas de Ribeirão Preto, cujos exames de DSC-MRI foram adquiridos por diferentes razões clínicas. O uso de pacientes com lesões distintas foi proposital, de modo a avaliar o programa construído com relação aos diagnósticos já conhecidos e comparar os resultados às análises obtidas por programas comerciais.

O primeiro paciente (identificado pelas iniciais BLS) evoluiu com uma hemiparesia do lado esquerdo, como resultado de uma isquemia cerebral no território da artéria cerebral média. Uma angiografia por ressonância magnética (MRA) indicou vasculite. O segundo paciente (identificado como MVV) foi submetido a um exame de acompanhamento de um glioma cerebral. Já o terceiro (identificado como AMM) realizou um controle para trata- 
mento radioterápico de um glioblastoma multiforme (GBM), que revelou possíveis áreas de radionecrose. O último paciente (identificado por IGV) possuía sinais importantes de déficit cognitivo e as imagens de RM indicaram a presença de um glioma infiltrativo. É de grande importância ressaltar que esses estudos estão de acordo com as regras estabelecidas pelo comitê de ética da nossa instituição.

O objetivo principal deste estudo era de poder utilizar os mapas de perfusão cerebral na análise de pacientes com anemia falciforme. Para este estudo foram inicialmente realizadas análises das imagens de um grupo de 23 pacientes de com Anemia falciforme, do Hospital das Clínicas de Ribeirão Preto (HC-FMRP). Pelo fato de ser recente o estudo da possibilidade da utilização da técnica de DSC-IRM em pacientes falcêmicos alguns dados de alguns pacientes foram perdidos. Além disso, a injeção do bolus de agente de contraste é realizada manualmente, o que dificulta manter uma velocidade constante de injeção em todos os pacientes. Portanto nosso grupo final contou com 6 pacientes, cujo diagnóstico clínico, pelo HCRP-USP, está mostrado na tabela 4.1.

\begin{tabular}{|c|c|c|}
\hline Iniciais dos pacientes & Ressonância Magnética & Angiografia RM \\
\hline paciente 1 - FSV & infarto frontal direito & oclusão ACI bilateral \\
\hline paciente 2- LDA & alteração periventricular & estenose ACI direita \\
\hline paciente 3 - FCO & Infarto frontal direito & estenose ACM bilateral \\
\hline paciente 4 - ALM & normal & normal \\
\hline paciente 5 - ARS & normal & normal \\
\hline paciente 6 - ADN & normal & normal \\
\hline
\end{tabular}

Tabela 4.1: Resultados das avaliações clínicas realizadas pelo exame de RM tradicional e Angiografia por RM. Legenda: ACI- artéria carótida interna, e ACM- artéria cerebral média. 


\section{Capítulo 5}

\section{Resultados e Discussão}

Mapas relativos de VSC foram obtidos e comparados usando tanto o método de ajuste de Levenberg-Marquardt (LM) quanto o método que faz uso de algoritmos genéticos (AG). Assim, as curvas de concentração-tempo do agente de contraste foram ajustadas usando uma função do tipo gama variada, para ambos os métodos, de modo que os mapas hemodinâmicos construídos fornecessem evidências das diferenças anatômicas e fisiológicas de um método em relação a outro.

\subsection{Mapas de CBV}

A figure 5.1 mostra o resultado da comparação entre os mapas de rCBV obtidos a partir de três procedimentos diferentes. As áreas apresentadas em vermelho representam os voxeis com maior volume de sangue cerebral, enquanto que as áreas azuladas representam as de menor volume sangüíneo. A figura 5.1a se refere aos mapas de perfusão fornecidos por programas computacionais da GE, que utiliza um método de minimização de Levenberg-Marquardt. Na figura 5.1b é exibido o mapa de perfusão realizado pelo programa desenvolvido nesta tese que também utiliza o método de LM. Este método é feito de modo a comparar a eficiência da plataforma Matlab usada de maneira a verificar se os mapas produzidos pela minha linguagem computacional satisfazem ou são comparáveis aos mapas produzidos pelo fabricante do tomógrafo. O que pode ser verificado fazendo este progra- 
ma foi que este método freqüentemente requer a interação com o usuário, ou seja, necessita-se fixar no programa os valores de Tc.

O procedimento que utiliza o algoritmo genético é mostrado na figura 5.1c. Esse algoritmo inicia com um conjunto de soluções possíveis, chamada de população, que são escolhidas aleatoriamente pelo programa de modo a garantir a seleção da melhor combinação dos parâmetros.
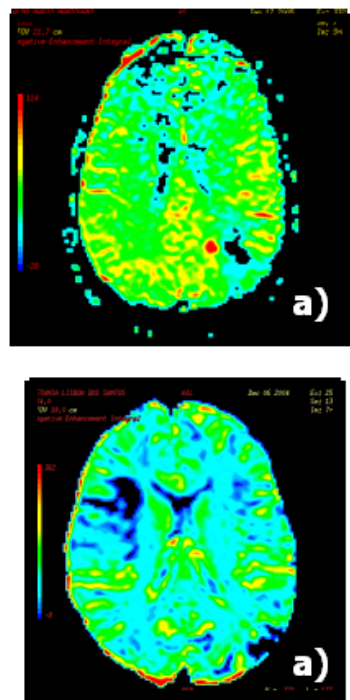
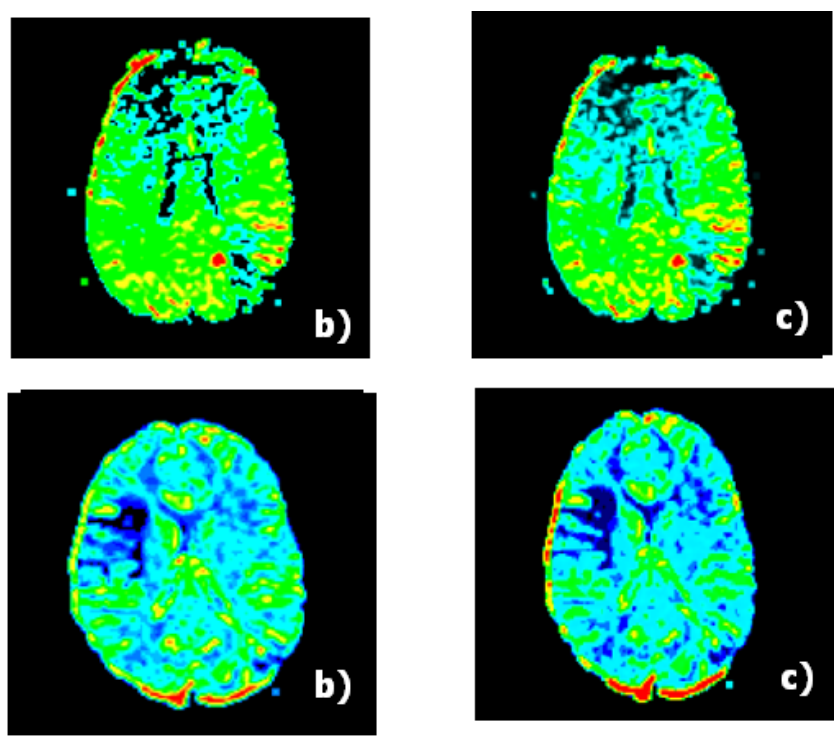

c)

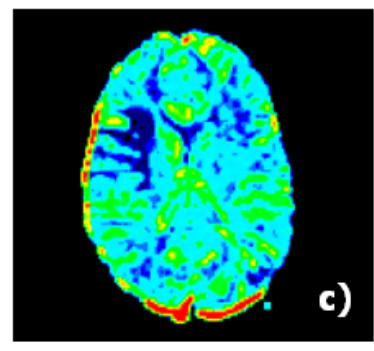

Figure 5.1. Resultado da comparação entre os mapas de rCBV usando: a) o programa da GE, b) o método de Levenberg-Marquardt (LM) e c) o método com Algoritmo Genético (AG).

Foi observado em nossos resultados, que os mapas construídos usando o AG foram no mínimo tão bons quantos os mapas construídos pelo programa da GE, sendo que, no exame descrito acima, forneceram uma imagem mais conspícua de modo que isso nos dá uma confiança em relação a qualidade dos programas escritos. Áreas de hipo-perfusão foram claramente observadas em dois pacientes. Na primeira fileira da figura 5.1 foi observada uma região de baixa perfusão na topografia do lobo parietal inferior a esquerda de um paciente e na fileira de baixo foi observada área de baixa perfusão cerebral na topografia do giro frontal inferior e na ínsula a direita. Portanto, como nós podemos 
observar, o método AG produz resultados similares aos outros dois métodos, com a vantagem de não possuir restrição aos valores iniciais, sendo completamente automatizado.

Portanto, os mapas demonstraram uma interessante concordância, revelando similaridades entre os métodos. Contudo, de modo a obter bons resultados com o método de LM, foi estimado, a priori, os melhores valores a serem utilizados para ajustar a curva de concentração. Enquanto isso, o método que usa AG encontrou todos os parâmetros, incluindo os valores de Tc, a partir de valores iniciais aleatórios.

\subsubsection{Comparação da eficiência em ambos os métodos.}

\section{LM versus AG}

O método também foi comparado quanto a sua eficiência no tempo. A tabela 5.1 mostra valores mínimos de qui-quadrado e o número de iterações que são necessárias para encontrar este valor mínimo usando tanto o método convenciona, LM, quanto o método que utiliza o algoritmo genético (AG). Os valores iniciais do qui-quadrado foram exatamente o mesmo para ambos os métodos. O que podemos observar é que no método que utiliza o algoritmo genético é mais lento do que o que usa o método de LevenbergMarquardt. Contudo, o método que utiliza algoritmo genético (AG) encontrou valores bem melhores.

Testes similares de eficiência demonstraram a determinação de parâmetros melhores, com uma exatidão maior e melhor usando o método de $A G$, em vários tipos de procedimentos, desde que o seu desempenho realiza uma de pesquisa global numa configuração ótima [Yun et al, 2000; Kudla, A, 2004; Dondeti et al, 2005].

Como mencionado anteriormente, o método de LM é limitado por um certo número definido de parâmetros a ser estimado, como também o fato de ser preciso fazer 
uma "estimativa" inicial de tais variáveis. No caso na construção dos mapas de rCBV, temse que estimar a priori o valor de Tc, que permanece fixo durante o procedimento da construção dos mapas hemodinâmicos. Sendo assim, ambos os métodos foram testados com respeito a sua efetividade no que diz respeito aos valores encontrados quando a função é dependente de Tc, que é o tempo de chegada do bolus.

No experimento seguinte, os mesmos testes foram realizados a partir de uma determinada curva de concentração-tempo, usando um valor de Tc fixo de modo a demonstrar que pequenas alterações sobre o valor de Tc podem afetar diretamente e drasticamente a eficiência e a confiabilidade dos dados, que são usados na construção dos mapas hemodinâmicos.

\begin{tabular}{|l|c|c|}
\hline & LM & AG \\
\hline qui-quadrado inicial & $2.0 \times 10^{+2}$ & $2.0 \times 10^{+2}$ \\
\hline qui-quadrado mínimo & $4.6 \times 10^{-3}$ & $4.7 \times 10^{-4}$ \\
\hline $\begin{array}{l}\text { Número de iterações para } \\
\text { encontrar o qui-quadrado } \\
\text { mínimo. }\end{array}$ & 10 & 22 \\
\hline
\end{tabular}

Tabela 5.1: Mostra os valores iniciais de qui-quadrado e o número de iterações necessárias para encontrar o valor mínimo usando tanto o método LM quanto o método AG.

\subsubsection{Comparação da influência de Tc usando LM e AG.}

A figura 5.2 mostra os valores de qui-quadrado versus os valores de Tc, para verificar a influência dos valores de Tc na construção dos mapas de CBV. O método de LevenbergMarquardt se mostrou muito mais sensível às variações de Tc, de modo que pequenas variações causaram grandes alterações sobre o valor de qui-quadrado. Por outro lado, o 
Método que usa Algoritmo Genético se mostrou mais estável. Independente do valor de Tc usado, o valor do qui-quadrado permaneceu mínimo, inalterado.

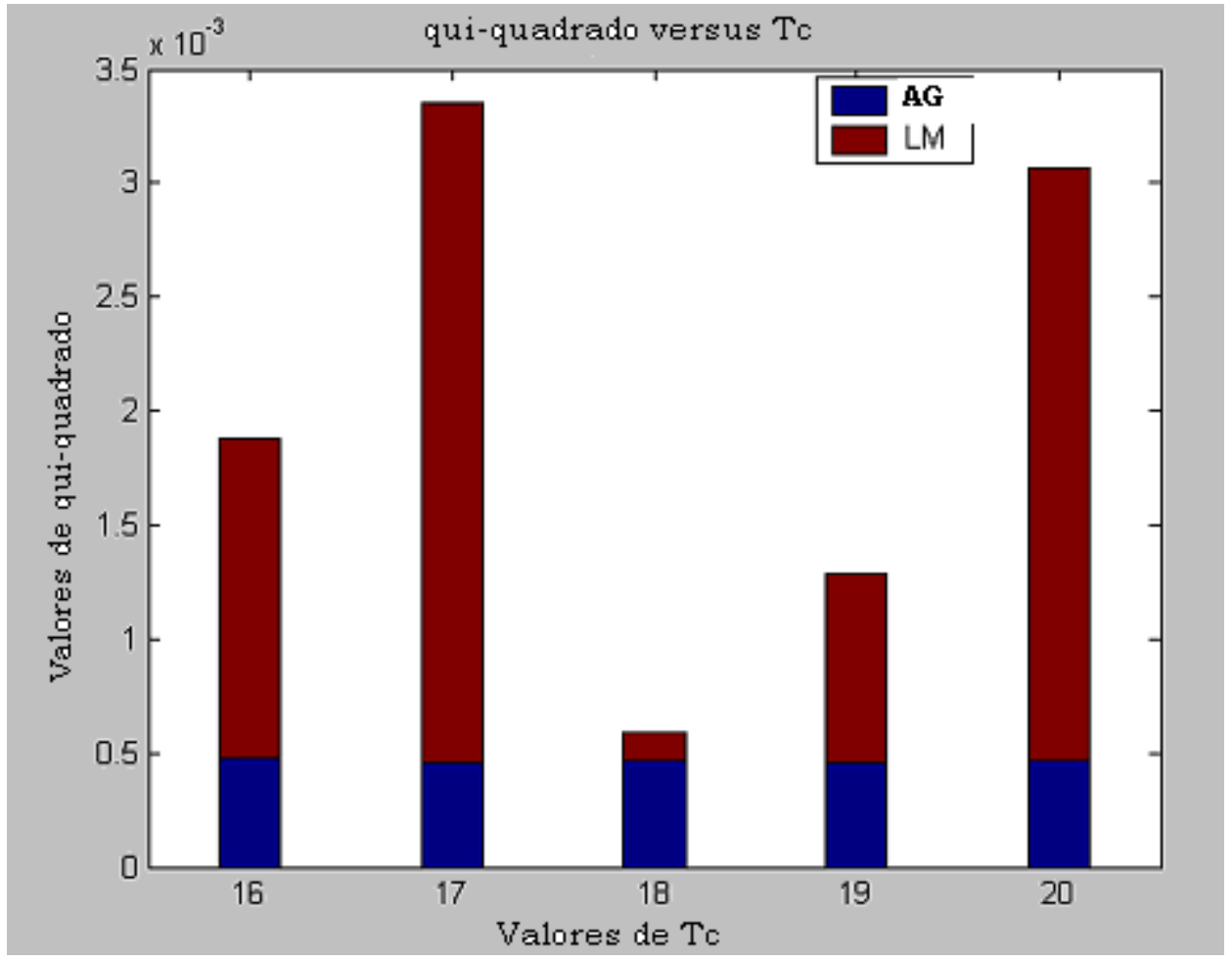

Figure 5.2: A figura mostra os valores de qui-quadrado versus os valores de Tc, de modo a verificar a sensibilidade do valor de qui-quadrado em relação ao Tc utilizado.

\section{Influência nos Mapas de CBV para um valor de Tc fixo}

$\mathrm{Na}$ figura 5.3 foram construídos mapas de CBV usando um valor fixo de Tc, Tc= $17 \mathrm{~ms}$, para ambos os métodos. Esse valor de Tc foi justamente escolhido num caso que resultou numa enorme discrepância entre os métodos, com respeito aos valores de quiquadrado.Contudo, nosso principal foco foi inspecionar exatamente em que essas discrepâncias resultariam no mapa de rCBV final. E como pode ser observado, a qualidade e a exatidão do mapa foram comprometidas, mostrando claramente a sua dependência do valor de Tc usado. Também pôde ser notado que o mapa que usa o método AG possui uma melhor precisão em relação à delimitação de estruturas e resultados da perfusão.

Além disso, uma nova aproximação neste estudo é justamente demonstrar a importância clínica nos casos onde o valor de Tc pode variar de uma região para outra ou 
ter valores distintos em regiões diferentes. Nesses casos, é evidente que os mapas de perfusão final não representariam valores confiáveis o suficiente para descrever a realidade.
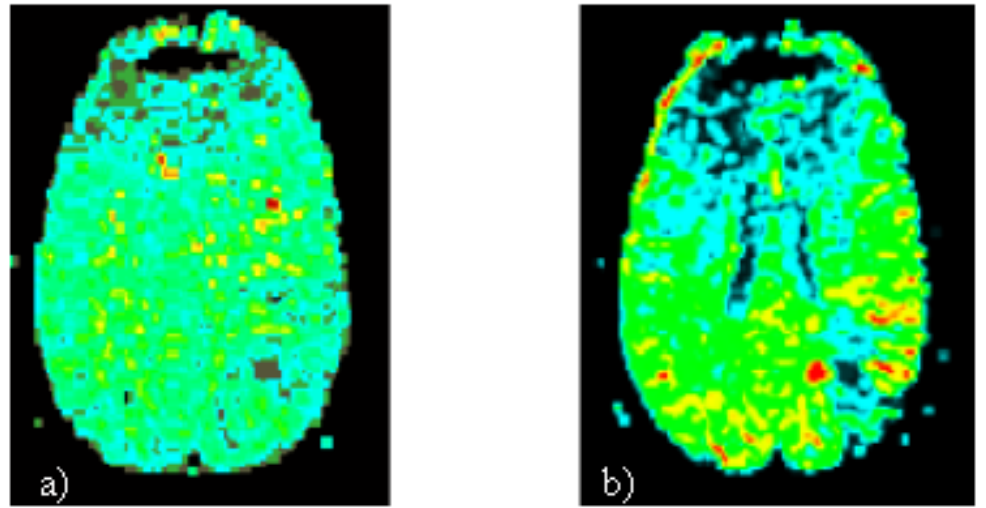

Figure 5.3: Construção de mapas de $\mathrm{CBV}$ usando $\mathrm{Tc}=17 \mathrm{~ms}$, para ambos os métodos. a) Levenberg-Marquardt e; (b) Algoritmo.Genético.

\section{Mapas de CBV, MTT e CBF}

A seguir, na figura 5.4, apresentamos os mapas de CBV, MTT e CBF para os dois pacientes apresentados na figura 5.1, anteriormente.
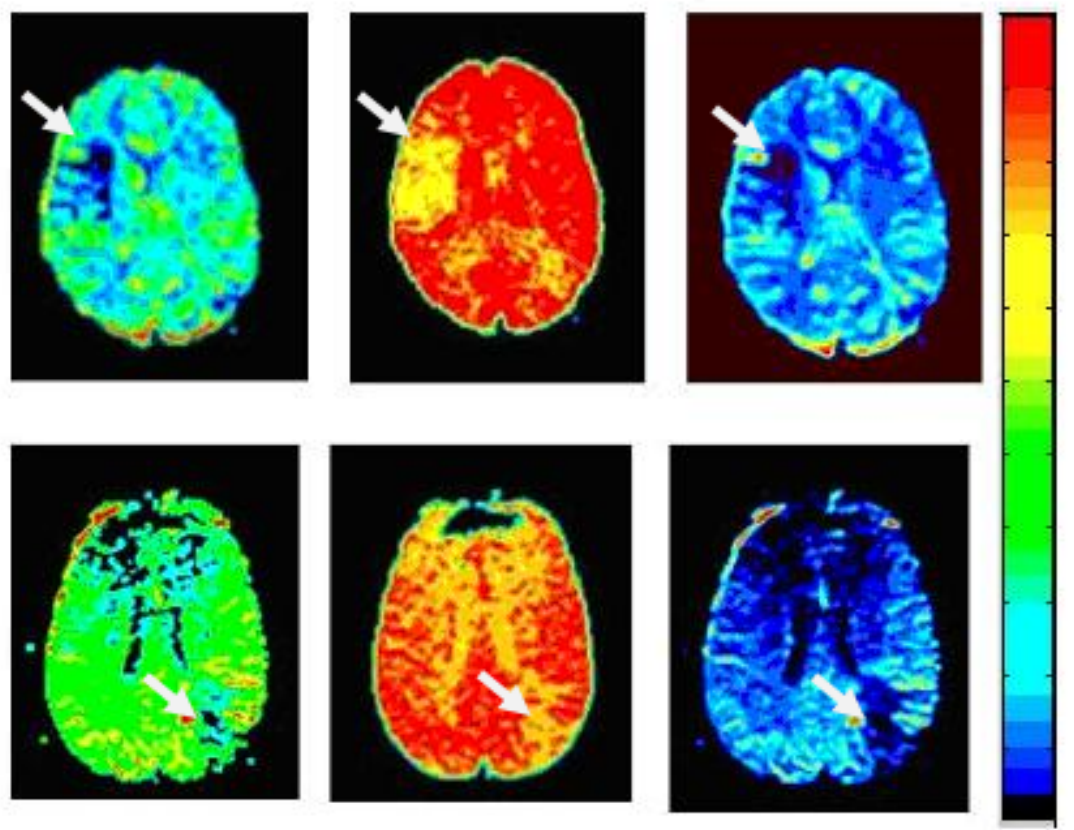

a)

b)

c) 
Figure 5.4: Mapas hemodinâmicos de 2 pacientes a) CBV, b) MTT e c) mapa de CBF.

A fileira superior da figura 5.4 se refere ao paciente 1 e a fileira inferior, ao paciente 2. O laudo clínico do paciente 1 evoluiu com uma hemiparesia do lado esquerdo, como resultado de uma isquemia cerebral no território da artéria cerebral média direita. Uma angiografia por ressonância magnética (MRA) indicou vasculite. Como pode ser visto na fileira superior da figura 5.4 (seta), o CBV (visto na fig. 5.4a) nesta região é praticamente nulo, mostrando um déficit de irrigação cerebral. O mapa de MTT desse paciente, figura 5.4b (fileira superior), confirma a área com uma redução do tempo de trânsito do sangue na região afetada. O Mapa de CBF (figura 5.4c) revela uma região isquêmica com pouco de fluxo de sangue na região.

Já o exame mostrado na linha inferior da figura 5.4, corresponde a um controle para tratamento radioterápico de um glioblastoma multiforme (GBM), que revelou possíveis áreas de radionecrose. O mapa de CBV exibe uma pequena área de redução de volume de sangue cerebral (ver seta). O seu mapa de MT'T confirma essa região de pouca circulação de sangue mostrando um tempo de transito maior do que na região. O mapa de CBF confirma esses dados, mostrando a redução do fluxo (indicada pela seta).

\subsection{Mapas hemodinâmicos em pacientes com Anemia Falciforme.}

Para este estudo foram realizadas análises das imagens de seis pacientes com Anemia falciforme, do Hospital das Clínicas de Ribeirão Preto (HC-FMRP). Pelo fato de ser recente o estudo da possibilidade da utilização da técnica de DSC-IRM em pacientes falcêmicos, antes foram testados os mapas de perfusão em pacientes cujo diagnostico clínico já era pré-avaliado e conhecido, como visto anteriormente.

A técnica de estudo da velocidade de fluxo das artérias intracranianas pelo Doppler Transcraniano (DTC) fornece parâmetros para o diagnóstico e acompanhamento da 
evolução temporal dos pacientes falcêmicos, através da análise das velocidades média na artéria cerebral média, em ambos os hemisférios. O acesso aos vasos intracranianos é possível através de áreas em que o ossos da calota craniana é fino ou através dos forames naturais (janelas acústicas), usando-se um transdutor de baixa freqüência $(2 \mathrm{mHz})$ que emite ondas de ultra-som de forma pulsátil [Nichols et al, 2001].

As janelas acústicas empregadas convencionalmente são a transtemporal (localizada acima do arco zigomático), transorbitária e transforaminal (forame magno), através das quais pode-se obter registros das velocidades de fluxo das artérias cerebral interna (ACI) intracraniana, cerebral anterior (ACA), cerebral média (ACM), cerebral posterior (ACP), comunicante anterior (ACoA), comunicante posterior (ACoP), oftálmica (AO), vertebral (AV) e basilar (AB). Para uma correta identificação das artérias a partir dos sinais obtidos, são usados vários parâmetros como a janela acústica utilizada, a orientação (angulação) do transdutor, a profundidade da amostra de sinal obtido, a direção do fluxo e o contorno da onda obtido após análise espectral. Os valores médios normais de velocidade de fluxo nas principais artérias são: ACM (41 a $67 \mathrm{~cm} / \mathrm{seg}$ ); ACA (36 a $64 \mathrm{~cm} / \mathrm{seg}$ ); ACP (31 a 49 $\mathrm{cm} / \mathrm{seg})$; $\mathrm{ACI}(30$ a $54 \mathrm{~cm} / \mathrm{seg}) ; \operatorname{AV}(27$ a $45 \mathrm{~cm} / \mathrm{seg})$ e $\mathrm{AB}(80$ a $110 \mathrm{~cm} / \mathrm{seg})$ [Razumovsky et al, 1995].

Geralmente velocidades entre 120 e $140 \mathrm{~cm} / \mathrm{seg}$ não estão correlacionadas com a presença de déficit isquêmico, embora isso possa ocorrer em alguns casos. Em pacientes com velocidade de fluxo acima de $140 \mathrm{~cm} / \mathrm{seg}$ há uma grande possibilidade de desenvolvimento de déficit isquêmico na ACM. Velocidades acima de $200 \mathrm{~cm} / \mathrm{seg}$ na ACM estão fortemente associadas à isquemia cerebral, embora alguns pacientes possam ainda permanecer assintomáticos graças aos mecanismos compensatórios de fluxo [Nichols et al, 2001]. 
No Hospital das Clínicas de Ribeirão Preto o valor utilizado como patamar para indicar a realização do exame de RM de encéfalo é de $170 \mathrm{~cm} / \mathrm{s}$ de velocidade média, medido na artéria cerebral média [Magalhães, J. F.G - Dissertação de mestrado, 2003].

Apesar da técnica DTC ser não-invasiva, as imagens de perfusão têm um grande potencial no que diz respeito a hemodinâmica cerebral, fornecendo um parâmetro a mais para o diagnóstico e acompanhamento dos pacientes portadores de anemia falciforme. A imagem por perfusão também é uma técnica não-invasiva, o que não acrescenta nenhum risco ao paciente, bem como seu papel auxiliar na programação terapêutica mais adequada ao paciente, além de uma informação visual imediata. Com os mapas de CBV, MT'T e CBF é possível uma melhor observação de áreas e zonas em risco de infarto em pacientes falcêmicos, além da monitoração preventiva destes pacientes e outros casos mais severos.

A tabela 5.2 mostra os resultados dos exames de Doppler Transcraniano, Ressonância Magnética e Angiografia por RM, do nosso grupo de pacientes realizados no HCRP.

\begin{tabular}{|c|c|c|c|}
\hline pacientes & DTC (velocidade média) & $\mathbf{R M}$ & Angio-RM \\
\hline 1 & $\mathrm{ACMd}=---\mathrm{cm} / \mathrm{s}$ ACMe $=10 \mathrm{~cm} / \mathrm{s}$ & Infarto frontal $\mathbf{d}$ & $\begin{array}{l}\text { oclusão bilateral da } \\
\text { carótida interna }\end{array}$ \\
\hline 2 & $\mathrm{ACMd}=95 \mathrm{~cm} / \mathrm{s} \mathrm{ACMe}=118 \mathrm{~cm} / \mathrm{s}$ & alteração periventricular & $\begin{array}{c}\text { estenose carótida } \\
\text { interna } \mathbf{d}\end{array}$ \\
\hline 3 & $\mathrm{ACMd}=117 \mathrm{~cm} / \mathrm{s} \mathrm{ACMe}=161 \mathrm{~cm} / \mathrm{s}$ & Infarto frontal $\mathbf{d}$ & estenose ACM bil \\
\hline 4 & $\mathrm{ACMd}=96 \mathrm{~cm} / \mathrm{s} \mathrm{ACMe}=96 \mathrm{~cm} / \mathrm{s}$ & normal & normal \\
\hline 5 & $\mathrm{ACMd}=123 \mathrm{~cm} / \mathrm{s} \mathrm{ACMe}=108 \mathrm{~cm} / \mathrm{s}$ & normal & normal \\
\hline 6 & $\mathrm{ACMd}=50 \mathrm{~cm} / \mathrm{s} A C M e=87 \mathrm{~cm} / \mathrm{s}$ & normal & normal \\
\hline
\end{tabular}

Tabela 5.2: Mostra os resultados do laudo feito através do Doppler Transcraniano, no HCRP. Legenda: ACM (artéria cerebral média), representado a letra e (esquerda) e d (direita). bil=bilateral. 
A seguir serão mostrados nossos mapas de perfusão, CBV, MT'T e CBF, para cada um dos seis pacientes com anemia falciforme e logo após, a análise dos mapas feita por um neurologista do Hospital das Clínicas de Ribeirão preto (HCRP-USP) com base na inspeção visual dos mapas hemodinâmicos.

- Paciente 1- identificado pelas letras FSV.

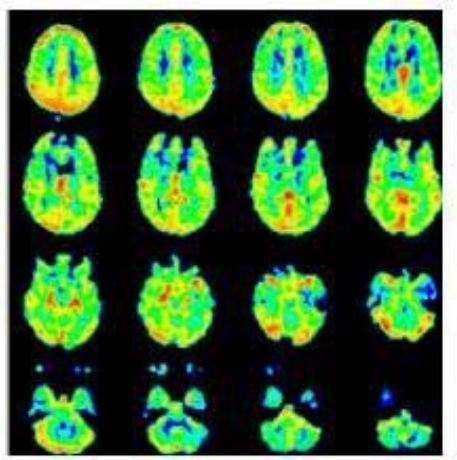

CBV

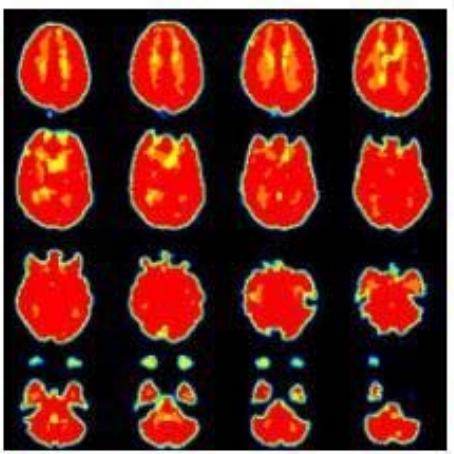

MTT

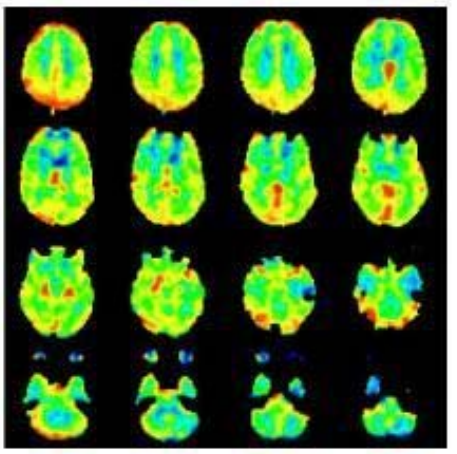

CBF

- Paciente 2- identificado pelas letras LDA.

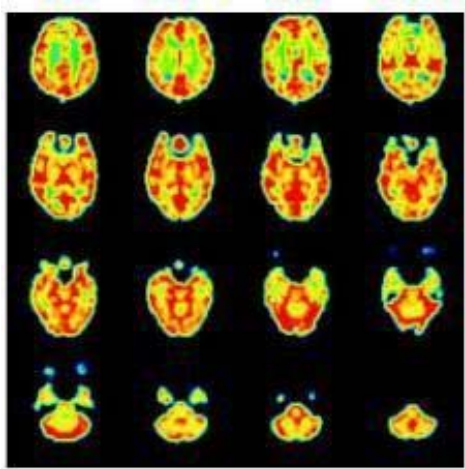

CBV

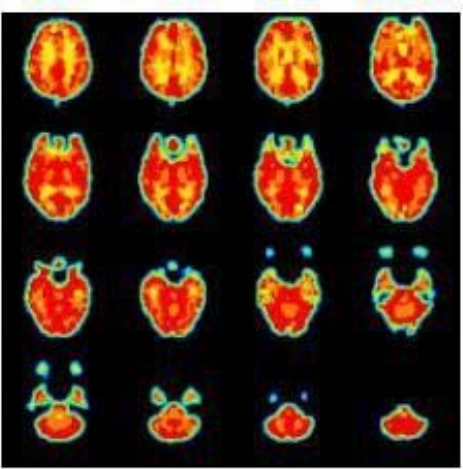

MTT

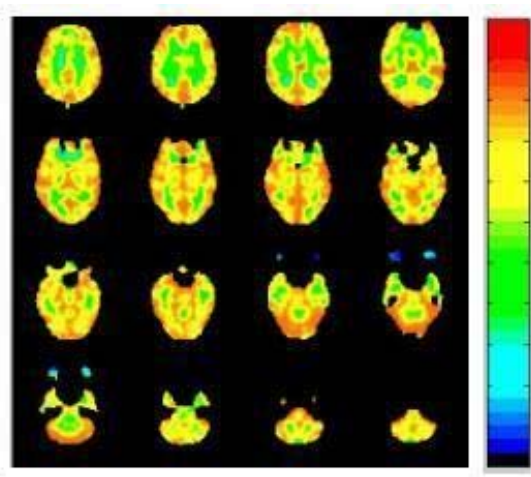

CBF

- Paciente 3- identificado pelas letras FCO. 


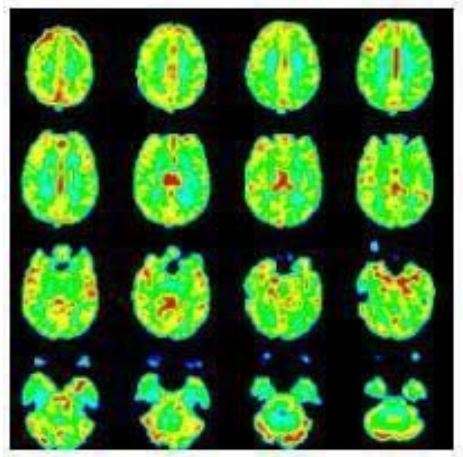

CBV

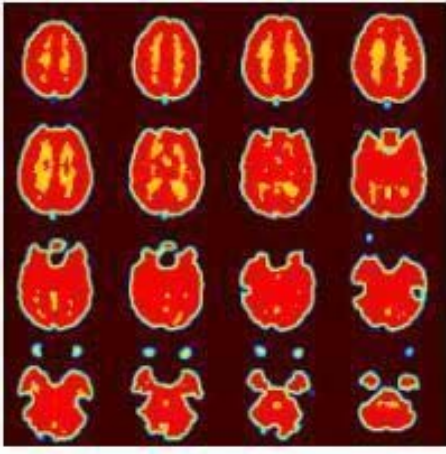

MTT

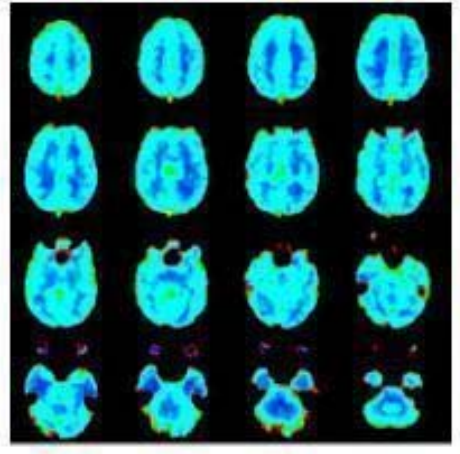

CBF

- Paciente 4-identificado pelas letras ALM.

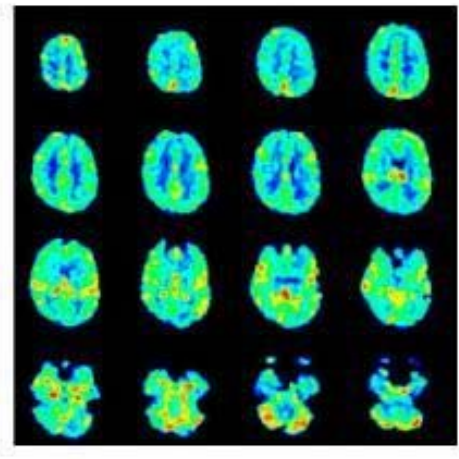

CBV

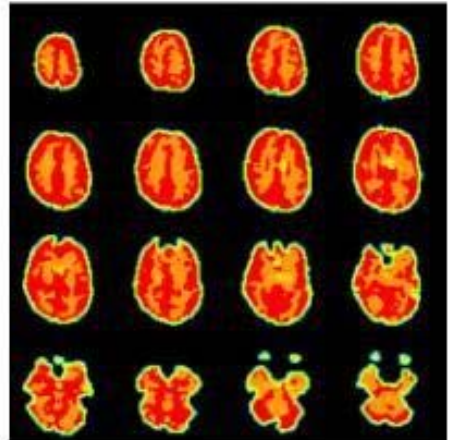

MTT

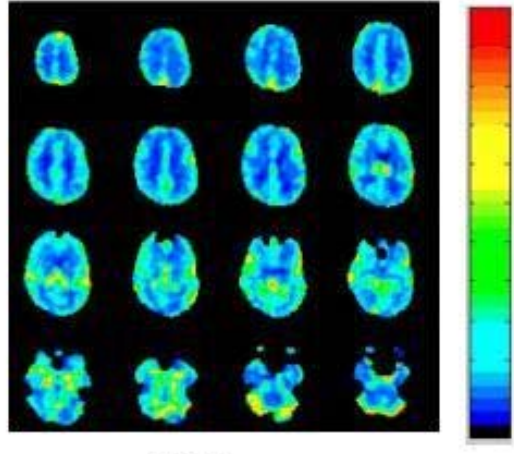

CBF

- Paciente 5 - identificado pelas letras ARS.

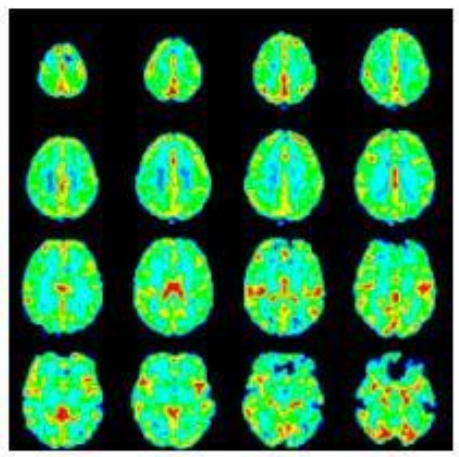

CBV

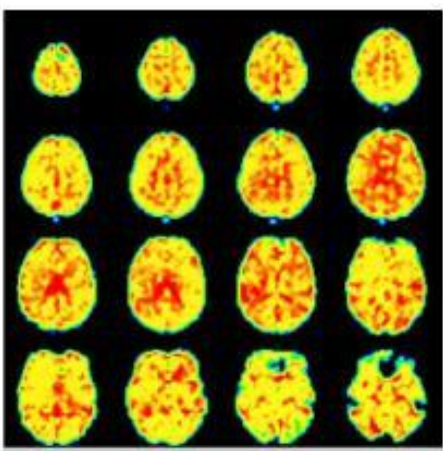

MTT

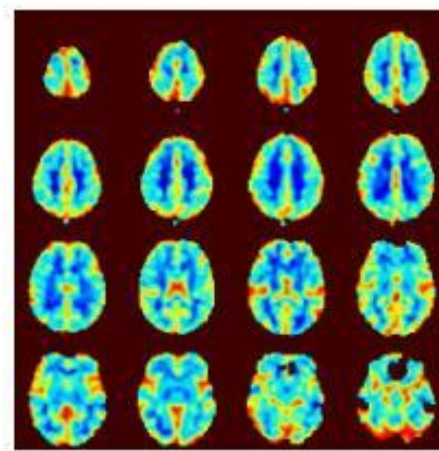

CBF

- Paciente 6 - identificado pelas letras ADN. 


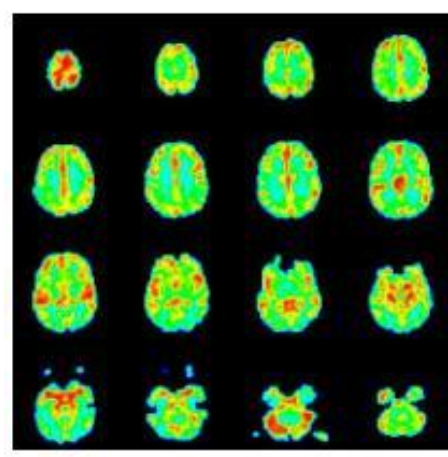

CBV

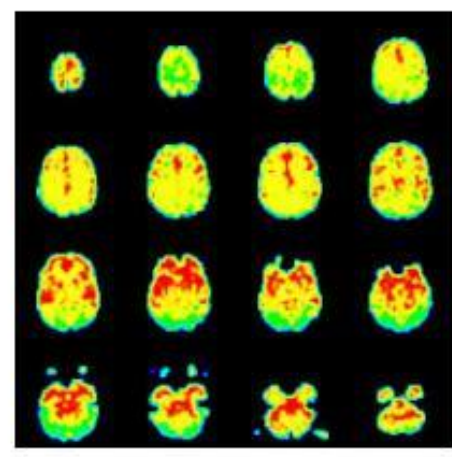

MTT

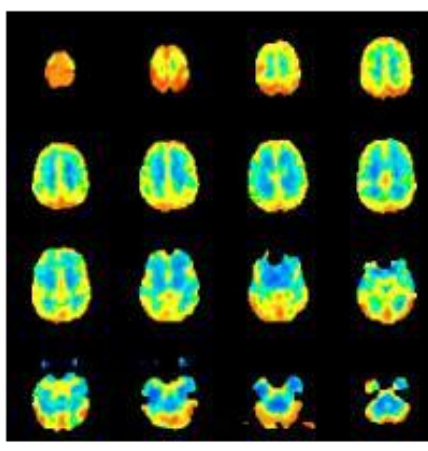

CBF

A tabela 5.3, mostra a análise dos mapas feita por um neuroradiologista do Hospital das Clínicas de Ribeirão Preto (HCRP-USP) com base na inspeção visual dos mapas hemodinâmicos.

\begin{tabular}{|c|c|c|c|}
\hline pacientes & CBV & MTT & CBF \\
\hline 1 & Redução frontal direita & Redução frontal direita & Redução frontal direita \\
\hline 2 & Redução frontal esquerda & Redução frontal esquerda & Redução frontal esquerda \\
\hline 3 & Redução parietal direita & Dado não significativo & Redução parietal direita \\
\hline 4 & Redução frontal direita & Redução frontal direita & Redução frontal direita \\
\hline 5 & Normal & Normal & Normal \\
\hline 6 & Normal & Normal & Normal \\
\hline
\end{tabular}

Tabela 5.3: Resultados observados por um neuroradiologista do HCRP-USP.

De acordo os dados que dispomos (tabela 5.2) o paciente 1 foi diagnosticado com um infarto frontal direito, provavelmente devido à oclusão da artéria carótida interna (ACI) identificada com a angioressonância. Esse paciente apresentou oclusão da ACI bilateralmente, porém o infarto ocorreu apenas no território da ACM D, devido à circulação colateral ter preservado os demais territórios. O DTC mostrou acentuado alentecimento da velocidade média em ambas ACM, devido ao fluxo colateral precário. Os mapas hemodinâmi- 
cos também mostraram a redução tanto do volume de sangue (CBV) quanto do fluxo sangüíneo cerebral $(\mathrm{CBF})$ na mesma região, frontal direita, com infarto e com preservação da perfusão ns demais regiões dependentes das ACIs. O Mapa de MTT' confirmou isso, exibindo na região um tempo de trânsito mais longo.

A imagem de Ressonância Magnética tradicional mostrou uma alteração periventricular no paciente 2 , enquanto que a angiografia por RM identificou uma estenose na ACI direita. Os mapas de CBV e CBF exibiram a redução do volume e fluxo de sangue, respectivamente, no lobo frontal esquerdo. E o MTT se mostrou mais prolongado nessa região. Mais uma vez, a circulação colateral preservou a perfusão nas demais regiões do território da ACI estenosada.

O paciente de número 3 tem como resultado da imagem por RM um infarto frontal do lado direito, e a angiografia por RM identificou uma estenose na ACM, bilateralmente. Nossos mapas de perfusão, segundo o neurorradiologista, mostraram uma redução tanto do CBV quanto do CBF na região parietal direita, território da ACM deste lado. Quanto ao mapa de MTT, não houve um dado visual significativo segundo o especialista, sugerindo um tempo de trânsito normal, apesar de um volume e fluxo sangüíneo reduzidos.

O paciente 4 teve um resultado considerado normal, nos dois exames realizados, imagem por RM e Angiografia por RM. Já os mapas de CBV e CBF, mostraram uma redução frontal do lado direito do cérebro. Assim como MTT prolongado nessa mesma região. Esse resultado mostra uma não concordância entre os mapas de perfusão e os outros dois exames feitos. Este resultado poderia ser explicado por uma alteração funcional precedendo a alteração estrutural, mas não temos o seguimento clínico desta paciente.

Os pacientes 5 e 6 tiveram resultados normais em todas as técnicas utilizadas, mostrando que estes resultados estão de acordo com os encontrados com as técnicas normalmente realizadas nos pacientes falcêmicos. 
Com base na comparação entre resultados comumente realizados nos pacientes com anemia falciforme e o uso dos mapas perfusionais nestes pacientes, pode-se constatar uma a concordância dos resultados em $80 \%$ dos pacientes, e um resultado não concordante (20\%), não encontrado nos exames estruturais, que poderia ser no mínimo motivo de reavaliação do paciente em questão.

O uso dos mapas de perfusão como ferramenta investigativa e auxiliar nos pacientes portadores de anemia falciforme é algo bem recente e sem resultados conclusivos a respeito do seu uso, justamente por ser uma área pouco estudada e, portanto sem resultados para a comparação, pois, infelizmente, não há muitos relatos com este tipo de doença cerebrovascular usando imagens de perfusão.

As lesões no SNC dependem basicamente da obstrução vascular decorrente de anormalidades como estreitamento ou oclusão completa das artérias. Tais lesões podem ocorrer, no caso da anemia falciforme, em conseqüência da oclusão dos capilares devido à capacidade de deformação das hemácias falcêmicas, que pode levar ao infarto de uma determinada região. No caso dos estreitamentos de artérias maiores, como as carótidas e cerebrais média, a estenose ocorre por obstrução de arteríolas nutridoras da parede arterial (“vasa vasorum"). Além disso, pode ocorrer lesão endotelial resultante da isquemia (redução da irrigação sangüínea) dos vasos. O endotélio danificado funciona então como um ninho para a adesão de plaquetas e células falcêmicas, resultando na formação de trombos.

Em crianças até 10 anos, encontra-se mais comumente a isquemia cerebral, com sinais e sintomas como: hemiparesia, distúrbios visuais, paralisia de nervos cranianos ou alteração súbita de comportamento. Eventualmente estes infartos ocorrem em regiões cerebrais não eloqüentes, resultando em lesões ditas "silenciosas", não detectadas clinicamente. Apesar da recuperação muitas vezes ser completa, são comuns seqüelas intelectuais, motoras e sensitivas. Além disso, estudos sugerem que a área atingida pelo infarto está associada 
com a redução do QI [Armstrong, et al, 1996] e déficits sutis de atenção e função executiva [DeBaun et al, 1998, Watkins et al, 1998].

Por ser uma doença genética, tem como principal condição a prevenção, o monitoramento e a evolução do estado do paciente, pois a identificação do risco de infarto indica o início da transfusão sangüínea, a qual deve ser retardada o máximo possível, para minimizar o risco de depósito anormal de ferro nos tecidos. Assim, o objetivo maior deste estudo foi o de melhorar a quantificação da perfusão medida por IRM realçada por contraste dinâmico e criar mapas hemodinâmicos que pudessem ser usados como ferramenta auxiliar na de prevenção de risco de infarto em pacientes portadores de anemia falciforme. $\mathrm{O}$ controle dessa doença e a racionalização do uso de transfusões de sangue melhoram não só a qualidade de vida, como também pode aumentar a expectativa de vida dos pacientes que necessitam de um monitoramento constante e periódico da doença.

No nosso caso, nossos resultados mostraram que os mapas hemodinâmicos podem fornecer informações auxiliares e serem utilizados como uma ferramenta a mais no acompanhamento dos pacientes de anemia falciforme como também ser um incentivo para mais estudos e métodos mais exatos para a avaliação de doenças, usando imagens perfusionais. 


\section{Capítulo 6}

\section{Conclusão e Perspectivas}

Os resultados obtidos com ambos os métodos, LM e AG, foram capazes de produzir um bom ajuste da função gama variável, nas curvas de concentração-tempo, para a futura construção dos mapas hemodinâmicos. Embora ambos os métodos tenham sido considerados satisfatórios, verificou-se que o LM se mostrou extremamente dependente dos valores iniciais atribuídos às variáveis $\alpha, \beta$ e $C_{\text {pico }}$, a ponto de influenciar o ajuste dos resultados e conseqüentemente a exatidão dos mapas.

Além disso, os mapas obtidos com o AG exibiram maior estabilidade com relação a seus parâmetros de controle, melhorando assim a estimativa dos valores de rCBV. Por exemplo, quando se observou os mapas de rCBV obtidos com valores iniciais não-ótimos de Tc, ficou evidente que o método que utiliza LM falha ou ao menos deixou muito a desejar quanto a produção razoável destes mapas hemodinâmicos. Portanto, de acordo com esses resultados, existe grande evidência da eficácia do uso dos algoritmos genéticos em relação ao método convencional, LM.

Com o uso do AG é possível obter um Tc para cada curva de um pixel ou região, no tempo. Por isso, teremos para cada região de interesse um tempo de chegada diferente, que é o que realmente acontece em um caso real. O bolus não anda compacto, na sua trajetória ele se dispersa chegando à região determinada por caminhos deferentes. O MTT é justamente o tempo que o bolus permanece numa determinada região. Por isso, e pelo fato de se tratar de pacientes que geralmente já possuem algum déficit na circulação cerebral, optamos por calcular o MT'T, como sendo a largura à meia altura do pico máximo de 
concentração do agente de contraste, ao invés da maneira tradicional, calculando uma AIF (função arterial de entrada) em uma das artérias de alimentação cerebral.

De acordo com os nossos resultados, os mapas de perfusão se mostraram bastante promissores quanto à identificação de eventos ligados a tecidos danificados e é uma técnica que pode ser usada como ferramenta auxiliar junto com a Angiografia por Ressonância Magnética e o Doppler Transcraniano que já são normalmente realizados.

Foi possível também verificar que déficits de perfusão em determinadas regiões, de pacientes com anemia falciforme, coincidem com as áreas enfartadas e zonas isquêmicas. Os mapas de perfusão parecem oferecer um grande número de possibilidades para o melhor entendimento da fisiopatologia das complicações neurológicas que o paciente portador de anemia falciforme possui. Mais importante, o uso destes mapas pode contribuir na prevenção de derrames e outros tipos de complicações, podendo monitorar desta forma os indivíduos falcêmicos, como uma ferramenta a mais em prol da prevenção de áreas de risco, bem como seu papel auxiliar na programação terapêutica mais adequada ao paciente.

Com este estudo, também se espera que mais pesquisas possam surgir nesta área a fim de aperfeiçoar, ou até mesmo renovar os métodos de obtenção de mapas perfusionais. Seria extremamente interessante ter um grupo maior de pacientes para serem analisados e que as imagens perfusionais fossem padronizadas com relação à injeção do agente de contraste, como no caso de uma bomba injetora, que daria a mesma velocidade de injeção constante a todos os pacientes, diminuindo assim o erro na aquisição das imagens. Enfim, tentar diminuir todos os erros externos de modo a fornecer resultados mais precisos e exatos que possam não só aprimorar o diagnóstico do paciente como proporcionar um melhor entendimento dos processos fisiológicos ligados às alterações perfusionais da doença. 


\section{Apêndice}

\section{A. A função Gama}

Tudo começou quando R. L. Evans [Evans, 1959] encontrou em seus estudos a seguinte família de curvas,

$$
c(\tau)=\tau^{n} e^{-a \tau}
$$

$$
\left\{\begin{array}{c}
\tau=\text { tempo após o tempo de chegada } \\
c(\tau)=\text { concentração do indicador no tempo } \\
a, n=\text { parâmetros arbitrários }
\end{array}\right.
$$

que dava ajustes razoáveis para as curvas de indicador sem recirculação, quando os valores de $n$ da integral eram testados $(n=2,3,4)$. De modo a ajustar um membro da família de curvas (A.1) para uma curva experimental, é conveniente introduzir um fator de escala, K, para permitir as variações nos fatores de calibração (relação da curva de concentração do indicador com a amplitude de deflexão nas curvas de indicador registradas). Se substituirmos os parâmetros a e $n$ por $\alpha$ e $1 / \beta$, respectivamente na (A.1), a correspondência entre esta expressão e a função de densidade de probabilidade [ver referência Thompson et al, 1964] para a gama variável (vista no capítulo 2) torna-se facilmente demonstrável. Essas mudanças resultam na seguinte equação:

$$
c(\tau)=K \tau^{\alpha} e^{-\tau / \beta}
$$

Note que $\tau=t-A T$ e que (A.2) é exatamente equivalente a equação 2.14 (capítulo 2). 


\section{$\underline{\text { A Função Gama }}$}

A função gama de $n$, designada como $\Gamma(n)$ é definida como:

$$
\Gamma(n)=\int_{0}^{\infty} x^{n-1} e^{-x} d x
$$

Uma vez $n$ sendo especificado, $\Gamma(n)$ é equivalente a área debaixo da curva,

$$
y=x^{n-1} e^{-x}
$$

de $x=0$, até $x=\infty$. A substituição de $(n+1)$ para $n$, na equação (A.3) conduz, através da integração por partes, a seguinte relação:

$$
\Gamma(n+1)=n \Gamma(n)
$$

A partir disso, pode-se facilmente mostrar que o valor para a integral de $n$,

$$
n !=\Gamma(n+1)
$$

Para derivar a expressão para a área debaixo da função, $\tau^{\alpha} \exp (-\tau / \beta)$, mencionado acima, podemos chamar $\alpha=\mathrm{n}-1, \tau=\beta \mathrm{x}, d \tau=(\beta) d x$ e proceder da seguinte maneira:

$$
\begin{aligned}
\int_{0}^{\infty} \tau^{\alpha} e^{-\tau / \beta} d \tau & =\int_{0}^{\infty}(\beta x)^{n-1} e^{-x}(\beta) d x \\
& =\beta^{n} \int_{0}^{\infty} x^{n-1} e^{-x} d x=\beta^{n} \Gamma(n) \\
& =\beta^{\alpha+1} \Gamma(\alpha+1)
\end{aligned}
$$

Exceto para valores inteiros de $n, \Gamma(n)$ não é exatamente integrável, mas seus valores têm sido determinados por métodos numéricos. Tabelas de valores de $\Gamma(n)$ são facilmente acessíveis [CRC Standart mathematical Tables, ed 12, ed. By C. D. Hodgman. Cleveland, Chemical Rubber Publishing Company, 1959, p. 316] 


\section{B. Programas computacionais para construção de mapas de perfusão, em Matlab, usando Algoritmo Genético}

1. Programa CBV: Calcula o Volume de Sangue Cerebral de uma fatia ou um conjunto de imagens usando o Algoritmo Genético

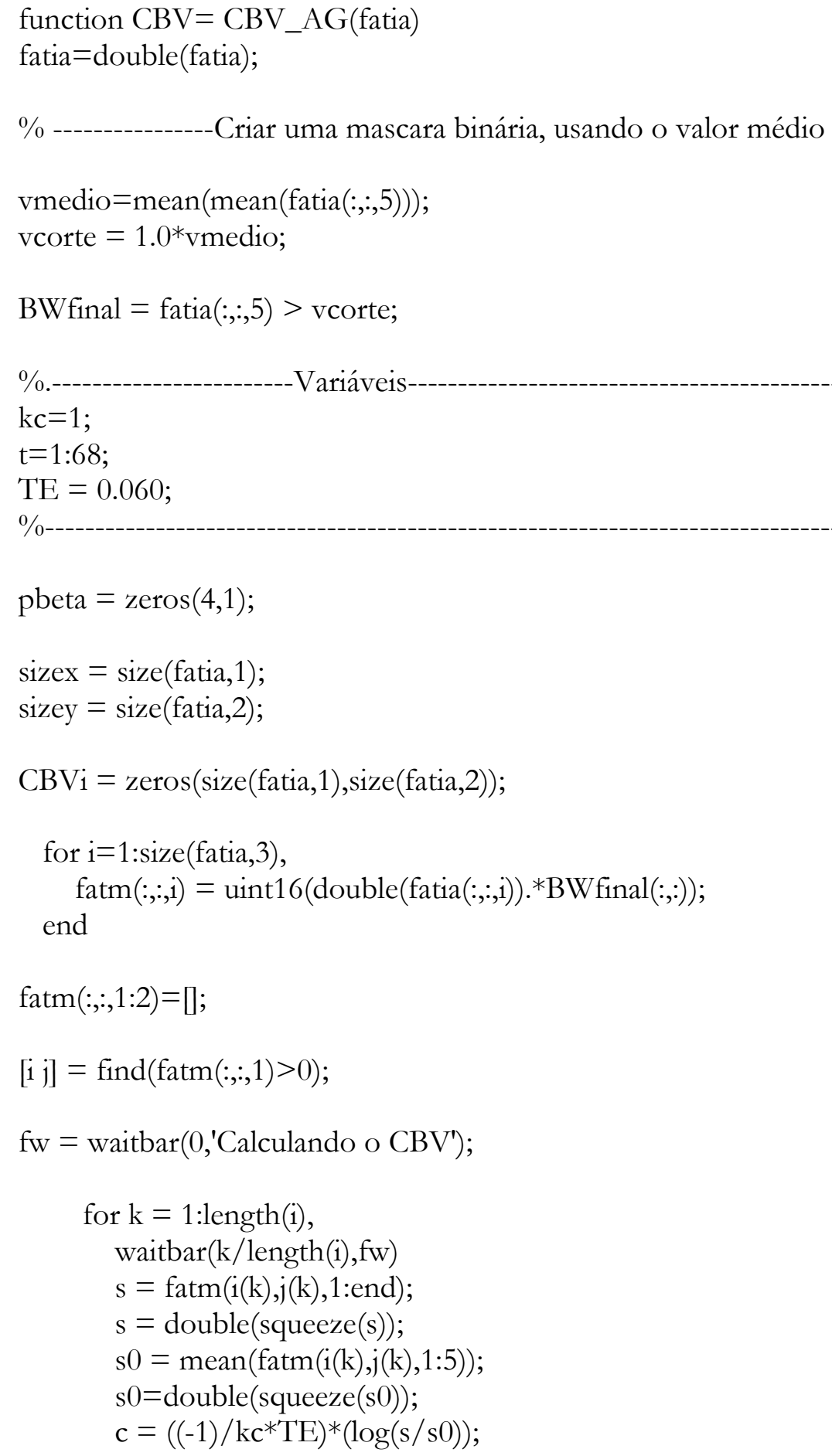


$\%========$ ajuste usando Algoritmo Genético $========$

[betahat, chi $]=\operatorname{genet}(\mathrm{c})$;

if $s>0$,

$\mathrm{c}=((-1) / \mathrm{kc} * \mathrm{TE}) *(\log (\mathrm{s} / \mathrm{s} 0))$;

[betahat, chi] $=\operatorname{genet}(\mathrm{c})$;

else

$\mathrm{c}=0$

chi $=10^{\wedge} 20$;

end

waitbar(k/length(i),fw)

if $\min (\operatorname{chi}(:))<1$

pbeta $=$ betahat;

$\%<<<<<<<<<<$ calculcando CBV $<<<<<<<<<<<<<<<<<<$

a1 $=\operatorname{pbeta}(1) *\left(2.71828 /\left(\operatorname{pbeta}(2)^{*} \operatorname{pbeta}(3)\right)\right)^{\wedge} \operatorname{pbeta}(2) ;$

$\mathrm{a} 2=(\operatorname{pbeta}(3)) \cdot \wedge((\operatorname{pbeta}(2)+1))$;

a3 $=(\operatorname{pbeta}(2)) *(\operatorname{gamma}(\operatorname{pbeta}(2)))$;

CBVi(i(k),j(k))=a1*a2*a3;

else

$\operatorname{CBVi}(\mathrm{i}(\mathrm{k}), \mathrm{j}(\mathrm{k}))=0$;

end

end

CBV = filtro_espacial(abs(CBVi));

close (fw)

figure, imagesc(CBV), axis image, axis off; colorbar

2.1 Programa genet:: Essa função faz um refinamento da outra função.

function $\left[\mathrm{m} \_\right.$pop, chi $]=$genet $($datain $)$

$\mathrm{t}=1: \max (\operatorname{size}($ datain $))$

$\operatorname{vcromolim}(1,1)=0$;

$\operatorname{vcromolim}(2,1)=0.09$;

$\operatorname{vcromolim}(1,2)=0.05 ;$

vcromolim $(2,2)=6$;

$\operatorname{vcromolim}(1,3)=0.05 ;$

$\operatorname{vcromolim}(2,3)=8$; 
$\operatorname{vcromolim}(1,4)=13$;

$\operatorname{vcromolim}(2,4)=$ length $(\mathrm{t})-20$;

$\left[\mathrm{m} \_\right.$pop, $\left.\mathrm{chi}\right]=\mathrm{ag}(\mathrm{datain}, \mathrm{vcromolim})$

[return

\subsubsection{Programa ag}

function $\left[\mathrm{m} \_\right.$pop, chi $]=\operatorname{ag}($ datain, $v$ cromolim $)$

tam_pop $=120$;

nb_cromo $=4$;

m_pop $=$ zeros $\left(n b \_c r o m o, 1\right) ; \quad \%$ Melhores parâmetros de resultados

m_pop_n $=$ zeros(nb_cromo, 1$) ; \quad \%$ Melhores parâmetros de resultados

$\mathrm{t}=1: \max (\operatorname{size}($ datain $))$;

valor_chi $=10^{\wedge} 30$;

maxiter $=100$;

iter $=1$;

prob = 0.9;

pop $=$ rand $\left(n b \_c r o m o, t a m \_p o p\right) ;$

for $j=1$ :tam_pop,

for $\mathrm{i}=1: \mathrm{nb}$ _cromo,

$\operatorname{pop}(\mathrm{i}, \mathrm{j})=\operatorname{pop}(\mathrm{i}, \mathrm{j}) *(\operatorname{vcromolim}(2, \mathrm{i})-\operatorname{vcromolim}(1, \mathrm{i}))+\operatorname{vcromolim}(1, \mathrm{i}) ;$ end

end

chi $=$ aval(pop,t,datain); $\quad \%$ Avalia essa população (chi-quadrado)

function [m_pop, chi] $=$ ag $($ datain, $v$ cromolim $)$

tam_pop $=120$

nb_cromo $=4$;

m_pop $=$ zeros $\left(n b \_c r o m o, 1\right) ; \quad \%$ Melhores parâmetros de resultados

m_pop_n = zeros(nb_cromo,1); $\quad \%$ Melhores parâmetros de resultados

$\mathrm{t}=1: \max (\operatorname{size}($ datain $))$

valor_chi $=10^{\wedge} 30$;

maxiter $=100$;

iter $=1$;

prob $=0.9 ;$

pop $=$ rand $($ nb_cromo,tam_pop);

for $j=1:$ tam_pop, 


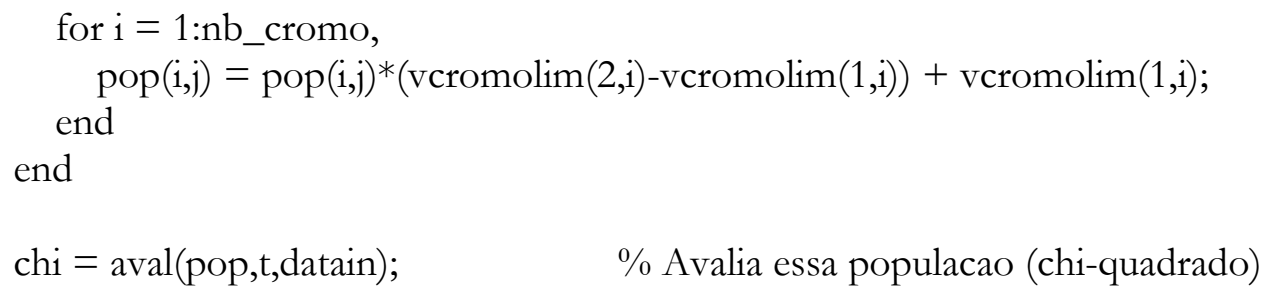

while iter $<$ maxiter

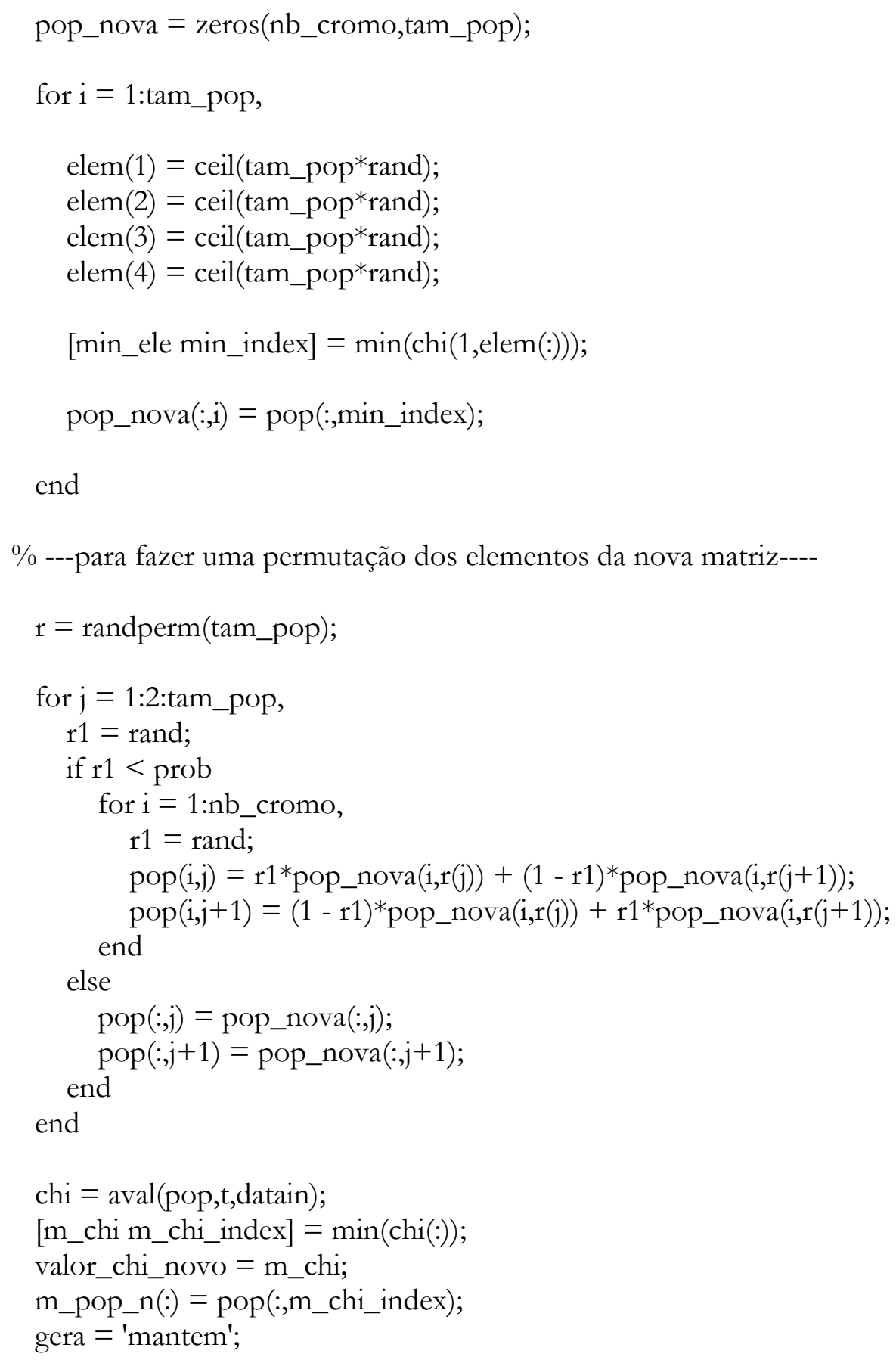




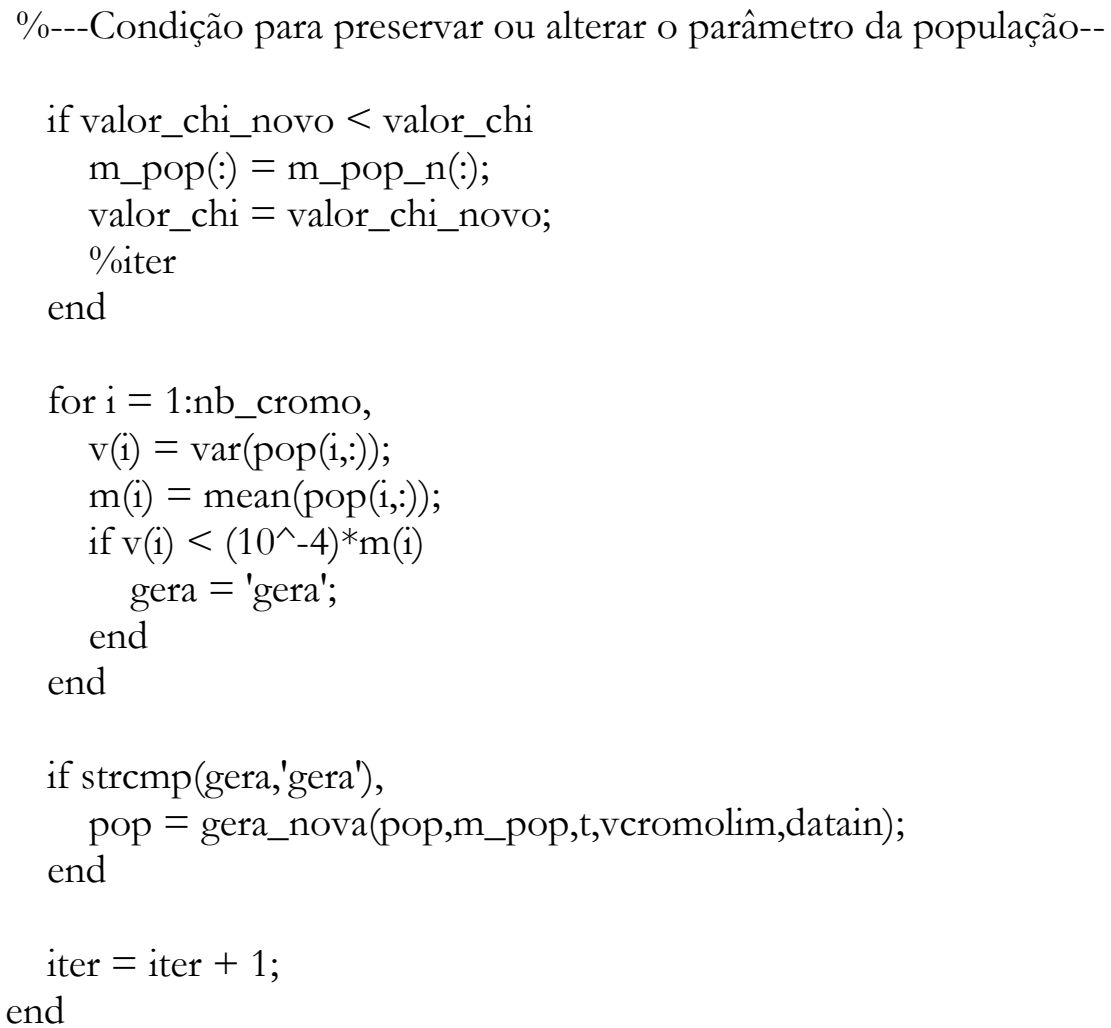

$\%==========$ Aqui estão as subfunções $==========$

function pred $=\operatorname{gammav}(\mathrm{t}, \mathrm{pbeta})$

Cpico $=\operatorname{pbeta}(1)$

alpha $=\operatorname{pbeta}(2)$;

beta $=\operatorname{pbeta}(3) ;$

$\mathrm{Ta}=\operatorname{pbeta}(4)$;

$\mathrm{K}=\mathrm{Cpico} *(2.71828 /(\text { alpha*beta }))^{\wedge}$ alpha;

$\mathrm{T} 1=(\mathrm{t}-\mathrm{Ta}) \wedge$ alpha;

$\mathrm{T} 2=\exp (-(\mathrm{t}-\mathrm{Ta}) \cdot / \mathrm{beta})$

pred $=\mathrm{K}^{*}\left(\mathrm{~T} 1{ }^{*} \mathrm{~T} 2\right)$

$\operatorname{pred}(1: \operatorname{round}(\mathrm{Ta}))=0$;

return

$\%========$ Subfunção de avaliação==ニ======-=

function chi $=\operatorname{aval}($ pop,t,datain $)$

chi $=\operatorname{zeros}(1, \max (\operatorname{size}($ pop $)))$;

for $\mathrm{k}=1: \max (\operatorname{size}(\mathrm{pop}))$,

pred $=$ gammav $(\mathrm{t}, \mathrm{pop}(:, \mathrm{k}))$;

pred $=$ pred'; 


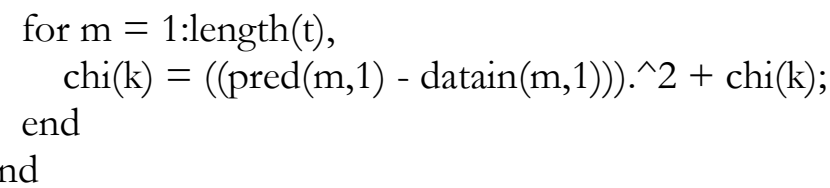

return

$\%=====$ Sub função para gerar uma nova população======

function $[$ pop,chi $]=$ gera_nova(pop,m_pop,t,vcromolim,datain);

pop $=\operatorname{rand}(\operatorname{size}(p o p))$

for $j=1: \max (\operatorname{size}(p o p))$, for $\mathrm{i}=1: 4$, end

$\operatorname{pop}(\mathrm{i}, \mathrm{j})=\operatorname{pop}(\mathrm{i}, \mathrm{j}) *(\operatorname{vcromolim}(2, \mathrm{i})-\operatorname{vcromolim}(1, \mathrm{i}))+\operatorname{vcromolim}(1, \mathrm{i}) ;$

end

$\operatorname{pop}(:, 1)=\mathrm{m} \_\mathrm{pop}(:)$

chi $=$ aval(pop,t,datain); \% Gera a avaliação dessa nova população (chi-quadrado)

\% -----------Sorteio de elementos da população antiga-

while iter $<$ maxiter

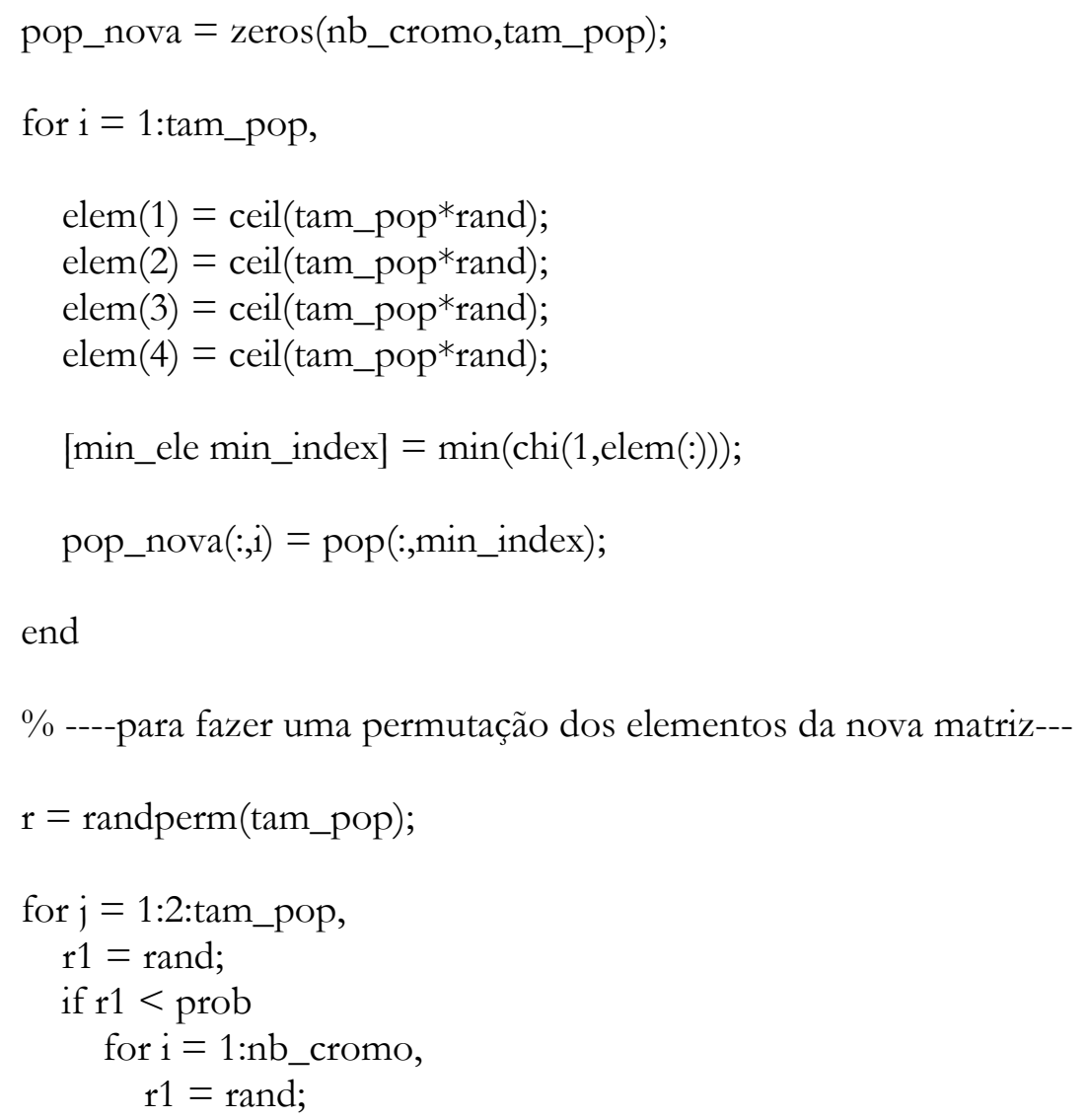




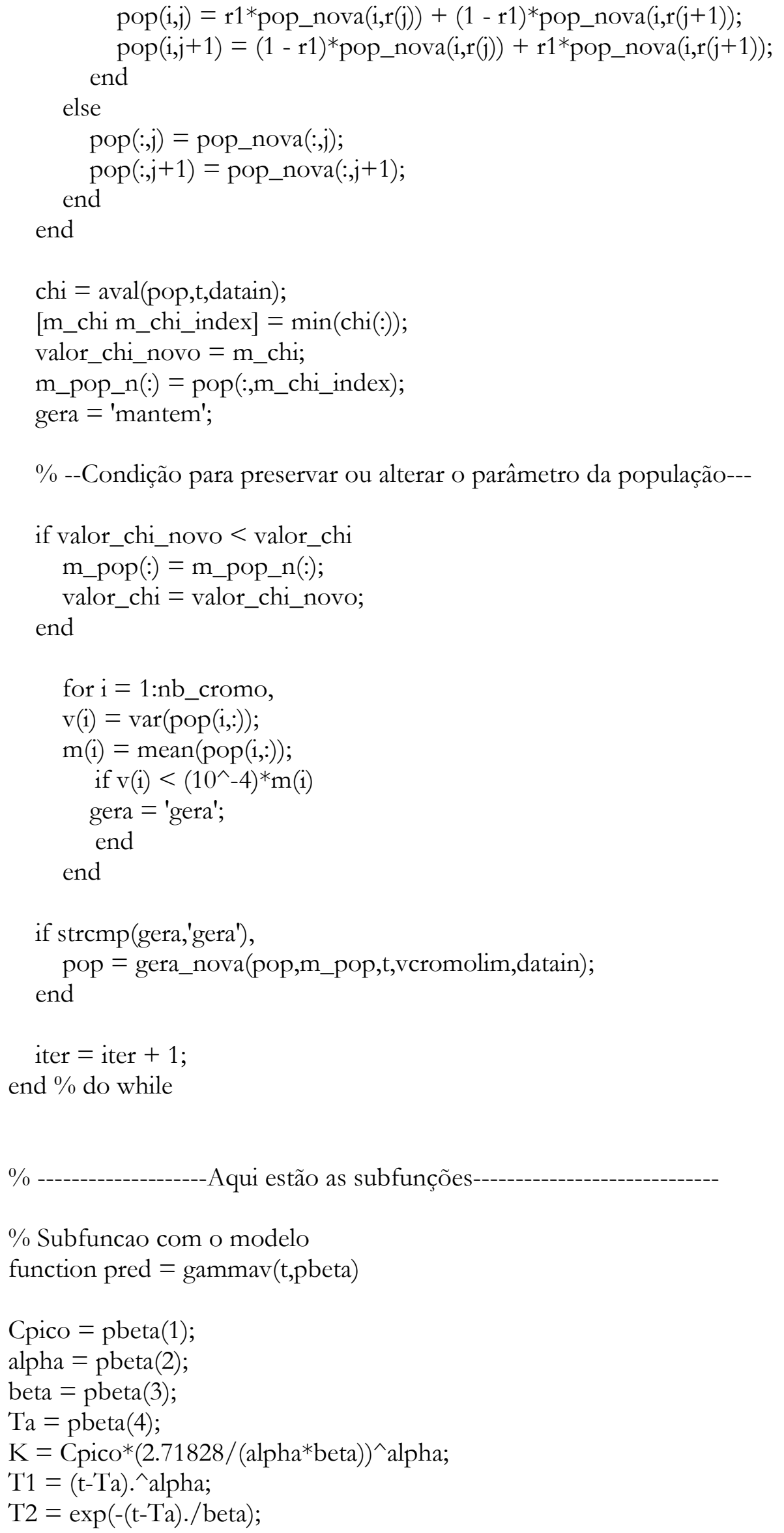

$\%$ Subfuncao com o modelo

function pred $=\operatorname{gammav}(\mathrm{t}, \mathrm{pbeta})$

Cpico $=\operatorname{pbeta}(1)$

alpha $=\operatorname{pbeta}(2)$;

beta $=\operatorname{pbeta}(3)$;

$\mathrm{Ta}=\operatorname{pbeta}(4)$;

$\mathrm{K}=\mathrm{Cpico}^{*}(2.71828 /(\text { alpha*beta }))^{\wedge}$ alpha;

$\mathrm{T} 1=(\mathrm{t}-\mathrm{Ta})$ ^ $^{\wedge}$ alpha;

$\mathrm{T} 2=\exp (-(\mathrm{t}-\mathrm{Ta}) \cdot /$ beta $)$; 
pred $=\mathrm{K}^{*}\left(\mathrm{~T} 1{ }^{*} \mathrm{~T} 2\right)$

$\operatorname{pred}(1: \operatorname{round}(\mathrm{Ta}))=0$;

return

$\%========$ Subfunçao de avaliação======-==ニ====

function chi $=\operatorname{aval}($ pop,t,datain $)$

$\operatorname{chi}=\operatorname{zeros}(1, \max (\operatorname{size}($ pop $)))$

for $\mathrm{k}=1: \max (\operatorname{size}(\mathrm{pop}))$,

pred $=\operatorname{gammav}(\mathrm{t}, \mathrm{pop}(:, \mathrm{k}))$;

pred $=$ pred';

for $\mathrm{m}=1:$ length $(\mathrm{t})$,

$\operatorname{chi}(\mathrm{k})=((\operatorname{pred}(\mathrm{m}, 1)-\operatorname{datain}(\mathrm{m}, 1))) \cdot{ }^{\wedge} 2+\operatorname{chi}(\mathrm{k}) ;$

end

end

return

$\%=====$ Subfunção para gerar uma nova população==========

function $[$ pop,chi] = gera_nova(pop,m_pop,t,vcromolim,datain);

pop $=\operatorname{rand}(\operatorname{size}(p o p))$

for $j=1: \max (\operatorname{size}(p o p))$, for $\mathrm{i}=1: 4$,

$\operatorname{pop}(\mathrm{i}, \mathrm{j})=\operatorname{pop}(\mathrm{i}, \mathrm{j}) *(\operatorname{vcromolim}(2, \mathrm{i})-\operatorname{vcromolim}(1, \mathrm{i}))+\operatorname{vcromolim}(1, \mathrm{i}) ;$ end

end

$\operatorname{pop}(:, 1)=\mathrm{m} \_\mathrm{pop}(:)$

chi $=$ aval(pop,t,datain); \% Gera a avaliação dessa nova população (chi-quadrado) 
2. Programa MTT: Calcula o Tempo de Trânsito Médio, ou seja, o tempo que o sangue demora em atravessar uma fatia ou uma região, usando o Algoritmo Genético.

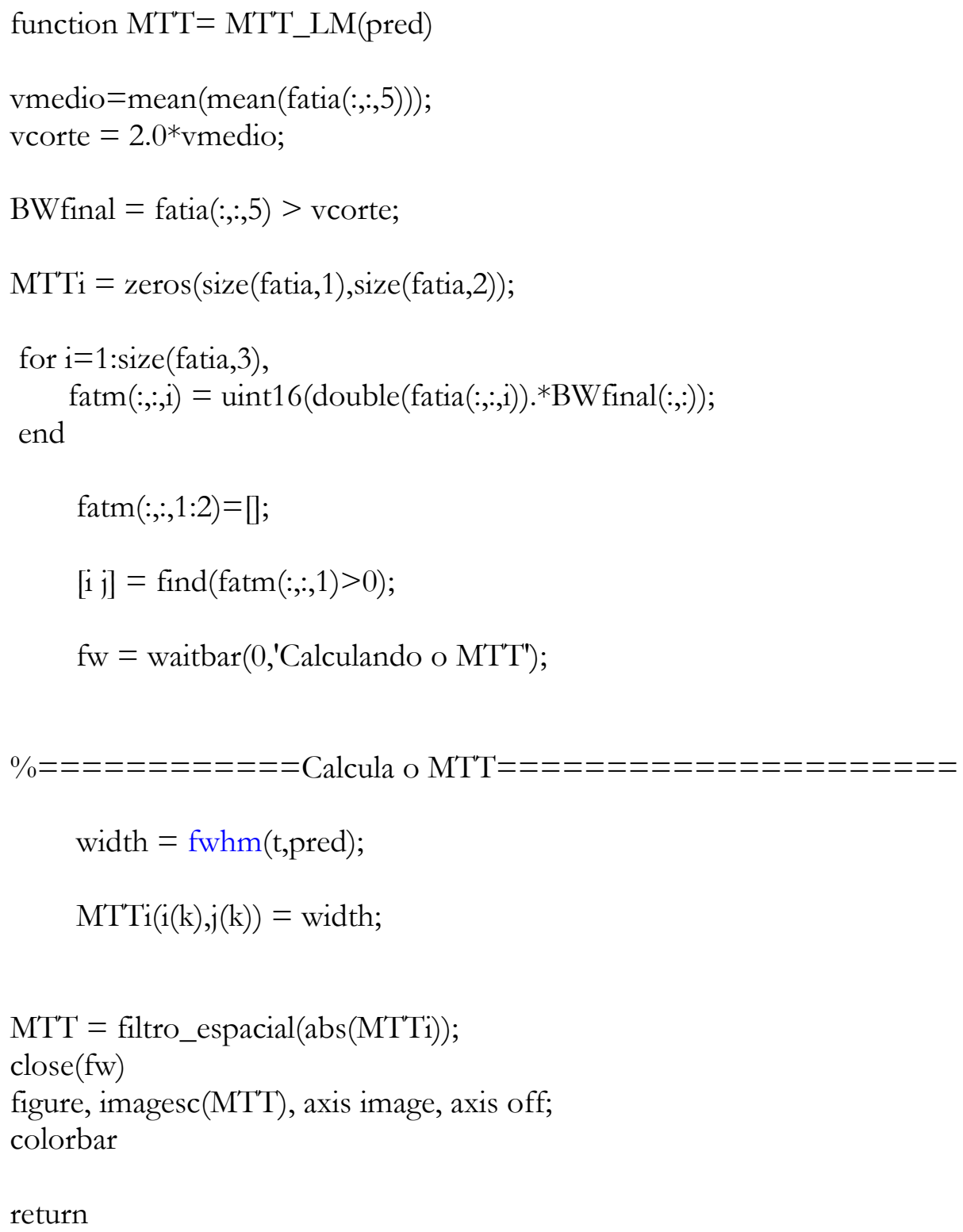


3.1 Programa fwhm: calcula a largura máxima a meia altura da curva.

function width $=$ fwhm $(\mathrm{x}, \mathrm{y})$

$\%$ function width $=$ fwhm $(\mathrm{x}, \mathrm{y})$

$\%$ Full-Width at Half-Maximum (FWHM) of the waveform $\mathrm{y}(\mathrm{x})$ and its polarity.

$\%$ The FWHM result in 'width' will be in units of ' $x$ '

$\%$

$\%$ Rev 1.2, April 2006 (Patrick Egan)

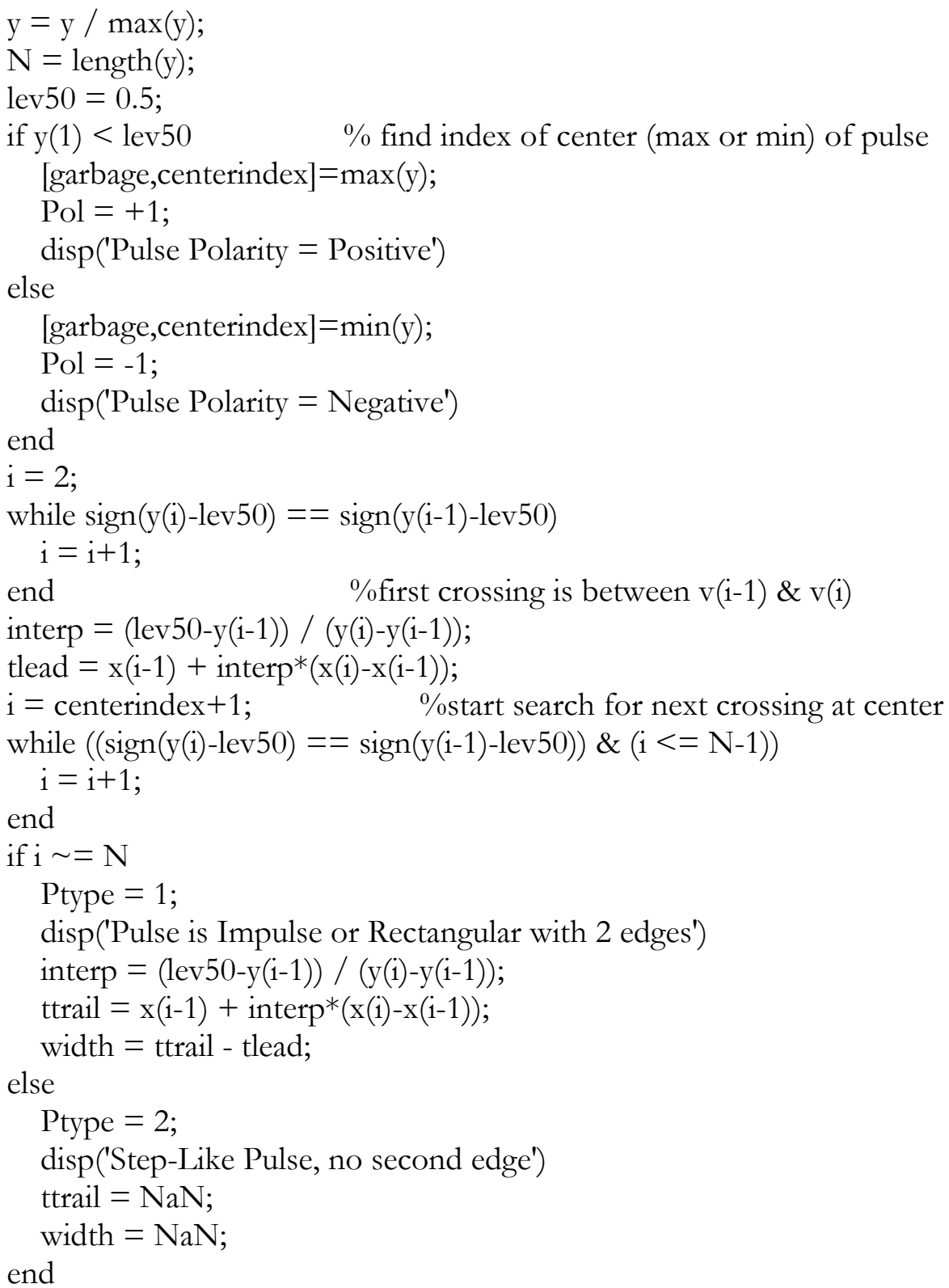


3. Programa CBF: calcula o Fluxo de Sangue cerebral através do princípio do volume central.

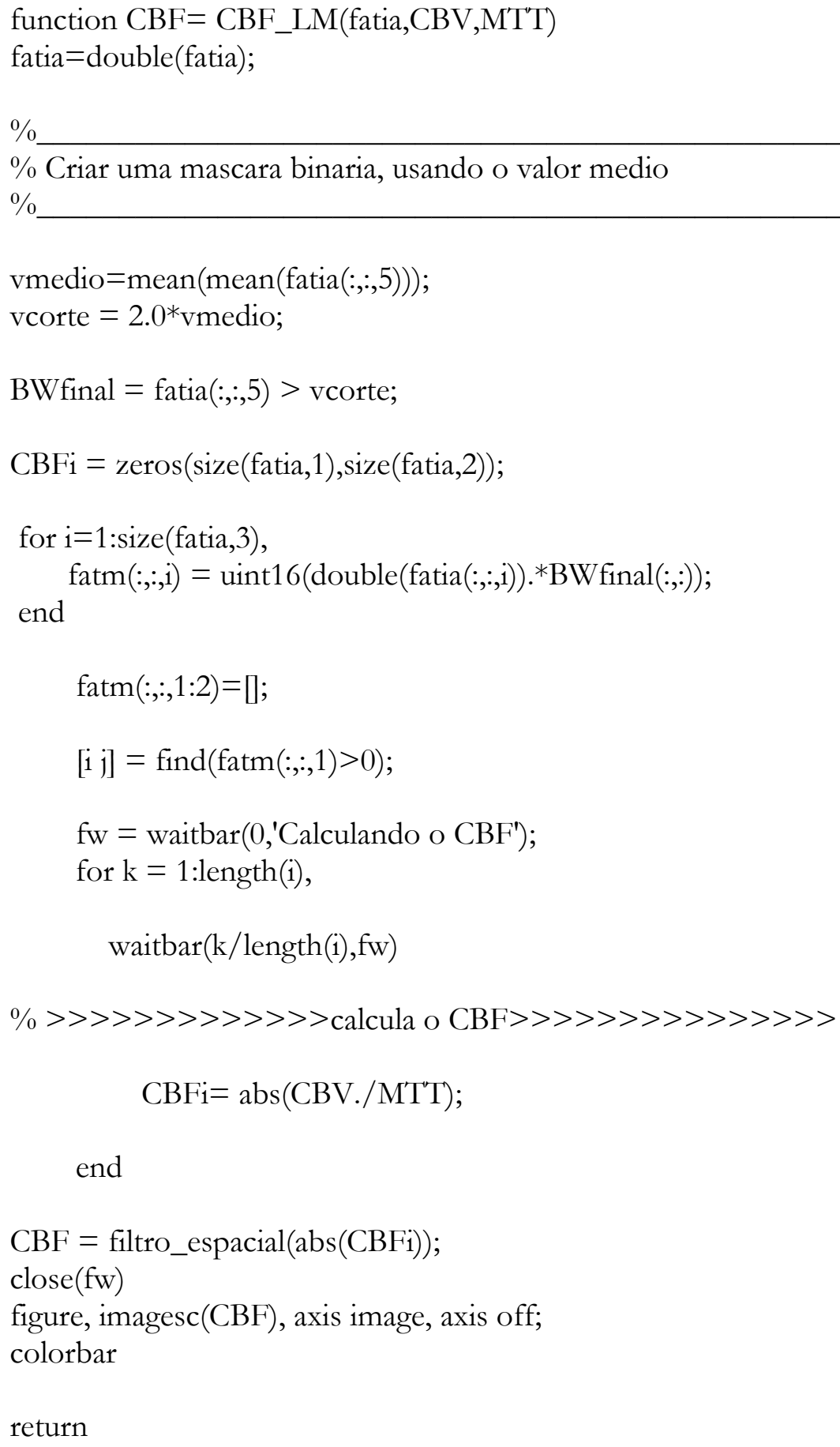

